\title{
Effect of elevated calcium level and calcium binding proteins in acute and chronic degeneration of motor neurons
}

\author{
Ph.D. Thesis
}

\section{Written by: Roland Patai}

Supervised by: László Siklós Ph.D., D.Sc.
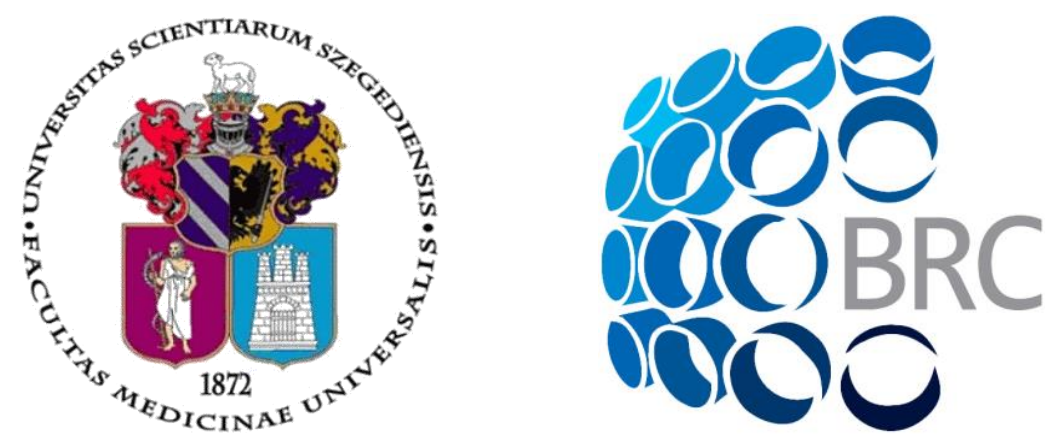

Laboratory of Neuronal Plasticity

Molecular Neurobiology Research Unit

Institute of Biophysics

Biological Research Centre of the Hungarian Academy of Sciences

\author{
Doctoral School of Theoretical Medicine \\ Faculty of Medicine \\ University of Szeged
}


"All interest in disease and death is only another expression of interest in life..."

Thomas Mann 
The Ph.D. thesis is based on the following in extenso scientific publications:

I. Roland Patai, Bernát Nógrádi, József I. Engelhardt, László Siklós: Calcium in the pathomechanism of amyotrophic lateral sclerosis - Taking center stage? Biochemical and Biophysical Research Communications, 2017; 483: 1031-1039. Impact Factor: 2.466; Quartile Score: Q1 (Biophysics)

II. Roland Patai, Melinda Paizs, Massimo Tortarolo, Caterina Bendotti, Izabella Obál, József I. Engelhardt, László Siklós: Presymptomatically applied AMPA receptor antagonist prevents calcium increase in vulnerable type of motor axon terminals of mice modeling amyotrophic lateral sclerosis. Biochimica et Biophysica Acta - Molecular Basis of Disease, 2017; 1863: 1739-1748. Impact Factor: 5.476; Quartile Score: Q1 (Molecular Biology)

III. Melinda Paizs, Roland Patai, József I. Engelhardt, Zoya Katarova, Izabella Obál, László Siklós: Axotomy Leads to Reduced Calcium Increase and Earlier Termination of CCL2 Release in Spinal Motoneurons with Upregulated Parvalbumin Followed by Decreased Neighboring Microglial Activation. CNS and Neurological Disorders - Drug Targets, 2017; 16(3): 356-367. Impact Factor: 2.506; Quartile Score: Q1 (Medicine)

Cumulative impact factor of the scientific publications providing the basis of the thesis: 
Further publications and manuscripts related to the field of the Ph.D. thesis:

I. Valéria Meszlényi, Roland Patai, Bernát Nógrádi, József I. Engelhardt, László Siklós: Commentary: Calcium in the pathomechanism of amyotrophic lateral sclerosis Taking center stage? Journal of Neurology and Neuromedicine, 2017; 2(4): 1-4. Impact Factor: not indexed yet; Quartile Score: not indexed yet

II. Roland Patai, Bernát Nógrádi, Valéria Meszlényi, Izabella Obál, József I. Engelhardt, László Siklós: Az amyotrophiás lateralsclerosis patofiziológiai tényezőinek központi kapcsolóeleme, a kalcium. (Calcium ion as a common denominator in the pathophysiological processes of amyotrophic lateral sclerosis.) Ideggyógyászati Szemle. (Clinical Neuroscience (Hungarian)), 2017; 70(7-8): 247-257. Impact Factor: 0.376; Quartile Score: Q4 (Neurology)

III. Roland Patai, Bernát Nógrádi, Valéria Meszlényi, Tamás F. Polgár, József I. Engelhardt, László Siklós: Diazoxide equally reduces microglial activation in motor nuclei with different susceptibility after acute injury of motor axons. (in preparation) 


\section{TABLE OF CONTENTS}

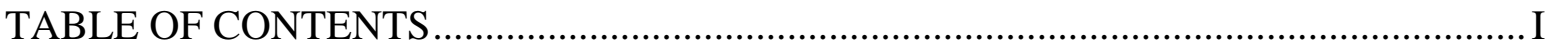

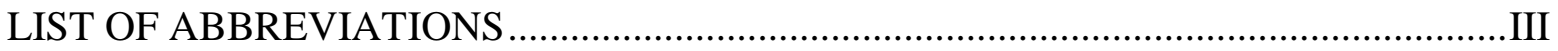

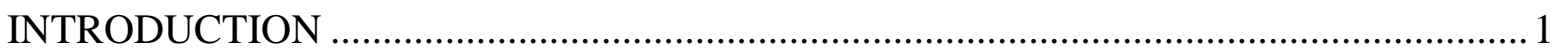

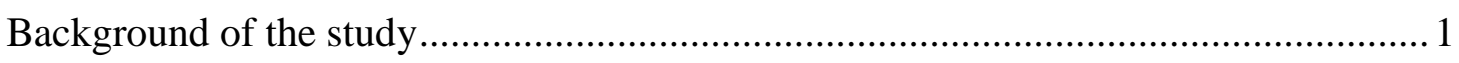

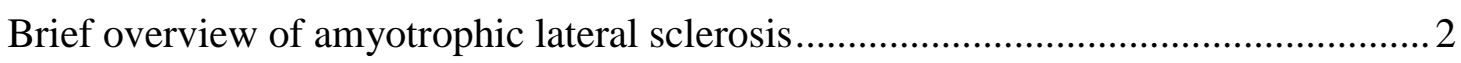

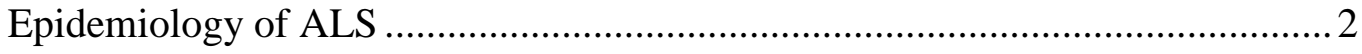

Clinical manifestation and diagnostic criteria of ALS ..................................... 3

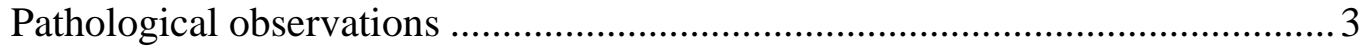

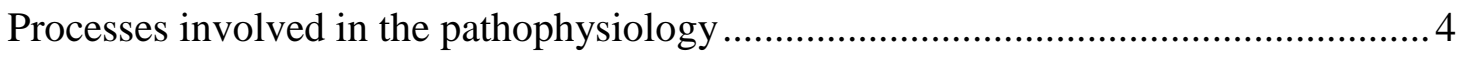

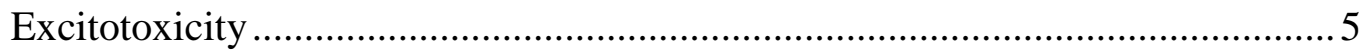

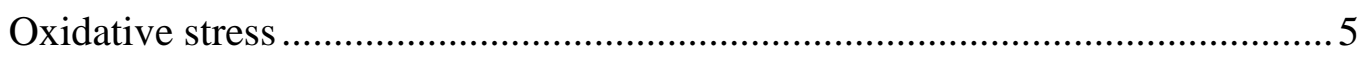

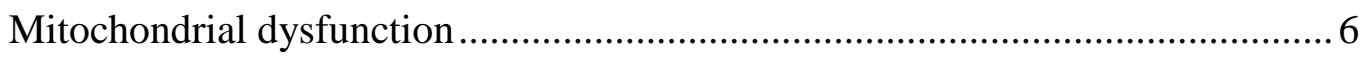

Immune/inflammatory processes .............................................................. 7

Calcium is a common denominator in the pathophysiology of ALS .......................... 9

Intrinsic properties influencing motoneuronal vulnerability ..................................... 10

Calcium binding protein content and relative resistance of motor neurons .......... 10

Calcium permeability of AMPA receptors and resistance of motor neurons ....... 11

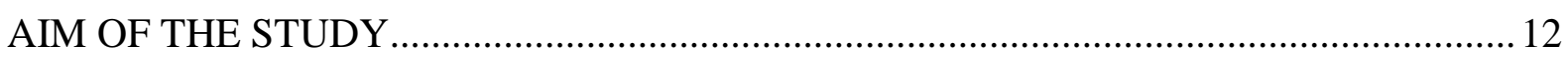

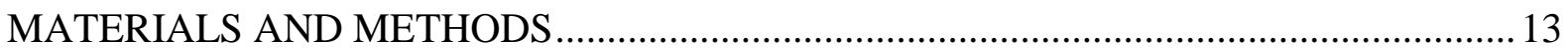

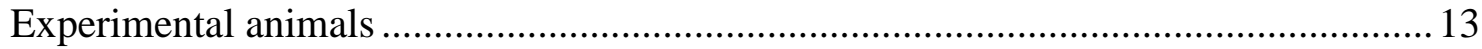

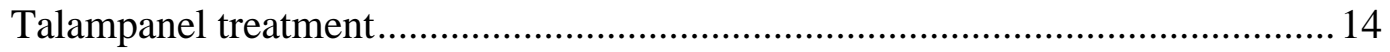

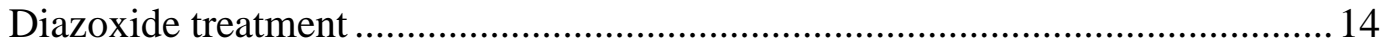

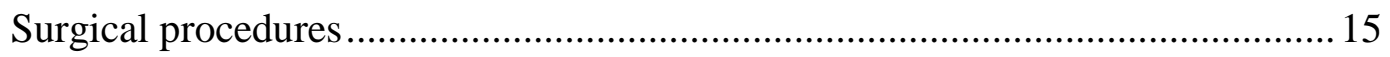

Characterization of the transgenic PV $+/+$ strain ............................................. 15

Immunohistochemical staining and quantification............................................... 16

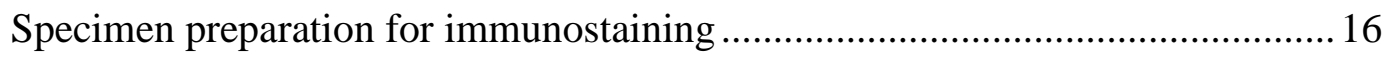

Single- and double staining for CCL2 and CD11b .......................................... 17

Fluorescent double labeling for PV and ChAT ............................................... 18

Fluorescent double labeling for ChAT and Iba1 ............................................. 18

Combined fluorescent and avidin-biotin based immunostaining.......................... 19

Quantification of axotomy-induced change of immunostained cells................... 19

Transmission electron microscopic detection of calcium .......................................... 20 


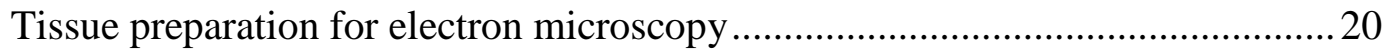

Specificity control of the calcium-specific histochemical reaction ..................... 21

Determination of the relative amount of EDDs ............................................... 21

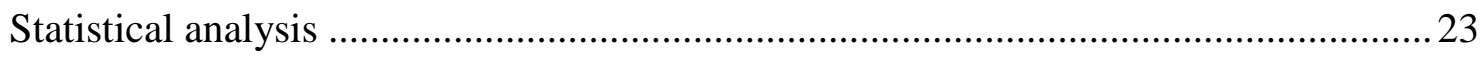

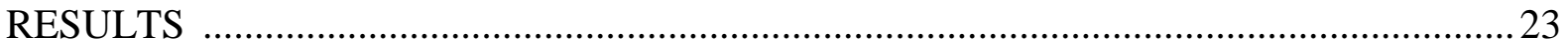

Effect of talampanel on the calcium level of motor neurons of mSOD1 mice ..............23

Controls of the electron microscopic calcium histochemistry .....................................229

Sciatic axotomy-induced changes in the spinal cord of PV+/+ mice ........................... 31

Effect of diazoxide treatment on microgliosis in the axotomized motor nuclei.............. 36

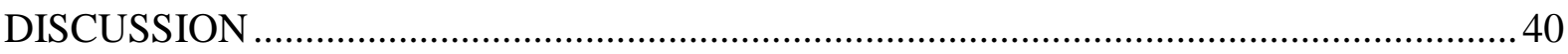

Role of AMPA receptors and excitotoxicity in chronic motor neuron degeneration ..... 41

Role of the neuron-microglia communication in neuronal degeneration .......................42

Protective effect of calcium binding proteins in motoneuronal injury .......................... 44

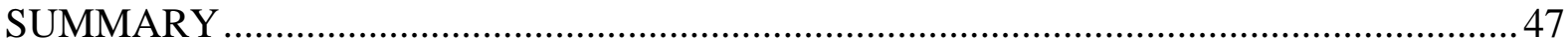

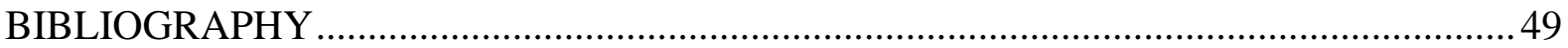

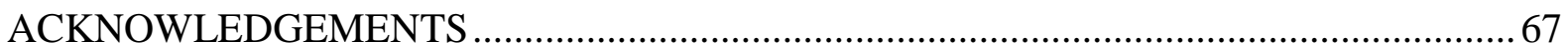

APPENDIX I. - MATERIALS AND COMMERCIAL EQUIPMENT USED .....................6 68

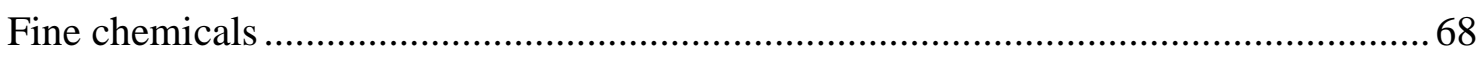

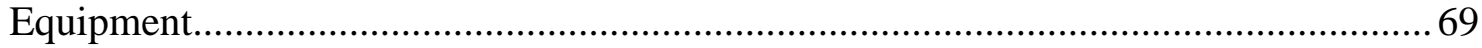

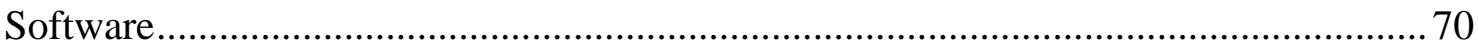

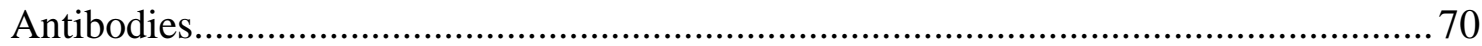

APPENDIX II. - CHARACTERIZATION OF THE PRIMER ANTIBODIES .................... 71

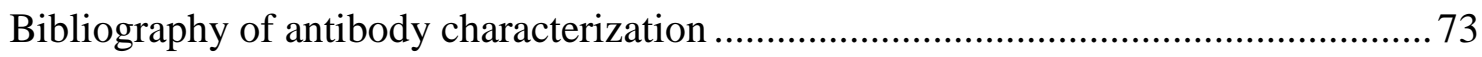




\section{LIST OF ABBREVIATIONS}

\begin{tabular}{|c|c|}
\hline Abbreviation & Meaning \\
\hline ADAR2 & adenosine deaminase acting on RNA 2 \\
\hline AFM & atomic force microscopy \\
\hline ALS & amyotrophic lateral sclerosis \\
\hline AMPA & $\alpha$-amino-3-hydroxy-5-methyl-4-isoxazolepropionic acid \\
\hline ANOVA & analysis of variance \\
\hline ATP & adenosin triphosphate \\
\hline $\mathrm{CaBP}$ & calcium binding protein \\
\hline $\mathrm{CCD}$ & charge-coupled device \\
\hline CCL2 & chemokine $\mathrm{C}-\mathrm{C}$ motif ligand 2 \\
\hline CD11b & cluster of differentiation $11 \mathrm{~b}$ \\
\hline CD68 & cluster of differentiation 68 \\
\hline ChAT & choline acetyltransferase \\
\hline CNS & central nervous system \\
\hline DAB & diaminobenzidine tetrahydrochloride \\
\hline DNA & deoxyribonucleic acid \\
\hline EAAT & excitatory amino acid transporter \\
\hline EDD & electron-dense deposit \\
\hline G93A & glycine-93 to alanine substituted form \\
\hline GluR2 & glutamate receptor subunit 2 \\
\hline Iba1 & ionized calcium-binding adaptor molecule 1 \\
\hline $\operatorname{IgG}$ & immunoglobulin $\mathrm{G}$ \\
\hline mRNA & messenger ribonucleic acid \\
\hline mSOD1 & mutant SOD1 \\
\hline PBS & phosphate buffered saline \\
\hline PET & positron emission tomography \\
\hline PV & parvalbumin \\
\hline $\mathrm{PV}+/+$ & PV upregulated \\
\hline $\mathrm{Q} / \mathrm{R}$ & glutamine/arginine \\
\hline ROS & reactive oxygen species \\
\hline s.e.m. & standard error of the mean \\
\hline SOD1 & $\mathrm{Cu} / \mathrm{Zn}$ superoxide dismutase 1 \\
\hline Tal & talampanel \\
\hline TPBS & $10 \mathrm{mM}$ PBS containing $0.2 \%$ Triton $\mathrm{x}-100$ \\
\hline Veh & vehicle \\
\hline
\end{tabular}




\section{INTRODUCTION}

\section{Background of the study}

Motor neuron degeneration could be used as a collective term for several neurological disorders that selectively affect motor neurons. These diseases include chronic pathological entities, for example, progressive muscular atrophy, hereditary spastic paraplegia or amyotrophic lateral sclerosis (ALS). Furthermore, motor neuron degeneration is not limited to chronic manifestations, since acute forms like motor axonal neuropathy or injury related motor neuron degeneration are also well-known. Regardless of the initial cause of degeneration, these degenerative events share common pathological processes, where calcium elevation might be a prominent factor ${ }^{1}$. The aim of our study — summarized in this thesis - is to understand the calcium mediated processes in motor neuron degeneration, with special attention on the relation between the intrinsic calcium mediated processes and the neighboring inflammatory reaction. Furthermore, we analyze whether neuroprotective approaches could be based on the alleviation of increased calcium level of motor neurons.

Our hypothesis underlying the protective attempts is based on the commonly observed neuronal calcium increase associated with most of the degenerative processes. Elevated calcium level was observed both in ALS patients, clinically ${ }^{2}$, and in experimental animal models using in vitro ${ }^{3}$ and in vivo approaches ${ }^{4}$. Such elevated calcium level could be observed in acute paradigms as well ${ }^{5,6}$. The most prominent mechanisms contributing to ALS have already been disclosed and characterized ${ }^{7-13}$. These detrimental phenomena can be observed simultaneously, furthermore, these processes may facilitate the deleterious effect of each other during degeneration. Calcium ions may act as a facilitating factor, since the neurodegenerative processes show a strong, positive calcium dependency, which creates a link between each individual mechanism ${ }^{14}$. Moreover, through a positive feedback loop, calcium may combine the individual pathological processes into a unified escalating mechanism of neuronal destruction. However, while certain groups of motor neurons succumb to degeneration, others are spared along the disease progression. This resistance was shown to correlate with their elevated calcium binding protein $(\mathrm{CaBP})$ content $^{15,16}$. This hypothesis was subsequently supported by a series of in vitro ${ }^{17}$, in vivo ${ }^{4,5}$ and ex vivo ${ }^{18,19}$ experiments.

Such protective effect might be based on moderating the calcium increase associated with injury either by reducing calcium influx or by buffering the excess calcium by CaBPs. These interventions, by confining the degree of injury of motor neurons, might be able to 
reduce neighboring inflammatory reactions as well as it was shown by reduced microglial reaction around injured motor neurons with high $\mathrm{CaBP}$ content compared to the regions with low $\mathrm{CaBP}$ content ${ }^{20}$. Such findings suggest that intrinsic and non-cell-autonomous processes can work in an orchestrated manner leading to a full-blown degenerative pathway ${ }^{14}$. Indeed, anti-inflammatory drugs, such as a semi-synthetic tetracycline derivative, minocycline, which are capable of reducing inflammatory responses in the central nervous system $(\mathrm{CNS})^{21}$, may target multiple injury mechanisms such as excitotoxicity and intracellular calcium content ${ }^{22}$.

\section{Brief overview of amyotrophic lateral sclerosis}

Epidemiology of ALS

ALS is the most common late-onset and relentlessly progressive motoneuron disease ${ }^{23}$ which - according to the classical definition - primarily affects upper and lower motor neurons in the motor cortex, brainstem and spinal $\operatorname{cord}^{24}$. This devastating disease became well-known when Lou Gehrig, one of the most famous American baseball players, died in this disease in $1941^{25}$. Patients diagnosed with ALS are traditionally classified into two different categories. $90-95 \%$ of the ALS cases are sorted to the most common form which is the sporadic, idiopathic type of $\mathrm{ALS}^{9}$. This nomenclature refers to the absence of any genetically inherited familial components. The remaining 5-10\% of ALS patients are pertaining to the familial type, where increased number of affected family members can be observed in the pedigree ${ }^{9}$.

The most well-characterized genetical disfunction is related to the $\mathrm{Cu} / \mathrm{Zn}$ superoxide dismutase 1 gene $(\mathrm{SOD} 1)^{26}$, where more than 160 mutations have been found ${ }^{27}$. Since the discovery of the role of SOD1 in ALS, more than 25 other genes have been identified ${ }^{27}$. The most prominent ones are the trans-activation response element deoxyribonucleic acid (DNA) binding protein 43 , fused in sarcoma, ubiquilin-2, alsin and profilin-1 genes. However, the recent discovery of an expansion of the intronic hexanucleotide repeat sequence in chromosome 9 open reading frame 72 in patients without family history blurred the distinction between these clinically indistinguishable classes ${ }^{28}$. Furthermore, these findings challenged the conventional differentiation of separate neurodegenerative diseases ${ }^{29}$.

Although the personal, societal and economic burden is substantial ${ }^{30,31}$, ALS is considered as a rare disease. Chio et al. showed that the median incidence rate in Europe (/100 000 population) was 2.08 , corresponding to an estimated 15300 cases $^{32}$. Median prevalence, for 100000 population respectively, was 5.4 cases $^{32}$. Since ALS is a neurodegenerative disorder, as a general rule, there is an escalating tendency toward 
increased incidence and prevalence with advancing age ${ }^{32}$. ALS incidence peaks between the age of 60 and $75^{32}$. Epidemiological studies showed that both incidence and prevalence of ALS are greater in men than in women ${ }^{33}$. However, this difference levels off after menopause. One obvious explanation for such phenomenon might be related to the role of gonadal hormones, particularly estrogen, which has neuroprotective effect ${ }^{34}$. Furthermore, in sporadic ALS, gender specific clinical features can be observed ${ }^{35}$.

\section{Clinical manifestation and diagnostic criteria of ALS}

The diagnosis of ALS may be difficult, since (except for the presence of identified mutations) there is no single diagnostic criterion for it. Thus, the diagnostic tests include a complex set of examinations and study of family history to distinguish from other conditions mimicking ALS. The key aspects of differential diagnosis of ALS to exclude alternative causes of symptoms are outlined in the original diagnostic criteria ${ }^{36}$. Furthermore, prominent clinical progression is also necessary which can be established only by repeated examinations in a timespan of several months. According to the revised El Escorial and Airlie House criteria, the diagnosis of clinically definite ALS requires progressive upper and lower motor neuron deficits at least three susceptible regions ${ }^{37}$. Laboratory, pathological, and clinical criteria have also been established for less definite categories ${ }^{38}$. Commonly, the primer symptoms are manifested as hyperreflexia and muscle weakness. As the disease advances, patients suffer from progressive manifestation of combined dysfunctions of upper motor neurons (spasticity, pathological reflexes) and lower motor neurons (cramps, fasciculation and atrophy) in absence of any sensory symptoms ${ }^{39}$. However, this recent postulation neglects one controversial issue in the diagnostic procedure, namely, the increased evidence of the involvement of sensory system in $10-20 \%$ of the patients. Furthermore, in some cases even polyneuropathy or sensory ganglionopathy has been reported ${ }^{40,41}$.

However, the probability categories for the ALS diagnosis are mostly depending on the clinical evidences described above, while electrophysiological examinations play a minor role. Since these electrophysiological findings can support the clinical observations, the Awaji Group suggested more prominent role for such examinations ${ }^{42}$. Since electrophysiological changes in the muscles are comparable to the clinical signs, these observations might be capable of confirming the affectability of weak muscles. Furthermore, body regions with strong muscles but electrophysiological sign of denervation may be included for the diagnosis ${ }^{42}$.

\section{Pathological observations}


French neurologist, Jean Martin Charcot, was the first who defined ALS as „la sclérose latérale amiotrophique" which is a French expression for the pathological manifestation of the disease ${ }^{43}$. Pioneering work of Professor Charcot was the autopsy report of the scar tissue in the anterolateral fasciculus of the spinal cord which manifested as spasticity and paralysis in the patients ${ }^{43}$. Until the late 90's the most prominent pathological observations in postmortem ALS tissue were loss of motor neurons in the spinal cord, brainstem and motor cortex. This neuronal degeneration was often accompanied by astrogliosis in the affected regions of the CNS. Moreover, even the surviving motor neurons showed pathological hallmarks of degenerations such as large number of lipofuscin granules or extensive atrophy of the cell bodies.

Other features of neuronal degeneration include the loss of nerve fibers, especially in the pyramidal tract and neurogenic abnormalities in the muscles. However, these pathological changes are not unique features of $\mathrm{ALS}^{44}$, other neurodegenerative diseases might show similar conditions, especially different motoneuron diseases and acute injuries ${ }^{45}$. In the last two decades, exclusive pathological alterations for ALS were identified by recognition of intracellular inclusions in routinely stained (hematoxylin and eosin) pathological samples, such as eosinophilic granular Bunina bodies that can be noticed in 65-95\% of ALS tissues ${ }^{44}$. Since the extensive use of immunohistochemical analysis in the pathological practice, ubiquitinated inclusions with nearly $100 \%$ occurrence and high specificity for ALS have been discovered $^{46}$.

\section{Processes involved in the pathophysiology}

According to the contemporary view, ALS is a highly heterogeneous condition, often accompanied with cognitive impairment and, though extrapyramidal, cerebellar, autonomic and sensory system involvement is rare, it is now considered a multisystem disorder ${ }^{47}$. Since the underlying pathological condition involves multiple cell types, such as astrocytes ${ }^{7}$, microglial cells ${ }^{28}$, infiltrating immune/inflammatory cells ${ }^{29}$, and due to the complex interaction between the identified genetic factors and basic molecular pathways of its pathophysiology, ALS is recognized as a non-cell-autonomous ${ }^{48,49}$, and multifactorial disease $^{50}$. Several excellent reviews are available providing an overview of the reciprocal relationships of the major individual toxic mechanisms leading to motoneuronal degeneration, such as excitotoxicity, oxidative stress, mitochondrial dysfunction and immune/inflammatory processes $^{7-13,51,52}$. Our discussion now will focus on the role of calcium ions, showing that regardless of the site and type of the primary lesion, increased 
intracellular levels of calcium ions could merge the identified individual toxic mechanisms into a single self-perpetuating cycle of motor neuron degeneration. In relation to these pathological processes, some properties of motor neurons predisposing them to calcium mediated injury, like low calcium buffering capacity and specific composition of glutamate receptors, will also be discussed.

\section{Excitotoxicity}

Early pioneering work in the late 60's by Olney, who coined the term excitotoxicity, led to the general appreciation that toxicity induced by excess exposure to excitatory amino acids was not restricted to retinal neurons exposed to glutamate, the experimental system in which the effect was first described. In fact, excitotoxicity might be responsible for a wide variety of brain damage observed in acute injury and slowly evolving neurodegenerative diseases $^{53}$. The role of excitotoxicity in ALS was then proposed ${ }^{54}$, based on the original observations that glutamate levels in the plasma of ALS patients were 2-fold higher than controls $^{55}$. Likewise, high levels of glutamate and aspartate have also been detected in cerebrospinal fluid of ALS patients ${ }^{56}$.

These data were further supported by reports of reduced levels of the excitatory amino acid transporter (EAAT) 2 in the motor cortex and spinal cord of the majority of ALS patients $^{57}$, since a rapid uptake of glutamate is accomplished by the EAAT1 and EAAT2 glutamate transporters, as it was timely reviewed by Mitsumoto et al. ${ }^{58}$. In parallel studies it was also documented that some ALS patients possess alterations to the structure of the $\alpha$ amino-3-hydroxy-5-methyl-4-isoxazolepropionic acid (AMPA) type glutamate receptor. Normally, AMPA receptors are impermeable to calcium. However, if one of their subunits the glutamate receptor subunit 2 (GluR2) - is missing, these receptors become permeable to calcium ions ${ }^{59}$. During neurotransmission, this alteration induces an increased calcium influx into the postsynaptic motor neuron, which may trigger injury. The low expression of the GluR2 protein subunit ${ }^{60}$, or the messenger ribonucleic acid (mRNA) for GluR2 ${ }^{61}$, was indeed seen in ALS patients, which could provide a molecular basis for the increased calcium influx, further amplifying the effect of the high glutamate level.

\section{Oxidative stress}

The presence of tissue damage due to oxidative stress in ALS has been shown by several postmortem studies. Elevated carbonyl derivatives were detected in the spinal cord and motor cortex of ALS patients ${ }^{62,63}$ due to direct oxidation of lysine, arginine, tyrosine, proline and threonine residues ${ }^{64}$. Additionally, increased 3-nitrotyrosine level was found in 
spinal motor neurons of patients ${ }^{65}$, which is a marker of peroxynitrite-mediated damage ${ }^{64}$. These autopsy findings were later corroborated with data obtained from cerebrospinal fluid or blood of ALS patients, demonstrating increased levels of 8-hydroxy-2'-deoxyguanosine, a marker of oxidized DNA ${ }^{66,67}$, and 4-hydroxy-nonenal, a marker of lipid peroxidation ${ }^{68,69}$.

Plasma membranes and embedded ion channel proteins are distinct targets of free radicals involved directly in changing the intracellular ionic milieu ${ }^{70}$. The action of free radicals on membrane fatty acids may either change membrane fluidity, resulting in secondary clustering or oversensitization of voltage-gated calcium channels ${ }^{71}$, or may directly alter ion channel properties resulting in increased P/Q-type calcium channel activity, as it was shown in calcium channels expressed in Xenopus oocytes ${ }^{72}$. Alternatively, reactive oxygen species (ROS) may interact with inositol 1,4,5-trisphosphate, ryanodine receptors and sarco/endoplasmic reticulum $\mathrm{Ca}^{2+}$ adenosine triphosphatase transporters present in the membrane of the endoplasmic reticulum, leading to increased calcium release and decreased uptake by the organelle under oxidative stress, resulting in increased intracellular calcium levels ${ }^{73}$.

ROS are continuously generated during physiological cellular processes, mainly due to leakage of electrons from the respiratory chain in the mitochondria, thus the cells are equipped with robust ROS detoxifying machinery. SOD1 is the major enzymatic defense system in the cytosol, catalyzing the conversion of superoxide radicals to hydrogen peroxide, which is converted by glutathione and catalase to harmless oxygen and water. Thus, the discovery of mutations in SOD1 in patients in 1993 led to expectations that the degenerative mechanism for motor neurons in ALS would soon be interpreted as impaired oxidative protection in motor neurons ${ }^{26}$. On the basis of the identified mutations, more than twenty rodent models were generated which recapitulated several aspects of the human disease and are being widely used in ALS drug studies ${ }^{74}$. However, despite more than two decades of intensive studies, the detailed mechanism of the toxicity of the mutant SOD1 (mSOD1) remains elusive ${ }^{75}$. While the importance of ROS mediated mechanisms in the pathophysiology of ALS is not questioned, it is now generally accepted that ROS mediated toxicity is multifactorial ${ }^{10,76}$, and is, at least partially, based on ROS produced by microglia ${ }^{77}$.

\section{Mitochondrial dysfunction}

Abnormalities of motoneuronal mitochondria in ALS were first identified as their fine structural alterations in the intramuscular nerves ${ }^{78}$ and in the anterior horn neurons ${ }^{79}$ in autopsy samples from patients. This was later corroborated by electron microscopic images 
also from autopsy cases by describing alterations in the intermembrane space and the inner compartments of mitochondria ${ }^{80}$. Altered mitochondrial functions were also described in postmortem ALS patients' spinal cord samples as reduced activity of citrate synthase and respiratory chain complexes I+III, II+III, and IV, which correlated with an increased level of mutant mitochondrial $\mathrm{DNA}^{81}$. Structural and functional mitochondrial abnormalities could be transferred to mitochondrial DNA depleted neuroblastoma cells by transferring mitochondrial DNA from ALS patients ${ }^{82}$, which corroborates significant mitochondrial involvement in the pathogenesis of $\mathrm{ALS}^{83}$. More direct evidence of mitochondrial alteration in ALS came from an electron microscopic study of motor nerve terminals performed in muscle biopsies of ALS patients at early diagnostic stages of disease, describing swelling and increased mitochondrial volume of motor axon terminals ${ }^{2}$. The assumption that mitochondrial malfunction is not a byproduct of degeneration but involved in disease progression at an early stage got further support from microscopic studies of transgenic animals created on the basis of the SOD1 mutations identified in the patients, describing degenerating mitochondria in the spinal motor neurons at presymptomatic stages of the disease ${ }^{84}$. In a follow-up electron microscopic study, Bendotti et al. documented mitochondrial swelling in mSOD1 mice as early as 2 weeks of age, which considerably preceded the development of the initial symptoms of the disease ${ }^{85}$.

Besides the endoplasmic reticula in neuronal cells, mitochondria are the major organelles shaping cytosolic calcium levels ${ }^{86}$, thus the described mitochondrial damage in motor neurons of patients and of mSOD1 transgenic mice may result in impaired calcium buffering and a consequent calcium increase in the cytoplasm through mSOD1 mediated mechanisms ${ }^{87,88}$. Indeed, Damiano et al. demonstrated impaired calcium handling in mitochondria isolated from mSOD1 mice already in the presymptomatic stage ${ }^{89}$. Accordingly, as Jaiswal and Keller demonstrated by using brainstem slices from mSOD1 mice, vulnerability of motor neurons may result from the disruption of the mitochondrial electrochemical potential, and, in relation to the powerful mitochondrial control of intracellular calcium levels, low calcium buffering ${ }^{90}$. Increased cytosolic calcium paired with loss of mitochondrial membrane potential was actually demonstrated in neuroblastoma cells transfected with plasmids directing expression of glycine-93 to alanine substituted form of (G93A) mSOD1 ${ }^{91}$.

\section{Immune/inflammatory processes}

The formation of glial scars as a consequence of inflammation at the lateral tract of the spinal cord was one of the first pathological observations in an ALS patient ${ }^{24,92}$. This 
finding was later corroborated by classical $20^{\text {th }}$ century techniques of neuropathology describing a massive astrocytosis particularly at entering points of the corticospinal tracts into the gray matter of the spinal cords of ALS autopsy cases ${ }^{93}$. Although astrocytes are not the authentic immune cells in the CNS, in the recent years it has become evident that they can produce components of the innate immune system which may be involved in the elimination of pathogens in the brain ${ }^{94,95}$.

Microglial cells are the primary immune cells resident in the nervous system ${ }^{96,97}$ and can be identified as ramified, cluster of differentiation $11 \mathrm{~b}$ (CD11b) expressing cells ${ }^{98}$, which shift from the surveillance mode to an activated state upon any kind of brain injury ${ }^{99}$. Accordingly, widespread microglial activation was demonstrated by $\left[{ }^{11} \mathrm{C}\right](\mathrm{R})-\mathrm{PK} 11195$ positron emission tomography (PET) in the motor cortex of ALS patients with significant correlation between the PET signal and a clinical observation of burden upon the upper motor neurons ${ }^{100}$. These observations were extended to the spinal cord in autopsy material, using the same technique which showed increased $\left[{ }^{11} \mathrm{C}\right](\mathrm{R})$-PK11195 binding in the lateral and the ventral white matter of the patients ${ }^{101}$. These findings were subsequently corroborated with cutting edge imaging techniques, allowing assessment of microglial activation in brain areas of the patients in vivo ${ }^{102,103}$.

In ALS, the main targets of the disease are motor neurons, however, the principal components of cellular inflammation, microglial cells and astrocytes, responding cooperatively to signals indicating neuronal malfunction, contribute to the degeneration of motor neurons ${ }^{50,104}$. Depending on the dialogue between neurons, microglia and astrocytes, which is also mediated by $\mathrm{T}$ lymphocytes, the concerted cellular neuroinflammatory reaction may act as a double edged sword, resulting in either a neuroprotective or neurotoxic outcome $^{29,49}$. Although inflammatory cells directly do not influence intracellular levels of calcium in motor neurons, they may act indirectly through ROS production by astrocytes ${ }^{105}$ or microglia ${ }^{106}$.

Humoral immunity may also play a role in the progression of ALS, since as recently has been documented, a panel of 20 serum antibodies could be identified which discriminate ALS patients from non-diseased control subjects with $100 \%$ specificity and $99.9 \%$ sensitivity ${ }^{107}$. Among other anti-motoneuronal antibodies present in the sera or cerebrospinal fluid of the patients ${ }^{50}$, those, interacting with voltage-gated calcium channels may directly influence the intracellular calcium level of motor neurons and their axon terminals ${ }^{108,109}$. Indeed, in an authoritative set of experiments conducted by S.H. Appel and coworkers ${ }^{110}$, the presence of immunoglobulin $\mathrm{G}(\mathrm{IgG})$ antibodies for L-type voltage gated $\mathrm{Ca}^{2+}$ channels were 
documented in $75 \%$ of sporadic ALS patients ${ }^{111}$. Subsequent experiments have shown that ALS IgG binds the ionophore containing $\alpha_{1}$ subunit of the voltage-gated calcium channels ${ }^{112}$. ALS IgG can interact and alter the function of muscular L type calcium channels ${ }^{113}$ and neuronal N-/ P-/ Q-channels as well ${ }^{114}$. The interaction of ALS IgG with these calcium channels enhances inward calcium current ${ }^{115}$ and increases intracellular calcium ${ }^{3}$ as it was demonstrated in a motor neuron cell line.

\section{Calcium is a common denominator in the pathophysiology of ALS}

As outlined above, the major pathological processes of ALS, identified so far, could lead to an increase of intracellular calcium in motor neurons, which suggests that calcium may play a central role in the pathobiology of the disease. Indeed, compared to other cations, due to its superior property of reversible complex formation by specific proteins ${ }^{116}$, the evolutionary choice for a ubiquitous intracellular messenger was calcium, triggering or modulating all aspects of neuronal functions ${ }^{117}$. As with most of the biochemical reaction, an inverted U-shaped curve characterizes the optimal range of concentration of the reaction components: either too low, or too high values are irreconcilable with life. At the lower end of the concentration range, the indispensable role of calcium for cellular functions was first evidenced by the landmark observation of Sidney Ringer ${ }^{118}$ on isolated hearts. At the other end of the scale, regarding the universal signaling function of calcium in nerve cells, it is not surprising that enduring or excess elevations of intracellular calcium may induce cell death as well ${ }^{119,120,121}$. Accordingly, the involvement of increased calcium was documented in the pathomechanism of a wide variety acute neuronal lesions or chronic neurodegenerative diseases, such as ischemic ${ }^{122}$ or traumatic brain injury ${ }^{123}$, Huntington's disease ${ }^{124}$, Parkinson's disease ${ }^{125}$, Alzheimer's disease ${ }^{126,127}$, multiple sclerosis ${ }^{128}$ or ALS ${ }^{129,130}$.

Abnormal calcium signaling has damaging effect on neurons, and can contribute to the death of nerve cells in several ways ${ }^{131-135}$. Briefly, calcium can activate calpains and caspases that break down cytoskeletal or membrane proteins and degrade metabolic enzymes ${ }^{136}$. Furthermore, increased calcium can lead to apoptotic cell death directly either by activating calcium-dependent apoptotic proteins ${ }^{137,138}$ or through processes involving mitochondrial functions ${ }^{12,139}$. Moreover, elevated intracellular calcium leads to formation of damaging free radicals and production of injurious superoxide anions either via mitochondrial calcium sequestration ${ }^{140,141}$ or because of activation of enzymes, such as nitric oxide synthase, phospholipase $\mathrm{A}_{2}$ and xanthine oxidase ${ }^{142,143,144}$. As a product of different intrinsic injurious pathways, distress signals can be released by neurons which lead to full- 
blown inflammatory reactions, mediated by reciprocal dialogues between neurons and neighboring astrocytes and microglial cells ${ }^{7,13,52}$.

In ALS, several specific features of abnormal calcium handling have been described. Thus, in in vitro synaptosome preparations - obtained from spinal cords of mSOD1 mice elevated calcium levels were detected. Furthermore, increased calcium-dependent exocytotic glutamate release could be evoked from presynaptic terminals, compared to wild type synaptosome. The phenomenon, extrapolating to in vivo, might contribute to augmented excitotoxicity $^{145}$. In biophysical experiments, performed also in vitro, a calcium-induced conformational change of SOD1 was demonstrated which facilitates its amorphous aggregation $^{146}$, a hallmark of ALS, thus contributing to SOD1-mediated pathomechanisms by causing mitochondrial oxidative stress ${ }^{84}$. These latter results accentuate the role of calciummediated protein misfolding in non-SOD1 ALS ${ }^{11,147}$.

\section{Intrinsic properties influencing motoneuronal vulnerability}

Clinically, not all groups of motor neurons are affected or degenerate at the same rate during the course of the disease. Typically, oculomotor neurons and sacral motor neurons innervating sphincter muscles, which are located in the nucleus of Onufrowicz, are spared in ALS, except in cases with unusually long survivals ${ }^{37}$. Several features may be responsible for the different susceptibility of certain types of motor neurons, such as size of perikaryon, length of axon, metabolic rate, lack of monosynaptic connection with corticomotor neurons, etc. $^{7,28}$. However, with regard to the stability of their calcium homeostasis, the roles of intracellular calcium handling and calcium influx through the plasma membrane are generally emphasized ${ }^{130}$.

\section{Calcium binding protein content and relative resistance of motor neurons}

The most common calcium binding domain of cytosolic proteins is the EF-hand motif, which forms a loop that can accommodate calcium ions ${ }^{148}$. Through their calcium binding, all the EF-hand proteins do influence local concentrations of calcium, however, for many of them, such as for calmodulin, or troponin C, calcium buffering is far less significant than their regulatory function ${ }^{149}$. Immunohistochemical mapping of the brain regions of rodents for the distribution of different calcium binding proteins ${ }^{150,151,152}$ finally led to the conclusion that high neuronal parvalbumin (PV) and/or calbindin- $\mathrm{D}_{28 \mathrm{k}}$ content could be a marker denoting the resistant types of motor neurons in $\mathrm{ALS}^{153}$. The relevance of these data in the human disease got support from similar studies performed in human autopsy material from ALS and non-ALS patients ${ }^{15,154}$. Finally, that the increased calcium binding protein 
content truly contributes to the improvement of calcium buffer capacity in resistant neurons was demonstrated in a series of seminal experiments performed in the laboratory of B.U. Keller. By using tissue slice preparation, calcium imaging and the "added buffer" technique, they documented a higher calcium buffer capacity in resistant oculomotor neurons relative to the low calcium buffer capacity in the susceptible hypoglossal and spinal motor neurons ${ }^{18,155,156}$.

The protective role of increased calcium buffering, represented by elevated calcium binding proteins, has been tested in various in vitro, ex vivo and in vivo experiments. In vitro, undifferentiated VSC 4.1 motoneurons with high calbindin- $\mathrm{D}_{28 \mathrm{k}}$ proved to be resistant if challenged with IgG from ALS patients, but became vulnerable after differentiation, and exhibited increased calcium after IgG application ${ }^{17}$. However, this vulnerability could be reversed by transfecting the cells with calbindin- $\mathrm{D}_{28 \mathrm{k}}{ }^{17}$. Neuromuscular preparations from extensor digitorum longus and external oculomotor muscles were challenged ex vivo with ALS IgG. Spontaneous transmitter release was selectively increased in the vulnerable types of terminals, suggesting that resistance to physiological abnormalities induced by ALS sera in mice parallels the resistance of extraocular motoneurons to dysfunction and degeneration in $\mathrm{ALS}^{157}$. In vivo, transgenic mice with upregulated motoneuronal PV were challenged either in acute sciatic nerve crush injury setting ${ }^{158}$, or chronically, by crossing to the mSOD1 transgenic mice, creating a double transgenic strain ${ }^{159}$, which suggests PV upregulation could confer reasonable neuroprotection. Calculations demonstrating a hyperbolic decrease of calcium amplitudes around calcium channels with increasing buffering capacity might provide a theoretical background for such protective effects ${ }^{19,156}$.

\section{Calcium permeability of AMPA receptors and resistance of motor neurons}

One leading hypothesis (excitotoxicity) for the selective death of motor neurons in ALS is based on the selective change of calcium permeability of AMPA receptors in the plasma membrane of postsynaptic motor neurons ${ }^{29}$. The AMPA receptors are assembled from 4 subunits and their permeability to calcium is determined by the absence of the glutamate receptor subunit type $2(\mathrm{GluR} 2)^{8}$. Although literature data are not fully consistent regarding the correlation of the susceptibility of motor neurons with the missing GluR2 subunit in their AMPA receptors ${ }^{160,161}$, it was repeatedly reported that both mRNA for GluR2 subunit, and GluR2 protein levels were decreased in vulnerable motor neurons ${ }^{60,162}$. Furthermore, a recent microarray analysis of transcriptional profiles of oculomotor and spinal motoneurons dissected from neurologically normal human controls, revealed an upregulation of all GluR1- 
4 subunits in the oculomotor neurons, compared to spinal motor neurons, including a 2.31fold increase of the GluR2 subunit ${ }^{163}$. The expected reduced permeability of AMPA receptors for calcium was then verified in patch clamp experiments performed in acute tissue slices cut from the spinal cord and the brainstem of adult rats indicating a reduced inward current in oculomotor neurons ${ }^{163}$. The absence of GluR2 was associated with an increased portion of unedited GluR2 mRNA at the glutamine/arginine $(\mathrm{Q} / \mathrm{R})$ site, as it was demonstrated in ALS tissue $^{164}$. Since RNA editing at this location is predominantly catalyzed by the adenosine deaminase acting on RNA 2 (ADAR2), these data suggest the relevance of the inefficiency of ADAR2 in the pathomechanism of ALS. Indeed, in a conditional ADAR2 knock-out mouse only the ADAR2-lacking spinal motor neurons degenerated, which could be prevented by generating $\mathrm{Q} / \mathrm{R}$ site edited GluR2 in the absence of ADAR2 by a point mutation in the endogenous GluR2 alleles ${ }^{165}$. These data point to the decreased level of ADAR2 mRNA as a molecular basis underlying the increased calcium permeability of AMPA receptors.

\section{AIMS OF THE STUDY}

Based on experimental data on the ability of an AMPA receptor antagonist, talampanel (Tal), reducing calcium influx into motor neurons and ameliorating disease progression in the mSOD1 model of ALS, clinical trial has been initiated to slow the evolution of the disease in ALS patients. However, the test was aborted, since the study did not meet its primary endpoint. In our previous experiment we gave evidence, that the failure of the clinical study might be attributed to the late initiation of the treatment relative to the disease onset. To prove that the rationale of the treatment based on reducing calcium influx is still compelling, it needed to demonstrate that the pitfall of the treatment is not due to its inefficiency at the distant motor axon terminals where the disease probably starts. Thus, our first aim was:

\section{To demonstrate that the soma targeted treatment with Tal is equally effective to} prevent calcium increase at the perikarya and at the distal axon terminals of motor neurons of mSOD1 mice if the treatment starts at an early phase of the disease.

It is now widely accepted that neurons could be protected from calcium-mediated injury by reducing the calcium influx through appropriate calcium channels on their plasma membrane. Previously we have shown that, alternatively, by elevating their CaBP content, an increased resistance could also be provided for motor neurons against acute injury or during chronic stress conditions. Besides their calcium buffering capacity, a crucial intrinsic property, nearby inflammatory reaction may also have an effect on the final fate of injured 
motor neurons. To demonstrate the possible connection between these two important factors shaping the survival of motor neurons after injury, our second aim was:

2a. To visualize the magnitude and time course of neighboring microglial activation of injured motor neurons with differently elevated calcium content achieved by upregulated calcium binding protein (in this case, PV) content.

2b. To standardize the measurement of the intracellular calcium content at electron microscopic level, a procedure was aimed to develop, which minimizes the variability of measurements by standardizing the thickness of sections used for analysis.

As it was shown, by increasing motoneuronal PV content, intracellular calcium elevation evoked by injury could be prevented, furthermore, the local microglial reaction could be moderately decreased. To investigate if injury-induced inflammatory reaction could be further reduced by mutually targeting microglia activation and stabilization of intracellular calcium, our third aim was:

3a. To test the effect of diazoxide treatment on microglia activation in different motor nuclei after axotomy, since besides its anti-inflammatory effect, diazoxide was shown to protect neuronal mitochondria from calcium overload in our previous hypoxiareperfusion experiments.

3b. To quantify microglia activation in identified motor nuclei, a doubleimmunostaining procedure was aimed to develop, which allows the determination of the volume of motor nuclei with fluorescently labeled motor neurons, and the simultaneous measurement of the relative volume of the non-fluorescently labeled microglial cells.

\section{MATERIALS AND METHODS}

\section{Experimental animals}

The animals were housed in plastic cages (five animals per cage, at most) in a thermoneutral $\left(21 \pm 3{ }^{\circ} \mathrm{C}\right)$ conventional animal facility under a 12-hour dark/light cycle, with free access to food (regular rodent chow) and tap water ad libitum. All experiments were carried out in compliance with institutional guidelines for the use and care of experimental animals and governmental laws for animal protection. Experimental protocols and animal care were approved by the Ethical Committee for the Protection of Animals in Scientific Research at the Biological Research Center (approval No. 72-45/b/2001 and No. 03876/0014/2006) and carried out in accordance with the national law (XXVIII. chapter IV. paragraph 31, 1998; 40/2013. (II.14)). These rules conform to the international laws and 
policies (Directive 2010/63/EU, 2013; NIH Guide for the Care and Use of Laboratory Animals, United States National Research Council, revised 1996). Tal treatment and the related experiments were in concordance with the Italian governmental law (Circolare No. 8, G.U., 14 luglio 1994). All efforts were made to minimize animal suffering and the number of animals used in this study.

\section{Talampanel treatment}

Hemizygotic transgenic mice (mean body weight of $21 \pm 4 \mathrm{~g}$ ), expressing a G93A substituted form of the human SOD1 gene, purchased originally from Jackson Laboratories, were maintained in a C57BL/6JOlaHsd mouse strain at the Mario Negri Institute for Pharmacological Research (Milan, Italy). Female transgenic mice were treated for two weeks with Tal $(5 \mathrm{mg} / \mathrm{kg}$ body weight dissolved in $0.1 \mathrm{ml}$ Tween $80 ; \mathrm{n}=12$ animals $)$ or vehicle (Veh; $0.1 \mathrm{ml}$ Tween 80; $\mathrm{n}=12$ animals) orally at the same time, daily. The appropriate dosage of Tal was selected on the basis of an unpublished pilot study in our laboratory. Tal was administered into the lower esophagus with a stainless steel gavage needle with a rounded tip. Treatments were started at 10 ( $n=6$ animals) or 17 weeks ( $n=6$ animals) of age corresponding to the presymptomatic and the symptomatic stage of neuromuscular dysfunction ${ }^{166}$. Tissue samples were harvested at 12 or 19 weeks of age. Age-matched female non-transgenic C57BL/6JOlaHsd mice were treated with Tal $(\mathrm{n}=12$ mice $)$ and Veh $(\mathrm{n}=12$ mice) similarly and used as controls. Altogether $n=48$ mice were used for the study, which were sorted into groups according to the strain $(n=24$ in the mSOD1 strain and $n=24$ in the control strain). Furthermore, these groups were divided into subgroups according to the treatment (Tal versus Veh) and the age of mice at the beginning of the treatment (10 weeks versus 17 weeks).

\section{Diazoxide treatment}

Balb/c non-transgenic mice (mean body weight of $22 \pm 5 \mathrm{~g}$ ) were donated by Prof. Dr. Engelhardt. Animals were housed in the conventional animal facility of the Biological Research Centre (Szeged, Hungary) for the period of the experiments. Examinations were performed on 30 adult (10-12 weeks old) male mice, altogether. To avoid multiple surgical procedures on individual animals (enucleation, hypoglossal and facial nerve transection), mice were assigned to three groups ( $n=10$ in each group) according to the type of surgery: unilateral eye enucleation, hypoglossal, or facial nerve axotomy. Five animals in each group were treated with diazoxide and five mice served as controls. Diazoxide (Sigma, $1 \mathrm{mg} / \mathrm{kg}$ body weight dissolved in $0.1 \mathrm{ml} 1 \%$ dimethyl sulfoxide solution) was administered at the 
same times, daily, by intraperitoneal injection for one week before surgery and for four days postoperatively until the immune/inflammatory reaction could be observed. Then the animals were sacrificed.

\section{Surgical procedures}

All surgical interventions were performed under deep and reversible anesthesia with Avertin (tribromoethanol, $240 \mathrm{mg} / \mathrm{kg}$ body weight in a $0.5 \mathrm{ml}$ volume) administered intraperitoneally. For axotomy/target deprivation of the oculomotor nerve, animals were enucleated, the right eyeball and the lacrimal gland was removed carefully from the orbit. In the case of hypoglossal axotomy, cranial nerve XII. was transected laterally to the hyoid bone and 2-3 mm nerve segment was dissected to prevent undesirable regeneration. Facial nerve axotomy was applied through an incision under the ear canal at the trunk of the facial nerve, then a $2-3 \mathrm{~mm}$ nerve segment was removed. For sciatic axotomy the nerve was transected at the mid-thigh and 2-3 mm nerve segment was removed to prevent undesirable regeneration. In each case the non-operated side served as an internal control. Following the surgery, mice were returned temporarily to empty cages until recovered from the narcosis. Then, animals were housed according to the previously described conditions.

\section{Characterization of the transgenic $P V+/+$ strain}

Two lines of PV overexpressing mice were generated in Dr. S.H. Appel's laboratory (The Methodist Hospital Neurological Institute, Houston, TX, USA) as described in details by Beers et al. ${ }^{159}$. The founder lines were bred to homozygosity and were characterized to prove that $\mathrm{PV}$ is transcriptionally and translationally expressed in the motor neurons of their spinal cords ${ }^{159}$. In situ hybridization, using the 5'-untranslated region of the rat CaMII promoter and the PV transgene confirmed the common presence of rat PV mRNA in the large motoneurons of the ventral horns, while immunohistochemistry was used to localize PV protein and proved its uniform presence in these cells (Fig. 1). Breeding pairs were obtained from the line $\operatorname{Tg}($ parv 14-4) and a transgenic colony was set up and maintained in the conventional animal facility of the Institute of Experimental Medicine (Budapest, Hungary). For the period of the sciatic axotomy experiments, animals $(n=48)$ were housed in the conventional animal facility of the Biological Research Centre (Szeged, Hungary). In our previous axotomy experiments, either non-transgenic B6/SJL mice, the parental strain for the $\mathrm{PV}+/+$ transgenic animals, or Balb/c mice were used as controls. Here, to provide unbiased comparability with the previous results and to exclude potential errors arising from straindependent sensitivity to axotomy, animals from both strains were used as controls. First, we 
compared their reaction to axotomy in all of the examined parameters (motoneuronal chemokine C-C motif ligand 2 (CCL2) staining, microglial activation and calcium content). Since the parameters showed no significant difference between the strains according to the Student's t-test ( $\mathrm{p}$ values between 0.96 and 1), pooled data obtained with the two strains were subsequently used as controls. These control mice, originally obtained from Charles River Laboratories (Budapest, Hungary), were bred in the conventional animal house of the Biological Research Centre (Szeged, Hungary).
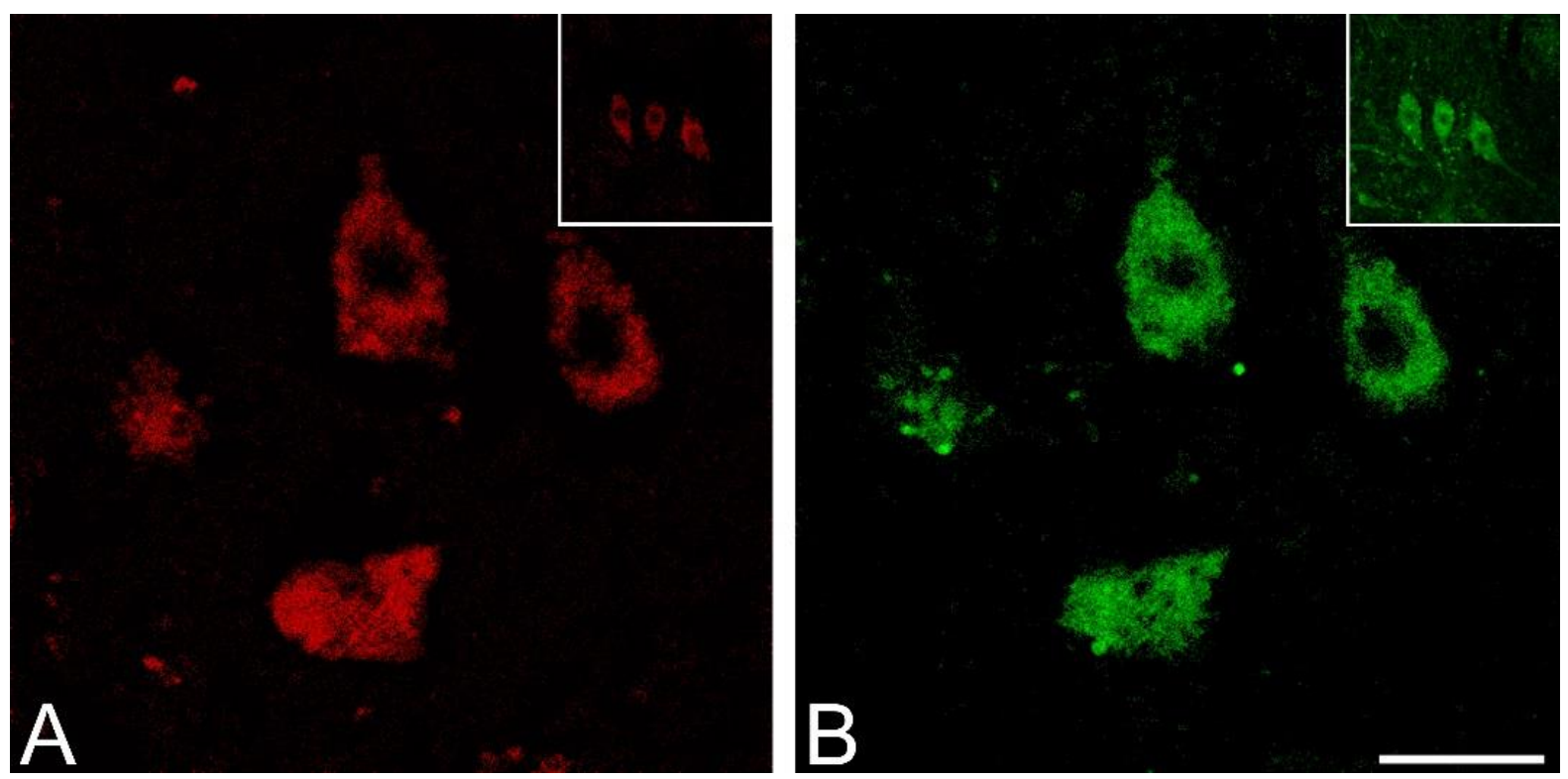

Fig. 1. Laser scanning confocal images from a double immunostained section at the ventrolateral region of the spinal cord from a homozygous mouse overexpressing PV. Colocalization of PV (red in panel A) with choline acetyltransferase (green in panel $B$ ) is clearly seen in large motoneuron-like profiles. In the inserts, a group of motor neurons is shown at retrodorsal lateral position, evidenced by the large number of PV immunopositive cross sectioned axons in the neighboring white matter ${ }^{150}$ (insert in B). Scale bar: $30 \mu m$.

Animals from the control and $\mathrm{PV}+/+$ strains were allocated for light microscopic immunocytochemistry at 1, 4, 7, 14 or 21 postoperative days, while mice were sacrificed for electron microscopic calcium histochemistry only at a single time point (postoperative day 7).

\section{Immunohistochemical staining and quantification}

\section{Specimen preparation for immunostaining}

Under irreversible anesthesia with Avertin (Fluka) or methoxyflurane (Fluka) mice were transcardially perfused with $10 \mathrm{mM}$ phosphate buffered saline (PBS; pH 7.4) followed by $4 \%$ paraformaldehyde (Sigma) in $10 \mathrm{mM}$ PBS (pH 7.4). The entire brain or spinal cord was exposed and removed then fixed further overnight in the same fixative at $4{ }^{\circ} \mathrm{C}$. After the fixation protocol, samples were cryoprotected in 30\% sucrose (Sigma), dissolved in $10 \mathrm{mM}$ 
PBS, for 24 hours at $4{ }^{\circ} \mathrm{C}$ and embedded in optimal cutting temperature medium (TissueTek). Series of consecutive sections of $30 \mu \mathrm{m}$ thickness were cut throughout the whole anatomical regions of interests with a cryostat (MNT, Slee), collected in $10 \mathrm{mM}$ PBS individually in wells of tissue culture plates and stored at $4{ }^{\circ} \mathrm{C}$ until processed for immunochemical staining. All of the immunostaining procedures were performed on $30 \mu \mathrm{m}$ thick free-floating cryostat sections.

\section{Single- and double staining for CCL2 and CD11b}

Series of sections from the lumbar spinal cords - containing the entire region of the expected inflammatory reaction - were used to evaluate the axotomy-induced changes in CCL2 or CD11b expression with immunohistochemistry according to the avidin-biotin technique. Sections were rinsed in $10 \mathrm{mM}$ PBS (3 changes, 5 min each) then endogenous peroxidase activity was blocked with $0.3 \% \mathrm{H}_{2} \mathrm{O}_{2}$ in $10 \mathrm{mM}$ PBS containing $0.2 \%$ Triton $\mathrm{x}$ 100 (TBPS; Sigma). After washing in $10 \mathrm{mM}$ PBS (3 changes, $5 \mathrm{~min}$ each), non-specific staining was blocked with $2 \%$ normal goat serum (Vector Laboratories; Cat\# S-1000) in $10 \mathrm{mM}$ TPBS for 1 hour, then the sections were incubated in the appropriate sequence of primary and secondary antibodies, according to the antigen to be detected. The CD11b antibody (AbD Serotec, Cat\# MCA711; 1:500) was applied at $4{ }^{\circ} \mathrm{C}$ overnight followed by washing in $10 \mathrm{mM}$ PBS (3 changes, $5 \mathrm{~min}$ each), then incubated in a biotinylated goat-antirat antibody (Vector Laboratories Cat\# BA-9400; 1:800). CCL2 antibody (PeproTech, Cat\# 500-P113-100 $\mu \mathrm{g}$; 1:1000) was applied at $4{ }^{\circ} \mathrm{C}$ overnight followed by washing in $10 \mathrm{mM}$ PBS (3 changes, 5 min each), then incubated in a biotin-labeled goat-anti-rabbit antibody (Vector Laboratories Cat\# BA-1000; 1:400). Next, all the sections were rinsed in $10 \mathrm{mM}$ PBS ( 3 changes, $5 \mathrm{~min}$ each), incubated in the avidin-biotin complex (Vector Laboratories Cat\# PK-6100; diluted to 1:1600 in PBS) for 1 hour at room temperature. Finally, after washing in $10 \mathrm{mM}$ PBS, the reactions were visualized by incubation in 5\% diaminobenzidine tetrahydrochloride (DAB; Sigma) in $10 \mathrm{mM}$ PBS for $15 \mathrm{~min}$. Stained sections were rinsed in $10 \mathrm{mM}$ PBS, mounted on silane coated glass slides, dehydrated in ethanol, processed through xylene and coverslipped with Entellan (Merck).

To display the relative location of the CCL2- and CD11b-stained profiles in the ventral horn of the spinal cords after axotomy, selected sections from the set of frozen sections obtained from the operated animals were double stained and visualized with fluorescent microscopy. Sections were rinsed, blocked to reduce non-specific staining in the same way as it was done with the avidin-biotin method. Sections were then incubated in the 
primary antibody cocktail of CD11b - 1:200 and CCL2 - 1:1000 in $10 \mathrm{mM}$ TPBS at $4{ }^{\circ} \mathrm{C}$ overnight. After washing in $10 \mathrm{mM}$ PBS (3 changes, 5 min each) sections were incubated for 1 hour at room temperature in a mixture of goat-anti-rabbit Alexa Fluor 546 (Life Technologies, Cat\# A11010) and goat-anti-rat Alexa Fluor 488 (Life Technologies, Cat\# A11006) fluorescent secondary antibodies, each dissolved at 1:200 dilutions in $10 \mathrm{mM}$ TPBS. Then, sections were washed in $10 \mathrm{mM}$ PBS (3 changes, 5 min each), mounted on silane coated glass slides, covered with Gel/Mount (Biomeda) and visualized in a fluorescent microscope (Vanox-T AH-2, Olympus). To improve quality and reduce noise, captured $1600 \times 1200$ pixel digital images were processed with the two-dimensional blind deconvolution module of the AutoQuant X program (Media Cybernetics).

\section{Fluorescent double labeling for PV and ChAT}

To demonstrate the presence of $\mathrm{PV}$ in the lumbar motor neurons of $\mathrm{PV}+/+$ mice, selected sections from these animals were pretreated with $2 \%$ normal donkey serum (Sigma, Cat\# D9663) in $10 \mathrm{mM}$ TPBS for 1 hour. Afterwards, sections were double stained with antibodies against PV and choline acetyltransferase (ChAT), then visualized using the appropriate primary (polyclonal rabbit-anti-rat antibody against PV (Swant Cat\# PV-28) and polyclonal goat-anti-ChAT antibody (Millipore Cat\# AB144P) diluted to 1:30000 and to 1:250 and fluorescent secondary donkey-anti-rabbit Alexa Fluor 546 (Life Technologies Cat\# A10040) and donkey-anti-goat Alexa Fluor 488 (Life Technologies Cat\# A11055) antibodies. However, the protocol of the fluorescent immunostaining remained the same as previously described. Sections were visualized under a laser confocal microscope (FV1000, Olympus). To improve the signal to noise ratio, captured digital images were processed with the twodimensional blind deconvolution module of the AutoQuant X program.

\section{Fluorescent double labeling for ChAT and Ibal}

To display the relative location of the ionized calcium-binding adaptor molecule 1 (Iba1)- and ChAT-stained profiles which represent the microglial inflammatory response after axotomy and the anatomical boundaries of motor nuclei, selected sections from the operated animals were double stained according to the previously described fluorescent staining protocol. Non-specific staining of the samples was blocked with $2 \%$ normal horse serum (Vector Laboratories, Cat\# S-2000) in $10 \mathrm{mM}$ TPBS for 1 hour. Sections were then incubated in the primary antibody cocktail of rabbit-anti-Iba1 (Wako Chemicals, Cat\# 01919741, 1:200) and sheep-anti-ChAT (EMD Millipore, Cat\# AB1582; 1:200) in 10 mM TPBS at $4{ }^{\circ} \mathrm{C}$ overnight. After washing in $10 \mathrm{mM}$ PBS, sections were incubated for 1 hour at room 
temperature in donkey-anti-sheep Alexa Fluor 488 (Jackson Immunoresearch, Cat\# 713-545003) dissolved at 1:100 in $10 \mathrm{mM}$ TPBS, then blocked for 1 hour with a mixture of $1-1 \%$ normal goat (Vector Laboratories, Cat\# S-1000) and normal donkey serum (Sigma Cat\# D9663) followed by goat-anti-rabbit Alexa Fluor 546 (Life Technologies, Cat\# A11010, 1:100). After immunostaining, sections were visualized in a fluorescent microscope (Eclipse 80i, Nikon). Captured $2560 \times 1920$ pixel digital images were processed with the twodimensional blind deconvolution module of the AutoQuant X program to enhance signal to noise ratio.

\section{Combined fluorescent and avidin-biotin based immunostaining}

A combination of the fluorescent staining protocol, to determine regions of interest in the sections, and the avidin-biotin technique, for the photostable visualization of cells, the number of which has to be quantified, was developed.

Sections were rinsed and blocked to reduce non-specific staining in the same way as with the fluorescent method, with an additional step to block the endogenous peroxidase activity with $0.3 \% \mathrm{H}_{2} \mathrm{O}_{2}$ in $10 \mathrm{mM}$ TPBS. This was followed by overnight incubation at $4{ }^{\circ} \mathrm{C}$ with a primary antibody cocktail containing a polyclonal rabbit-anti-rat antibody against Iba1 (Wako Chemicals, Cat\# 019-19741) and a polyclonal sheep-anti-ChAT antibody (Merck Millipore, Cat\# AB1582) diluted to 1:250 and to 1:500, respectively, in $10 \mathrm{mM}$ TPBS. After washing in $10 \mathrm{mM}$ PBS (3 changes, $5 \mathrm{~min}$ each), sections were incubated at room temperature in a donkey-anti-sheep Alexa Fluor 488 (Jackson Immunoresearch, Cat\# 713545-003) fluorescent secondary antibody for 1 hour, dissolved in 1:100 in $10 \mathrm{mM}$ TPBS. Then non-specific staining was blocked for 1 hour with a mixture of 1-1\% normal goat (Vector Laboratories, Cat\# S-1000) and normal donkey sera (Sigma Cat\# D9663) in $10 \mathrm{mM}$ TPBS, for 1 hour followed by incubation in a biotinylated goat-anti-rabbit antibody (Vector Laboratories, Cat\# BA-1000; 1:400). Next, all the sections were rinsed in $10 \mathrm{mM}$ PBS (3 changes, 5 min each), incubated in the avidin-biotin complex (Vector Laboratories, Cat\# PK6100) diluted to 1:1600 in PBS for 1 hour at room temperature. Then, after washing in $10 \mathrm{mM}$ PBS, the reactions were visualized by incubation in 5\% DAB (Sigma) in $10 \mathrm{mM}$ PBS for $15 \mathrm{~min}$. Finally, sections were washed in $10 \mathrm{mM}$ PBS (3 changes, 5 min each), mounted on silane-coated glass slides, covered with Gel/Mount (Biomeda) and visualized under a brightfield/fluorescent microscope (Eclipse 80i, Nikon).

Quantification of axotomy-induced change of immunostained cells 
For quantitative assessment of the axotomy-induced change of CCL2 and CD11b in the spinal cord, or Ibal in the brainstem nuclei, sets of $30 \mu \mathrm{m}$ thick consecutive sections were prepared from the appropriate CNS regions in such a way, that the entire volume affected by the surgery was sliced. The sections were stained with the DAB technique in case of CCL2 and $\mathrm{CD} 11 \mathrm{~b}$ antibodies, or with the combined DAB-fluorescent technique in case of ChAT and Iba1 antibodies. After immunostaining, digital images of the sections, displaying both the injured- and contralateral side of the appropriate anatomical region were made in a Nikon Eclipse 80i microscope equipped with a $2560 \times 1920$ pixel resolution MicroPublisher 5.0 RTV charge-coupled device (CCD) camera (QImaging). In sections from the brainstem, the fluorescently labeled ChAT positive cells were used as guides to delineate the boundaries of the motor nuclei. Then a consistent background subtraction algorithm was applied, based on internal controls in each section, to dissect the significantly stained DAB-labeled profiles in identical areas at the operated and contralateral sides. This was performed by using an interactive macro developed in our laboratory ${ }^{21}$ for Image-Pro Plus image analysis software (Media Cybernetics). Then the significantly stained partial profile areas were determined at both sides, expressed as percentage of the area of interest, and the algebraic differences between the operated and the contralateral sides were summed up throughout the series of sections to arrive at a single number characterizing the net change in the area induced by the axotomy in each animal.

\section{Transmission electron microscopic detection of calcium}

Tissue preparation for electron microscopy

To detect intracellular calcium, tissue samples were processed using the oxalatepyroantimonate technique, originally described by Borgers et al. ${ }^{167,168}$, adapted, and routinely used in our laboratory $5^{5,169,170,171}$. The method provides fine ultrastructural preservations and results in electron-dense deposits (EDDs) due to the precipitation of tissue calcium by the fixative. Briefly, animals, under terminal anesthesia with intraperitoneally applied Equithesin (1\% phenobarbital, $4 \%$ chloral hydrate, $6 \mathrm{ml} / \mathrm{kg}$ body weight), were transcardially perfused with $90 \mathrm{mM}$ potassium oxalate (Sigma; $\mathrm{pH}$ adjusted to 7.4 with $\mathrm{KOH}$ ) followed by $3 \%$ glutaraldehyde (Polysciences; $\mathrm{pH}$ adjusted to 7.4 with $\mathrm{KOH}$ ) containing $90 \mathrm{mM}$ potassium oxalate. The brains, spinal cords, hindlimb interosseus muscles, and external oculomotor muscles were removed and fixed in the same fixative overnight $\left(4^{\circ} \mathrm{C}\right)$. Specimens were then rinsed in 7.5\% sucrose (Molar) containing $90 \mathrm{mM}$ potassium oxalate ( $\mathrm{pH} 7.4$ ), postfixed with $2 \%$ potassium pyroantimonate (Merck) $+1 \%$ osmic acid (Sigma; $\mathrm{pH}$ adjusted to 7.4 with 
acetic acid (Molar) for 2 hours $\left(4^{\circ} \mathrm{C}\right)$. Next, specimens were rinsed in distilled water $(\mathrm{pH}$ adjusted to 10 with $\mathrm{KOH}$ ) for 10 minutes, dehydrated in a graded series of ethanol (Molar), processed through propylene oxide (Sigma), and embedded in Durcupan ACM (Fluka). Blocks were polymerized for 48 hours at $56^{\circ} \mathrm{C}$. Semithin $(0.3 \mu \mathrm{m})$ sections were cut from the blocks on an Ultracut UCT ultramicrotome (Leica), etched ${ }^{172}$, stained $^{173}$, and evaluated under an Eclipse 80i light microscope (Nikon) to identify pools of motor neurons in the CNS and zones of innervation in the muscles. After trimming the blocks to the appropriate regions, systematic sets of ultrathin sections $(50 \mathrm{~nm})$ were cut, mounted on single-hole formvar coated or uncoated 300 mesh copper grids (Electron Microscopy Sciences) and contrasted with uranyl acetate (Electron Microscopy Sciences; $2 \%$ in 50\% ethanol) and lead citrate (Electron Microscopy Sciences; $2 \%$ in distilled water). The distance between the sections was $15 \mu \mathrm{m}$ and $50 \mu \mathrm{m}$ in muscle samples and blocks containing brain tissue respectively, to avoid sampling identical neuromuscular synapses or motor neurons during the collection of electron microscopic fields of views.

\section{Specificity control of the calcium-specific histochemical reaction}

The calcium content of the EDDs was tested by electron probe X-ray microanalysis. For this purpose, non-contrasted sections were prepared and examined in a JEOL JEM-1400Plus transmission electron microscope operated at $120 \mathrm{kV}$, equipped with an $8 \mathrm{MP}$ JEOL camera and a JEOL Dry SD30GV SDD $30 \mathrm{~mm}^{2}$ X-ray detector. X-ray spectra were recorded in the $0-40 \mathrm{keV}$ energy range for $200 \mathrm{~s}$, and were analyzed by the Visual Identification- and Thin Film Standardless Quantitative Analysis Programs of the JED-2300 Analysis Station.

\section{Determination of the relative amount of EDDs}

Ultrathin sections were analyzed under a CEM 902 electron microscope (Zeiss) in conventional transmission mode. Sections were systematically screened at low magnification $(1000-3000 \times)$ for the presence of profiles of motor neurons and profiles of motor nerve terminals from the interosseus and the oculomotor muscles until 15 fields of view could be spotted from each muscle or neuroanatomical region of each animal. The screening protocol was applied for all experimental groups identically regardless of the experiment. Then the relative volume of the perikaryal, mitochondrial and cytoplasmic regions and the partial volume of the axon terminals occupied by the EDDs were determined by point counting methods ${ }^{174,175}$. Briefly, 8-bit gray scale images were recorded at instrumental magnification of $12000 \times$ (for axon terminals) or at $20000 \times$ (for motor neuron somas) with a Spot RT 14.0 monochrome charge-coupled device camera (Diagnostic Instruments Inc.) and saved in 
tagged image format. Recorded images were analyzed with the built-in modules of the Image-Pro Plus (Media Cybernetics) image analysis program. Tessellation of sampling points was superimposed on each electron microscopic image, then sampling points hitting the perikaryal profile or the axoplasmic area of the nerve terminals in each image served as reference areas and were counted. Sampling points hitting EDDs within the reference areas were counted, as well. The corresponding counts obtained in the individual fields were summed up throughout the series of the identified motor neurons or end plates in each animal, and the appropriate ratios expressing the relative amount of EDDs within these structures were calculated for each animal. In the case of the $\mathrm{PV}+/+$ mice and their controls the ratios expressing the relative amount of mitochondrial and cytoplasmic calcium in the motor neurons at the operated and contralateral side were calculated and expressed as fold increase.

The above summarized counting protocol results in the partial volume (volume/volume) of EDDs within a selected reference space (e.g. mitochondrial volume) assuming that the test object is a two-dimensional plane with zero thickness. Since this cannot be achieved physically, the possible overprojection of the EDDs through the thickness of the sections was visualized by electron tomography. For tomographic imaging, sections with thickness of $50 \mathrm{~nm}$ were prepared, mounted on formvar coated single hole copper grids, contrasted with uranyl acetate and lead citrate, then examined in a FEI Tecnai Spirit transmission electron microscope. Tomography tilt series were acquired at $120 \mathrm{kV}$ accelerating voltage with a FEI Eagle 4k CCD camera, using the integrated FEI tomography software. Tomograms were reconstructed using FEI Inspect 3D software. This test indicated the necessity of the standardization of the thickness of the sections used for such measurements. Since a constant thickness of the section could not be guaranteed by either the nominal thickness setting of the ultramicrotome or the interference color of the sections, a procedure for in situ measurement of actual section thickness in the electron microscope was adapted, based on the Bouguer-Beer-Lambert beam attenuation law ${ }^{176}$. The precision of the method was tested by correlating the calculated thickness according to the attenuation law to the true thickness of the same section measured by atomic force microscopy (AFM). For this correlative analysis, sections with different thicknesses in the range of $20-80 \mathrm{~nm}$ were prepared, mounted on single-hole copper grids and examined in the electron microscope (Zeiss CEM 902). Beam intensities with and without the section in the beam path were determined using the central $100 \times 100$ pixel area of the CCD camera set to manual mode with constant exposition time. Then the logarithmic value of the ratio of the incident to 
transmitted beam intensity, which is proportional to the section thickness at that tissue point, was calculated. Then, sections were removed, inserted into an AFM equipped with an Asylum Research MFP-3D head and Molecular Force Probe controller (Asylum Research). The measurements were taken with rectangular silicon OMCL-AC240TS type cantilevers (Olympus), with tetrahedral tip. The AFM topographic images were taken with tapping mode in air, and the height of the sections (i.e. the section thickness) were measured from the level of the supporting formvar foil in line scan mode.

\section{Statistical analysis}

All statistical analyses were performed with R (3.3.1) statistical computing software with RStudio Integrated Development Environment (version 3.0) for Windows. Data are presented as a mean value \pm the standard error of the mean (s.e.m.).

To determine the average volume occupied by the EDDs within the cellular compartments of motor neurons, data derived from individual electron microscopic fields were pooled according to animals, treatments and neuronal regions. Fifteen fields of view were analyzed in the perikaryal regions, from each animal, with 6 animals in each treatment group. At the axon terminals in the oculomotor- and the interosseus muscle 15 fields were obtained for each, respectively, from each animal, with 6 animals in each treatment group. Differences among multiple means were assessed, as indicated, by one-way analysis of variance (ANOVA), followed by a Bonferroni post-hoc test.

Differences among multiple means of Ibal immunostaining intensities and areas of Ibal in each anatomical structures were assessed by two tailed Student's t-test.

Integrated value of intensities and areas of CCL2 and CD11b were assessed by oneway ANOVA, followed by a Fisher's least significance difference post-hoc correction. Differences among the mean calcium concentrations in different subcellular compartments of PV upregulated $(\mathrm{PV}+/+)$ and their control animals were assessed by Student's t-test.

\section{RESULTS}

\section{Effect of talampanel on the calcium level of motor neurons of mSOD1 mice}

Qualitative electron microscopic examination of motor axon terminals in the interosseus muscle of mSOD1 mice revealed no structural alteration at the presymptomatic stage (Fig. 2B) compared to the age matched controls treated with Veh only (Fig. 2A). 

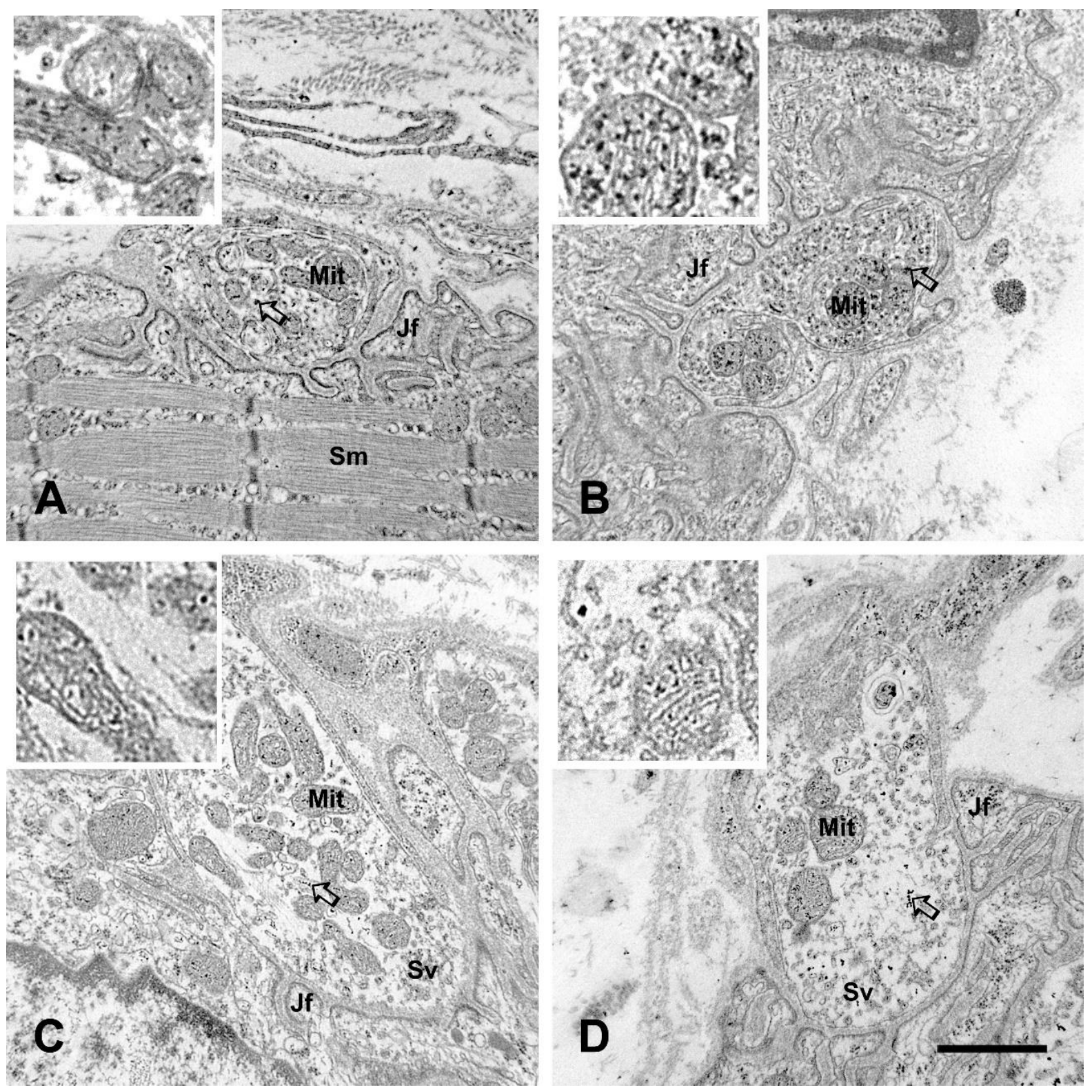

Fig. 2. Calcium-containing EDDs in motor nerve terminals in the interosseus muscle of 12 weeks old mice. A, C: nerve terminal from non-transgenic mice treated with Veh or Tal, respectively. B, D: axon terminals from mSOD1 mice treated with Veh, or Tal, respectively. Qualitatively, Tal treatment has no effect on the EDD content in wild type animals (A vs. C), but the presence of the mSOD1 enzyme increases the amount of EDDs relative to controls ( $B$ vs. A), which could be prevented by Tal (D vs. B and A). Arrows point to small clusters of EDDs. Inserts show zoomed images to highlight changes, or lack of changes in the number of EDDs. Mit: mitochondrion, Jf: junctional fold, Sv: synaptic vesicle, Sm: skeletal muscle. Scale bar: $10 \mu m$.

However, at an early symptomatic stage (19 weeks of age), a slight swelling of mitochondria could be observed (Fig. 3B) relative to controls (Fig. 3A). The possible nonspecific effect of Tal was excluded by comparing axon terminals from Tal-treated nontransgenic mice to those from non-transgenic Veh treated controls, which revealed neither 
structural alterations nor calcium increase at either time point (cf. Fig. 2A with Fig. 2C, and Fig. 3A with Fig. 3C).
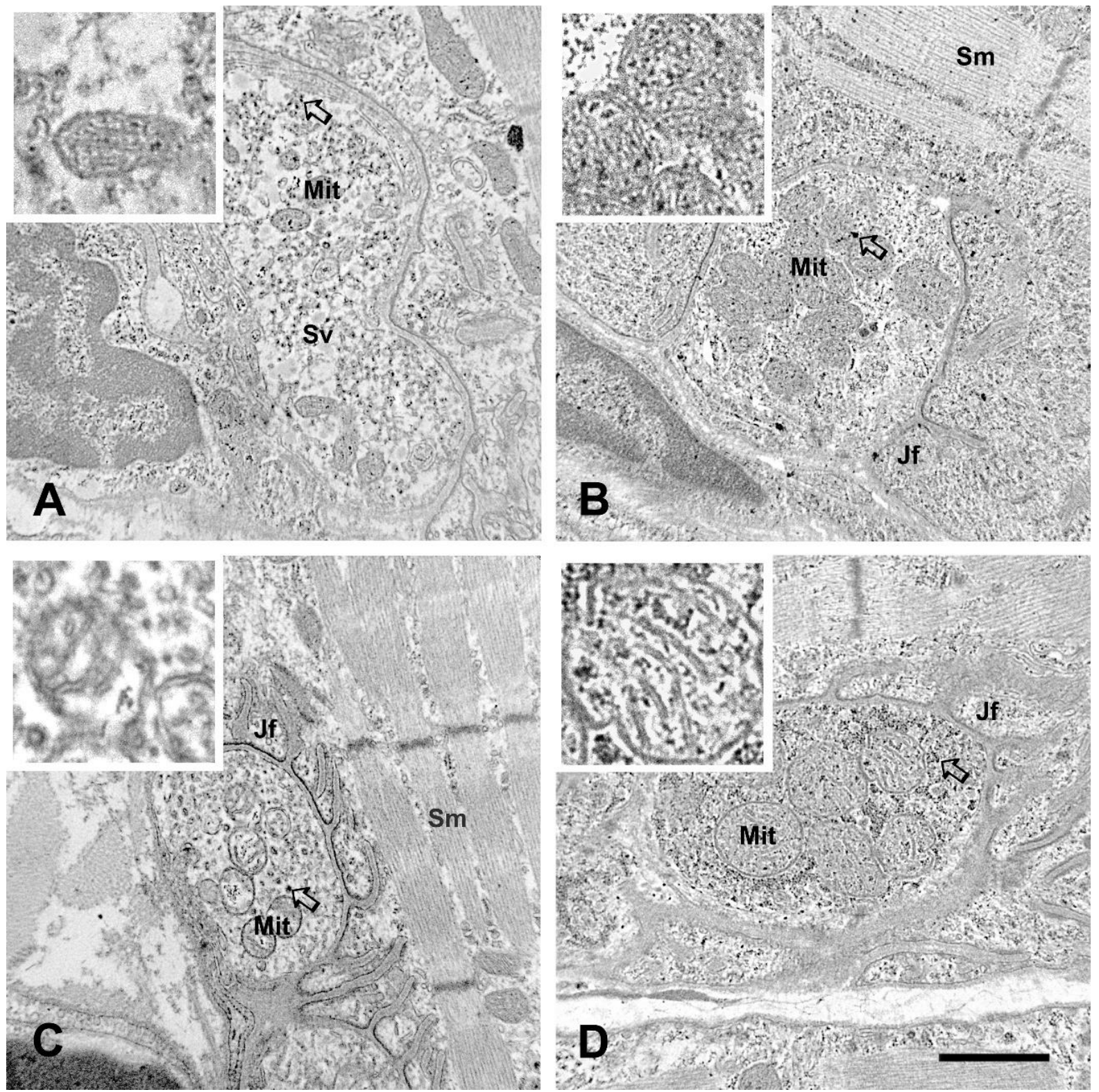

Fig. 3. Distribution of EDDs, representing calcium in motor nerve terminals in the interosseus muscle of 19 weeks old mice. A, C: nerve terminal from non-transgenic mice treated with Veh or Tal, respectively. $B, D$ : axon terminals from mSOD1 mice treated with Veh or Tal, respectively. Similarly to mice at 12 weeks of age, by visual comparison, no effect of Tal on the content of EDDs could be seen in wild type mice (A vs. C). However, in axon terminals of mSOD1 animals mitochondrial swelling and increased amount of EDDs relative to controls is present (B vs. A). This calcium increase could not be prevented by Tal (D vs. B). Arrows point to clusters of EDDs. Inserts highlight changes, or lack of changes in the number of EDDs. Mit:

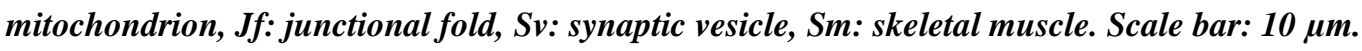


Visual inspection showed an increased number of EDDs in the tissue from mSOD1 mice, compared to controls, at both time points (Fig. 2B; Fig. 3B), which indicates an increased amount of calcium in the axon terminals of mSOD1 animals. Qualitatively, this calcium increase could be prevented by Tal, but only if the treatment was started presymptomatically (cf. Fig. 2B and D with Fig. 3B and D).
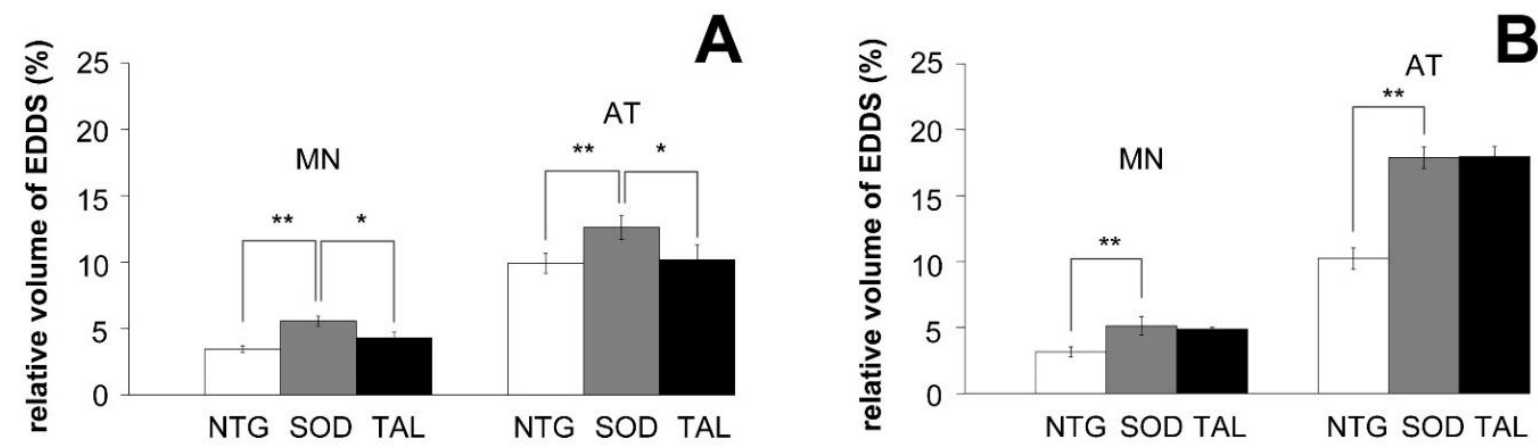

Fig. 4. Quantitative analysis of changes of the partial volume of EDDs relative to the volume of the somata or axon terminals of spinal motor neurons at 12 weeks of age (A) and 19 weeks of age (B). At the axon terminals (AT) of 12 weeks old mice (A) the presence of the mutant enzyme (SOD) induces a significant calcium increase relative to the non-transgenic control (NTG), which could be prevented by talampanel treatment (TAL). At 19 weeks of age (B), a more pronounced calcium accumulation could be detected at the axon terminals (AT) of mSOD1 mice (SOD), compared to controls (NTG), which could not be affected by talampanel treatment (TAL). To illustrate that a similar efficacy of treatment could be demonstrated at both presymptomatic and early symptomatic phases of the disease at the axon terminals and the perikarya of motor neurons, data representing the relative content of EDDs in the cell bodies (MN) were redrawn from our previous experiment ${ }^{177}$. Data are shown as mean \pm s.e.m. $(n=6$ in each group). *: $p<0.05$, **: $p<0.001$.

Quantitative assessment of the volume of EDDs in the axoplasmic space, was based on 15 motor axon terminals, illustrated in Fig. 2, Fig. 3 and Fig. 5, from each examined muscle of each animal, thus were based on the analysis of 90 fields of view in each experimental group. The volume of the EDDs relative to the axoplasmic volume, expressed as percentage, revealed a 1.27-fold increase at the age of 12 weeks ( $p<0.01)$, and a 1.75-fold increase at the age of 19 weeks $(\mathrm{p}<0.001)$ in the motor axon terminals of the interosseus muscle of mSOD1 animals compared to those of non-transgenic wild types (Fig. 4A and B AT). This calcium increase could be prevented by Tal application at 10 weeks of age (Fig. 4A - AT; p < 0.05) but not at 17 weeks (Fig. 4B - AT; p =1). To compare the changes occurring at the motor axon terminals with similar changes at the cell bodies, corresponding data characterizing the relative amount of EDDs at the spinal motor neurons were imported from our previous experiments ${ }^{177}$ and redrawn in Fig. 4A and B - MN. Similarly, to the axon 
terminals, calcium increase in the spinal motor neurons of mSOD1 mice was significant at both time points, compared to non-transgenic controls (Fig. 4A - MN, p <0.001; B - MN; $\mathrm{p}<0.001)$. This could be prevented by Tal treatment only if the treatment was started presymptomatically (Fig. 4A - MN; $\mathrm{p}<0.05$ ).
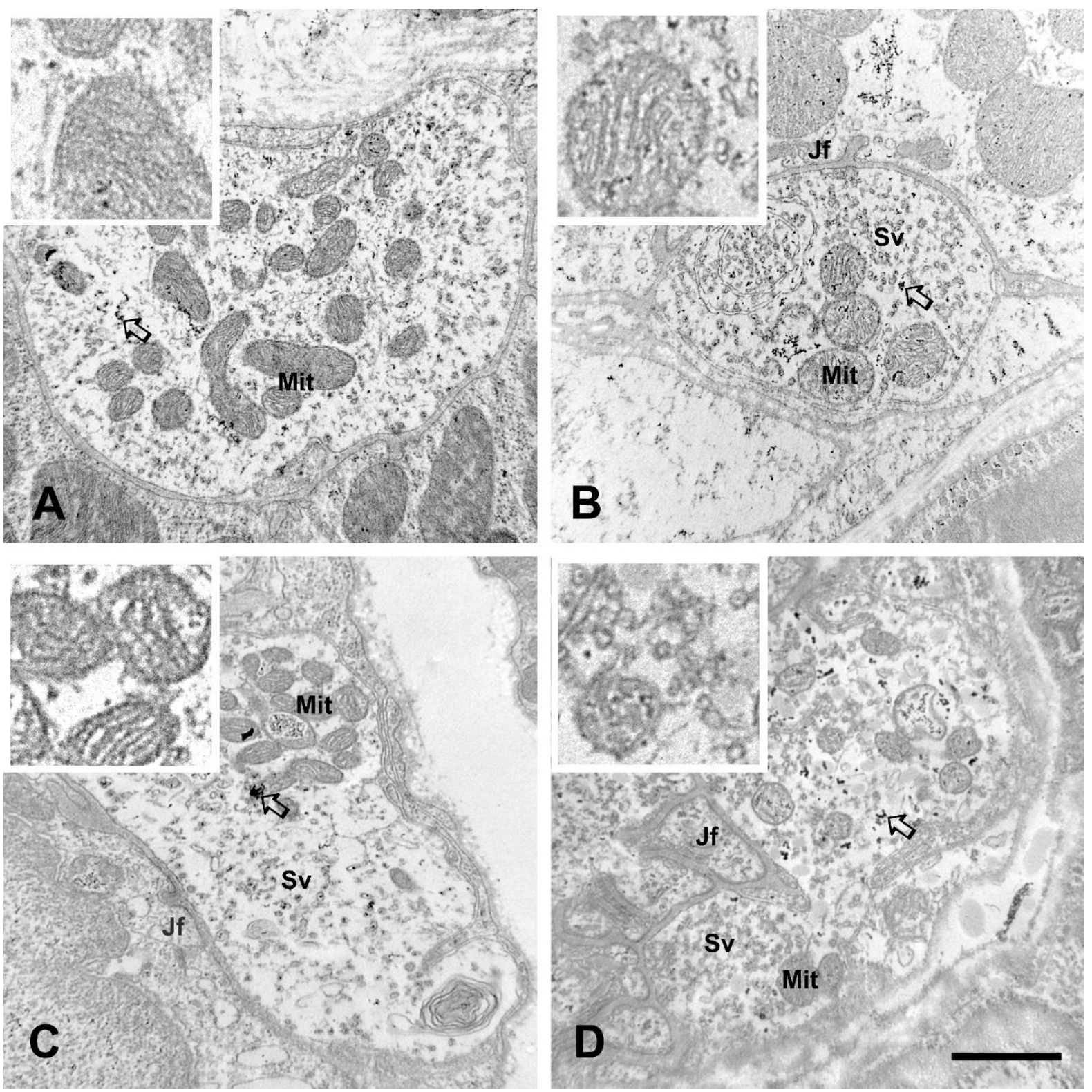

Fig. 5. Distribution of EDDs, representing that of calcium in motor nerve terminals in the superior rectus muscle of 12 weeks old mice. A, C: nerve terminal from non-transgenic mice treated with Veh or Tal, respectively. B, D: axon terminals from mSOD1 mice treated with Veh or Tal, respectively. Qualitatively, Tal treatment has no effect on the EDD content in wild type animals (A vs. C). Furthermore, neither calcium increase (B vs. A), nor Tal effect ( $D$ vs. B) could detected in motor axon terminals of mSOD1 animals. Arrows point to clusters of EDDs. Inserts highlight changes or lack of changes in the number of EDDs. Mit: mitochondrion, Jf: junctional fold, Sv: synaptic vesicle. Scale bar: $10 \mu \mathrm{m}$. 

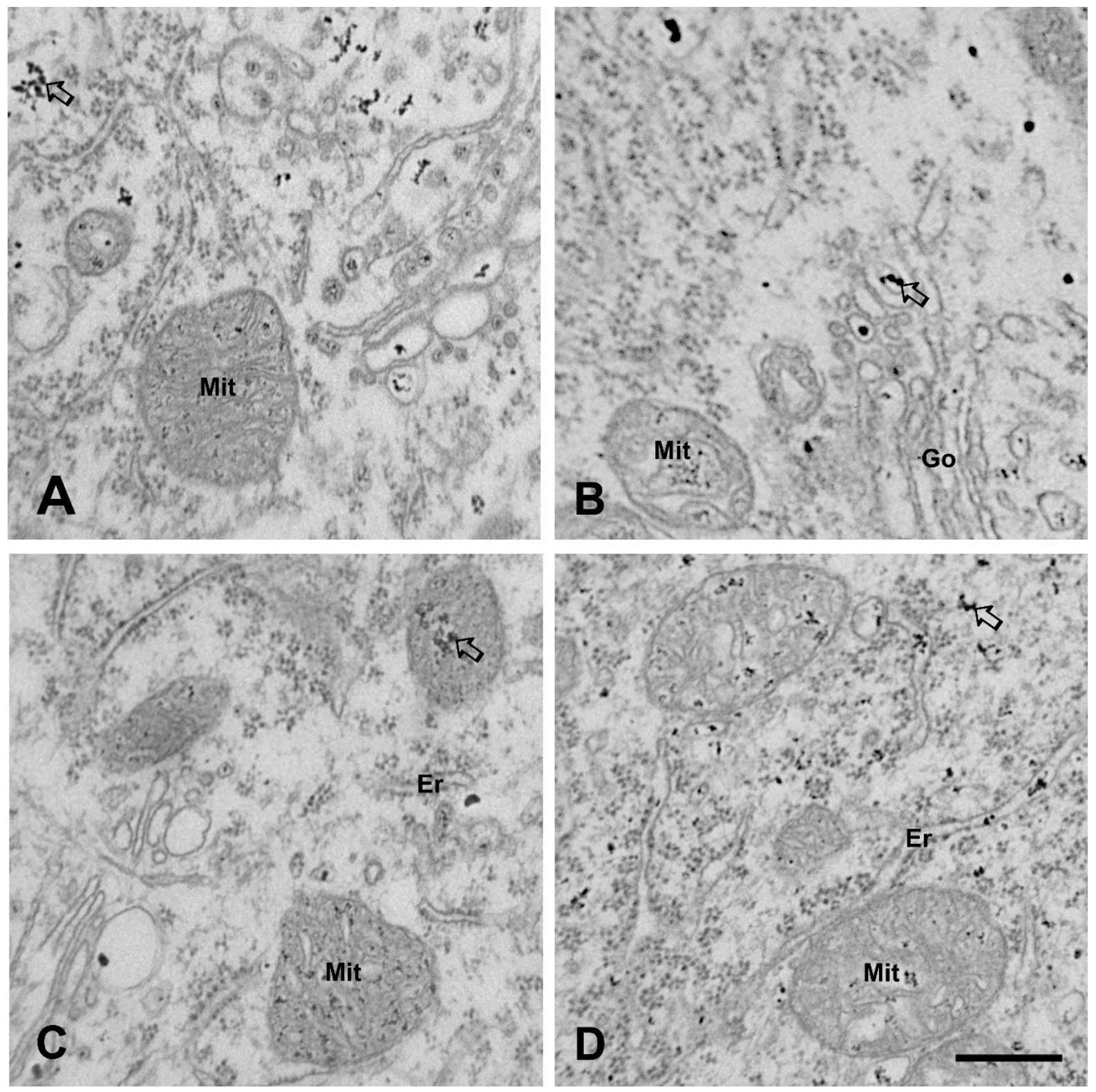

Fig. 6. Distribution of EDDs, representing calcium in the cell bodies of oculomotor neurons of 12 weeks old mic. A, C: perikaryal view of motor neurons from non-transgenic mice treated with Veh or Tal, respectively. B, D: perikaryal area of oculomotor neurons from mSOD1 mice treated with Veh or Tal, respectively. Similarly to their motor axon terminals, by visual comparison, neither calcium increase (B vs. A), nor Tal effect (D vs. B) could be detected in the cell bodies. Arrows point to small clusters of EDDs. Mit: mitochondrion, Er: endoplasmatic reticulum, Go: Golgi complex. Scale bar: 5 um.

Motor neurons innervating the extraocular muscles, which represent groups of motor neurons resistant to calcium-mediated injury, were analyzed by electron microscopy as well, in the mSOD1 mice at the ages of 12 and 19 weeks. Representative figures obtained from motor axon terminals (Fig. 5) and cell bodies (Fig. 6) are displayed at 12 weeks of age only. Qualitatively, relative to non-transgenic controls, neither structural alterations of the neuromuscular junctions (Fig. 5A versus Fig. 5B) and of the cell bodies (Fig. 6A versus 
Fig. 8B) could be observed, nor increased number of EDDs could be noticed. By expressing the relative amount of the EDDs, based on the analysis of 15 fields of view obtained from the cell bodies and motor axon terminals respectively, from each animal, neither an increased amount of EDDs in mSOD1 motor neurons compared to those from non-transgenic mice, nor their change after Tal treatment could be documented at 12 weeks (Fig. 7A; $p=1$ ), or at 19 weeks (Fig. 7B; $\mathrm{p}=1$ ).
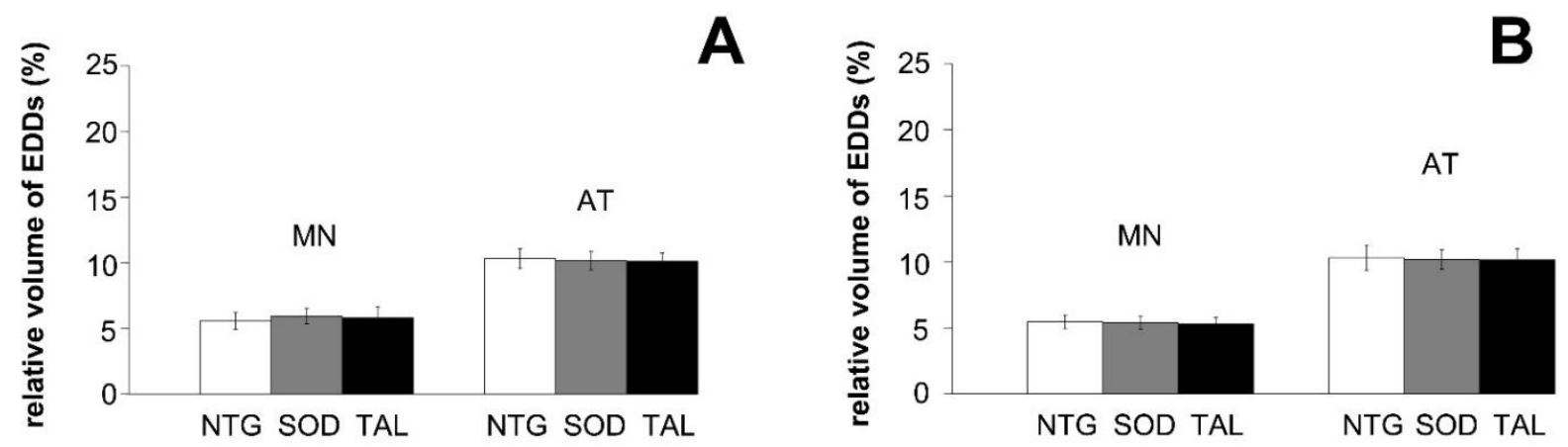

Fig. 7. Quantitative analysis of changes of the partial volume of EDDs relative to the volume of the somata or axon terminals of oculomotor neurons at 12 weeks of age (A) and 19 weeks of age (B). At either time point, neither calcium increase in the axon terminals (AT) or cell bodies (MN) of oculomotor neurons of mSOD1 (SOD) animals, compared to controls (NTG), nor talampanel effect (TAL) could be detected $(p=1)$. Data are shown as mean \pm s.e.m.

\section{Controls of the electron microscopic calcium histochemistry}
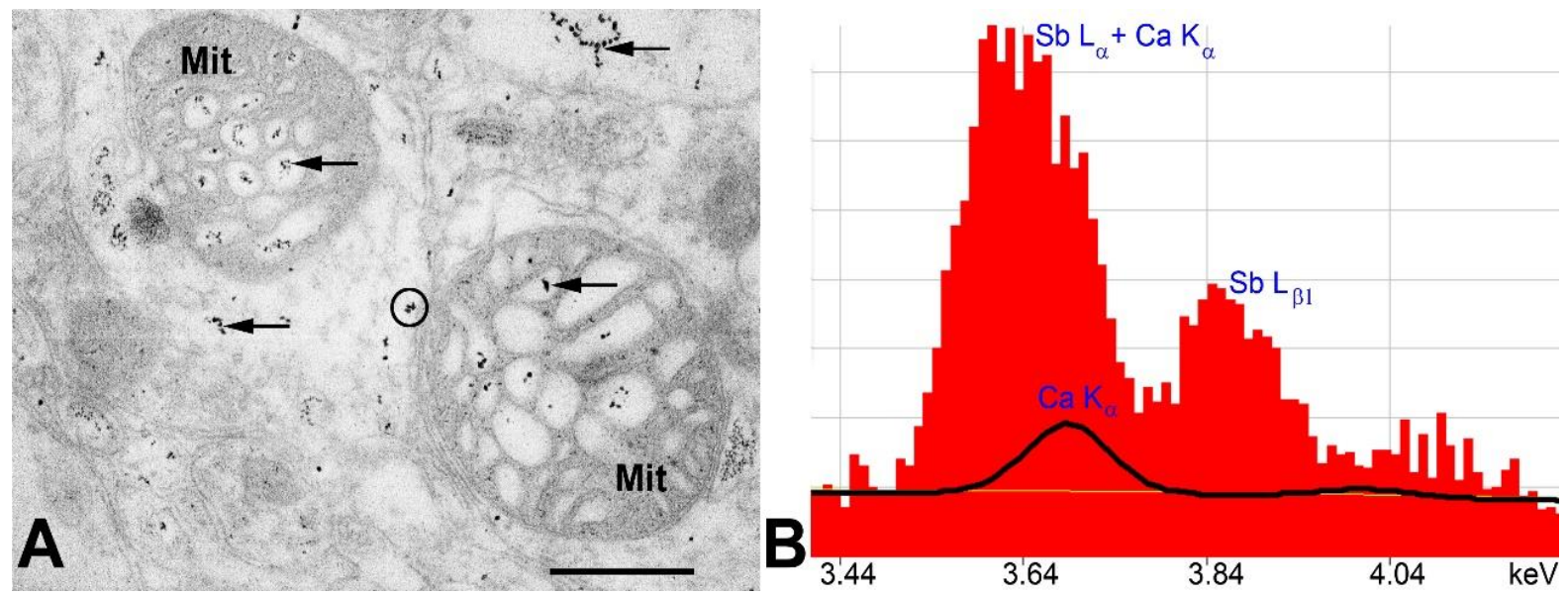

Fig. 8. Microanalysis of EDDs. A: Perikaryal view of a motor neuron from an mSOD1 mouse spinal cord (scanning transmission electron microscopy; unstained section). EDDs (arrows) in the cytoplasm and within the dilated cristae of mitochondria (Mit) can be seen. The encircled group of EDDs was probed by X-ray microanalysis. Scale bar: $500 \mathrm{~nm}$. B: Typical X-ray spectrum of EDDs is shown in red. The La peak of antimony at $3.604 \mathrm{keV}$ partially overlaps with the Ka peak of calcium at $3.690 \mathrm{keV}$, but the peaks could be deconvoluted with a fitting coefficient of 0.9949, demonstrating the presence of calcium (black line) in the electron-dense reaction products. 
In this series of experiments, the analytical composition of the EDDs was tested for the presence of calcium by electron probe X-ray microanalysis (Fig. 8). Randomly selected EDDs were irradiated by a focused electron beam (Fig. 8A), then the emitted secondary Xrays were collected. Afterwards, their spectral composition was analyzed and after mathematical deconvolution the calcium peak was separated from the overlapping antimony peak (Fig. 8B). Thus, by demonstrating the presence of calcium specifically within the EDDs, the use of EDDs in determining the distribution of tissue calcium was justified.

Electron tomographic reconstruction of the EDDs within the volume of the sections with thickness routinely used in electron microscopy revealed the possibility of their variable degree of overposition with variation in section thickness (Fig. 9A).
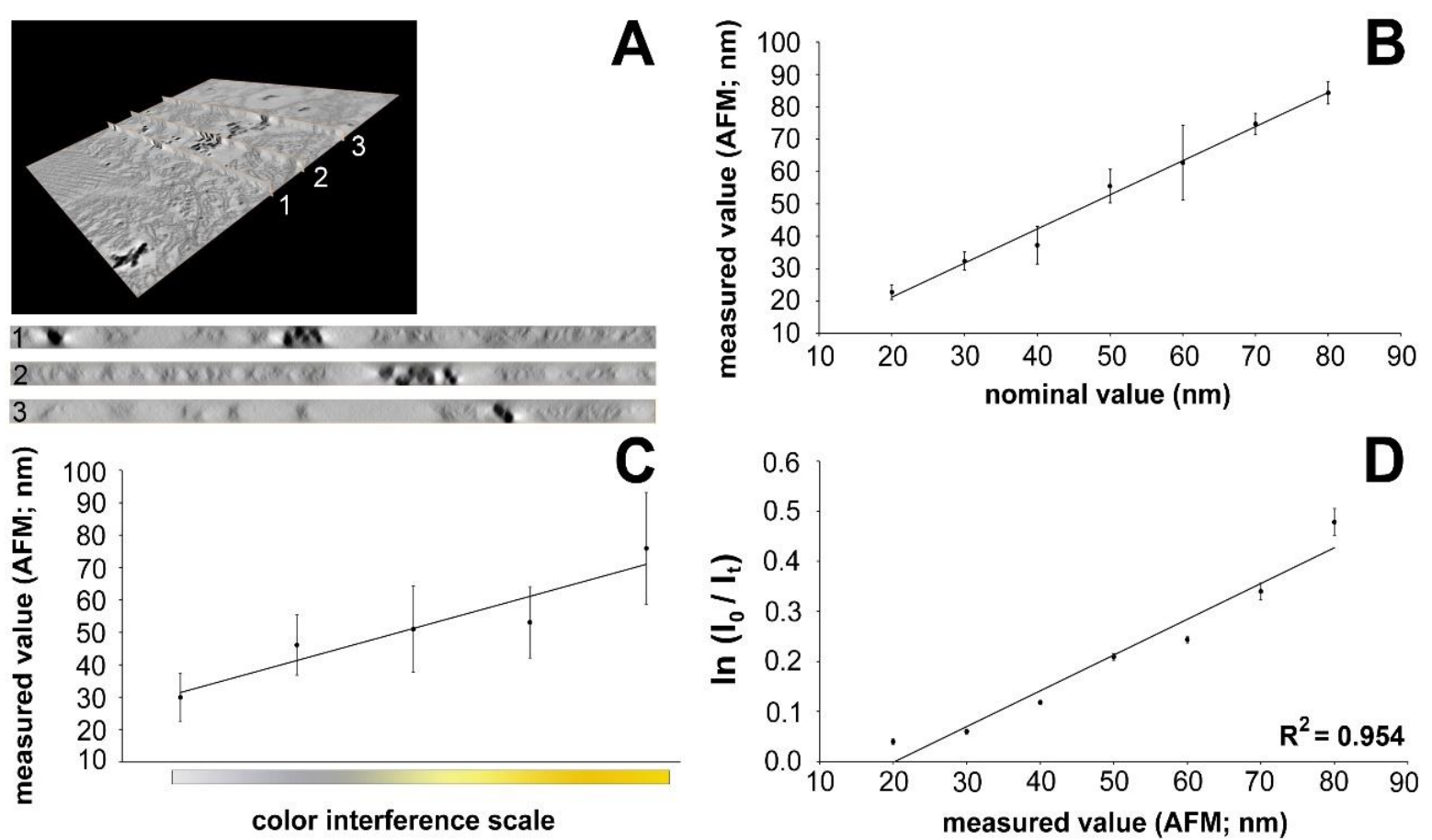

Fig. 9. Control of overprojection of EDDs. A: After volumetric reconstruction of a $50 \mathrm{~nm}$ thick electron microscopic section by means of electron tomography, side views of the section containing EDDs at lateral positions 1, 2 and 3 show that the characteristic size of the deposits is comparable to the thickness of the section. Thus variability of the thickness of the sections cut in series at different positions of the sample does influence the calculated density of EDDs. B, C: Ultrathin sections were repeatedly cut with thickness set according to the digital setting of the ultramicrotome $(B)$ or on the basis of their interference color during sectioning (C), and their actual thickness was measured by atomic force microscopy (AFM). Evidently, section thickness can be reproduced only with large variability with these techniques. D: The good correlation ( $R 2=0.954)$ of the true section thickness with their measured value in the electron microscope on the basis of the Bouguer-Beer-Lambert law enables this method to select sections only with uniform thickness for the measurement of the amount of EDDs. 
Since this may considerably influence the size of the projected image of EDDs, and thus affect their calculated density, standardization of section thickness during the series of measurements was needed. As an objective method to measure the true thickness of the section AFM was used. AFM analysis of a series of microscopic sections revealed that the routinely used methods to select sections with a predetermined thickness based either on the nominal setting of the ultramicrotome (Fig. 3B), or on their interference color (Fig. 3C) are not suitable for standardization. However, the application of the beam attenuation law (Bouguer-Beer-Lambert law) provides an accurate method to measure the thickness of each section in situ in the electron microscope (Fig. 3D). This method could be used to eliminate sections with non-standard $(50 \mathrm{~nm})$ thickness from further analysis thus reduce the variance of the measurements of the density of the EDDs.

\section{Sciatic axotomy-induced changes in the spinal cord of $\mathrm{PV}+/+$ mice}

In each mouse strain, axotomy of the sciatic nerve induced a marked expression of CCL2 in the injured motor neurons which was paralleled by an increased microglial reaction at their vicinity (Fig. 10). Microglial cells could often be seen at close positions to the CCL2expressing motor neurons (Fig. 10). CCL2 immunostaining was detectable only in the motor neurons at the operated side (Fig. 11A).
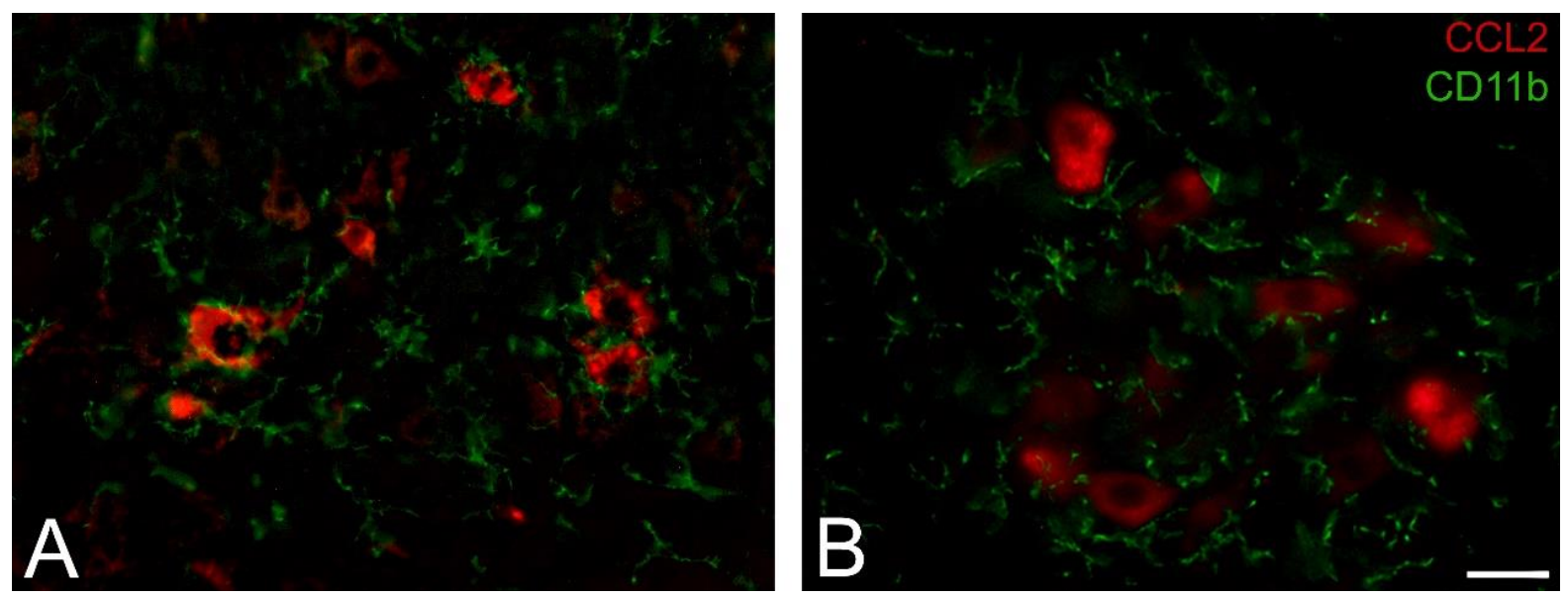

Fig. 10. Immunofluorescent imaging of CCL2 and microglia in the ventral horn after axotomy show similar pattern from control (A) and $\mathrm{PV+}++(B)$ mice at day 3 after operation. Microglial cells (green) surround the CCL2 expressing motor neurons (red). Scale bar: $30 \mu m$.

The relative change in the intensity of CCL2 staining in the operated side compared to the non-operated side in each animal was expressed quantitatively at postoperative days 1, 4, 7, 14 and 21 (Fig. 11B). The net amount of staining ipsilateral to the injury increased gradually until day 7 after axotomy, and declined thereafter (Fig. 11B). The rate of decline of the CCL2 signal, however, was different in the control and PV $+/+$ mouse strains: while the 
CCL2 expression in the PV+/+ mice returned close to the baseline already at day 14 after operation, the CCL2 level in the spinal cords of the control mice reached this level at day 21 only after axotomy (Fig. 11B). The difference between the CCL2 immunostaining in the control and the $\mathrm{PV}+/+$ transgenic mice at day 14 was significant $(\mathrm{p}<0.05)$, as well as the difference between the staining intensity in the PV+/+ animals at day 7 and 14 after the nerve cut (Fig. 11B).

CONTROL MOUSE

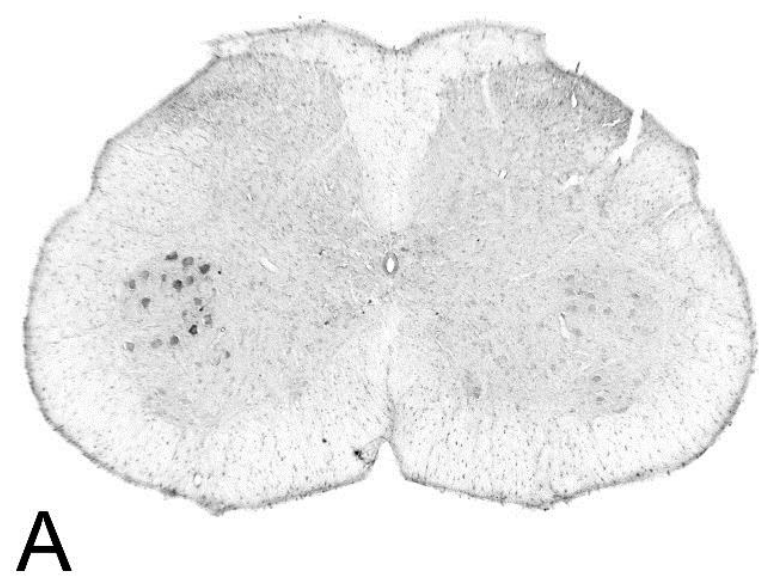

PV+/+ MOUSE

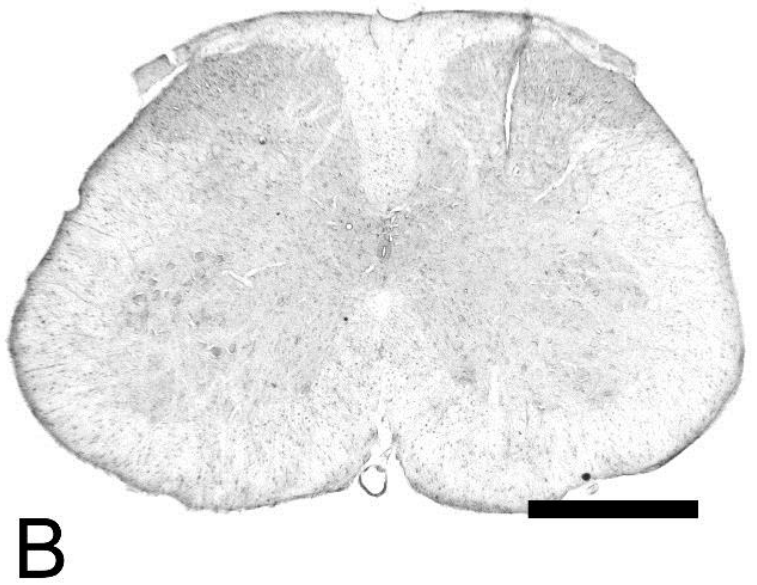

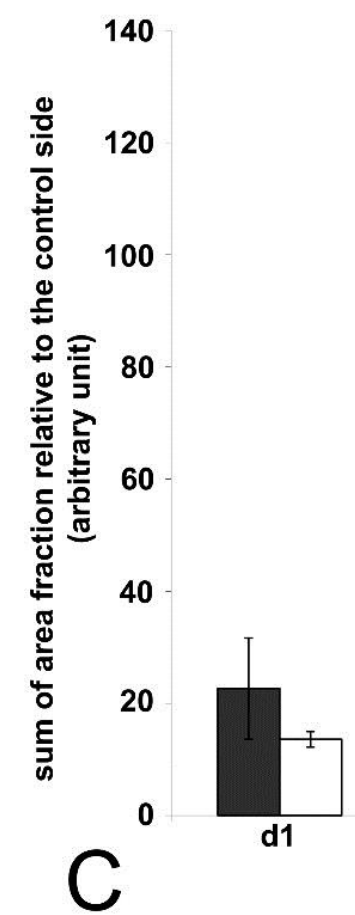

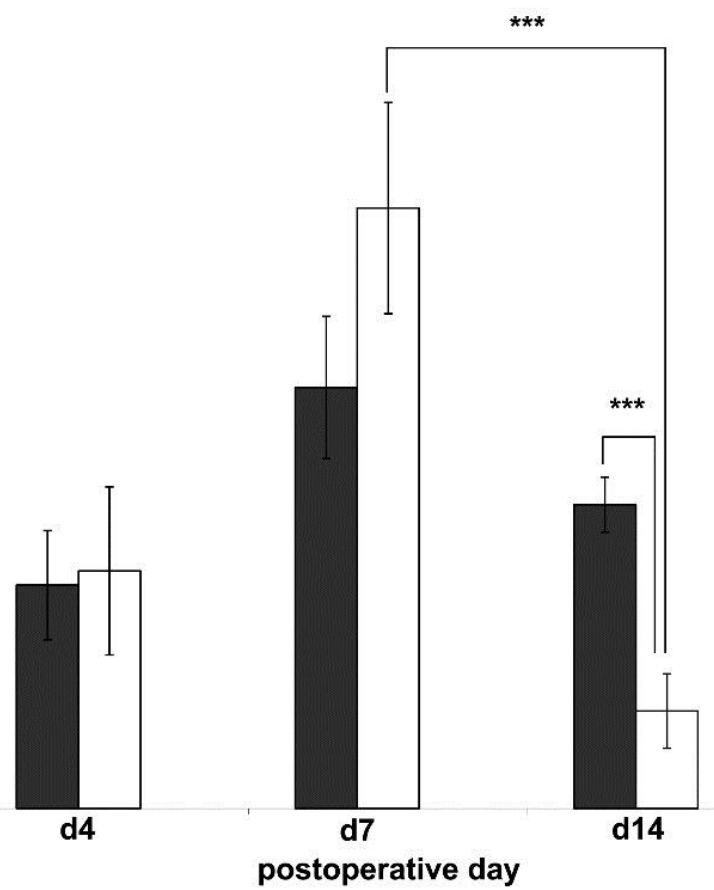

$\square \mathbf{P V + / +}$

control

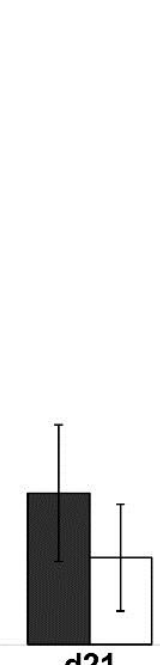

d21

Fig. 11. CCL2 immunostaining after sciatic axotomy. A: CCL2 staining is confined to the ventrolateral motor neurons at the lesion side; control mouse postoperative day 14. B: At postoperative day 14 only faint CCL2 staining is visible in the spinal motor neurons of PV+/+ mice. Scale bar: $500 \mu m$. C: After a transient increase, CCL2 staining intensity declined faster in PV+/+ mice (white bars; ***: $p<0.001$ ), and was significantly different from those in the controls (gray columns $* * *: p<0.001$ ) at postoperative day 14 (d14). 
Besides the increased CD11b staining intensity at the ventrolateral pool of motor neurons after axotomy, marked microglial activation could also be seen in the substantia gelatinosa of each animal at the operated side, since sensory nerves and motor axons were mutually transected in the mixed sciatic nerve (Fig. 12A).

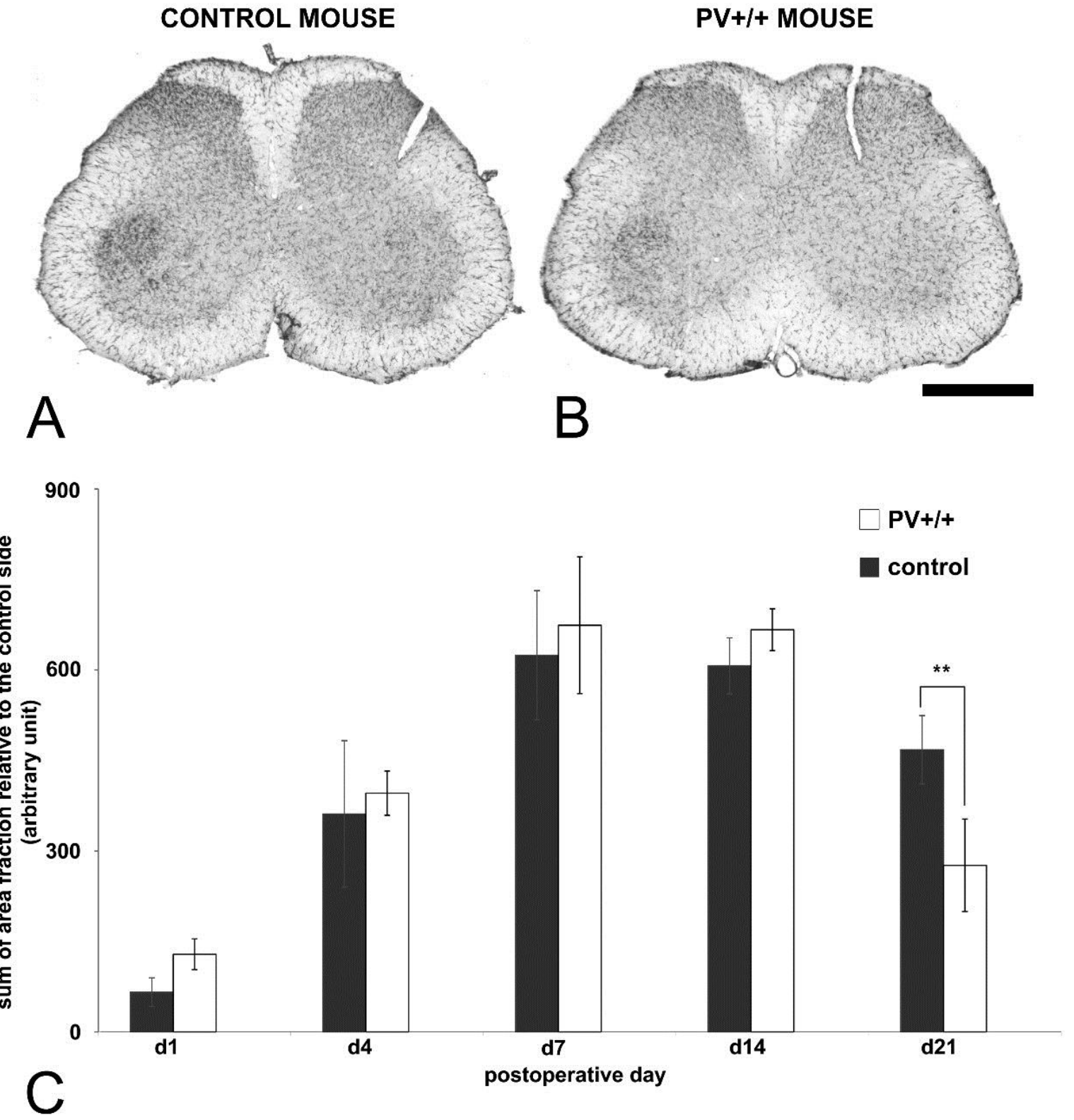

Fig. 12. Microglia staining in the spinal cord after axotomy. A: CD11b is uniformly distributed in the gray matter, but increased staining is visible at the dorsal horn and in the ventrolateral area at the side of injury as shown in the spinal cord section from a control mouse at postoperative day 21. B: At postoperative day 21, compared to controls, weaker microglia reaction is visible around the spinal motor neurons from a PV overexpressing homozygous transgenic $(P V+/+)$ mouse. Scale bar: $500 \mu m . C$ : The decrease of CD11b staining intensity in PV+/+ mice (white bars), compared to controls (grey bars) is significant only at postoperative day 21 (d21; **: $p<0.01)$. 
The CD11b staining at the dorsal horn, however, was not evaluated in this study. Similarly to the CCL2 staining, the intensity of the CD11b staining was quantitatively evaluated in Lamina IX at days 1, 4, 7, 14, 21 after operation, and was expressed relative to the non-operated side (Fig. 12B). The area fraction occupied by CD11b-positive profiles gradually increased in the spinal cords in all animals, regardless of their strain, peaked at day 7-14 after operation, and decreased afterward, which is evident at day 21. Similarly to the decrease of the CCL2 staining, in PV+/+ animals the intensity of CD11b staining decreased faster than in the control strains, but reached significantly different level only at day 21 ( $p<0.05$ ). By comparison of Fig. 11B and Fig. 12B, it seems that the sequence of changes in CD11b staining intensity after the postoperative day 7 , in the declining phase, follows that of CCL2 in the injured motor neurons with a time delay.

By identifying the distribution of EDDs with that of calcium there is no need for regular analytical microscopy for quantification of calcium content, since EDDs are visible in conventional microscopy. With X-ray measurements performed in selected sections, it was confirmed that the distribution of EDDs might indeed be identified with that of calcium (Fig. 8B). Determination of calcium content of motor neurons of control and PV+/+ mice was performed at postoperative day 7 , when the immune/inflammatory reactions reached their maximum. Qualitative comparison of the EDDs in injured motor neurons relative to uninjured controls suggested an increased calcium in control mice, but not in PV+/+ animals (Fig. 13).

Quantification of the relative volume of motoneuronal compartments occupied by the EDDs at the operated and control side revealed approximately a 2-fold calcium increase induced by the injury in each of the examined cellular compartments of the control mice, while no calcium elevation could be measured in motor neurons of the PV $+/+$ animals at postoperative day 7 , which difference from the controls proved to be highly significant (Fig. 14). 

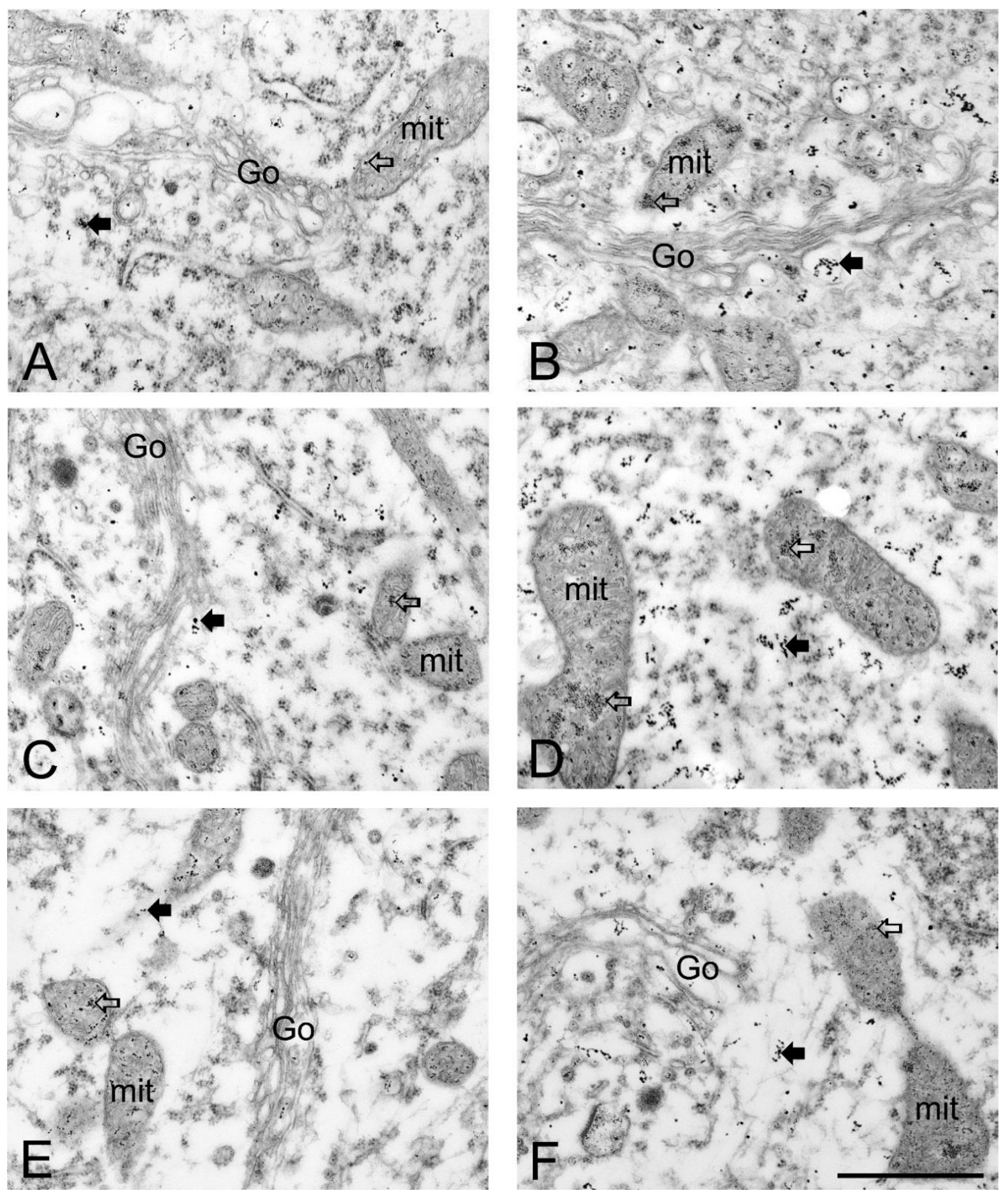

Fig. 13. Calcium distribution in spinal motor neurons from Balb/c $(A, B), B 6 / S J L(C, D)$ and $P V$ overexpressing homozygous transgenic $(P V+/+)(E, F)$ mice. In uninjured motor neurons from Balb/c $(A)$, B6/SJL $(C)$ and PV+/+ (E) mice few scattered electron-dense deposits, characterizing the distribution of calcium, are visible either in the mitochondria (outlined arrows), or at cytoplasmic location (black arrows). At day 7 after axotomy the number of deposits considerably increased in motor neurons of Balb/c (B) as well as in B6/SJL (D) mice, but not in the motor neurons of PV+/+ animals (F). Go: Golgi complex, mit: mitochondrion. Scale bar: 1 $\mu \mathrm{m}$ 


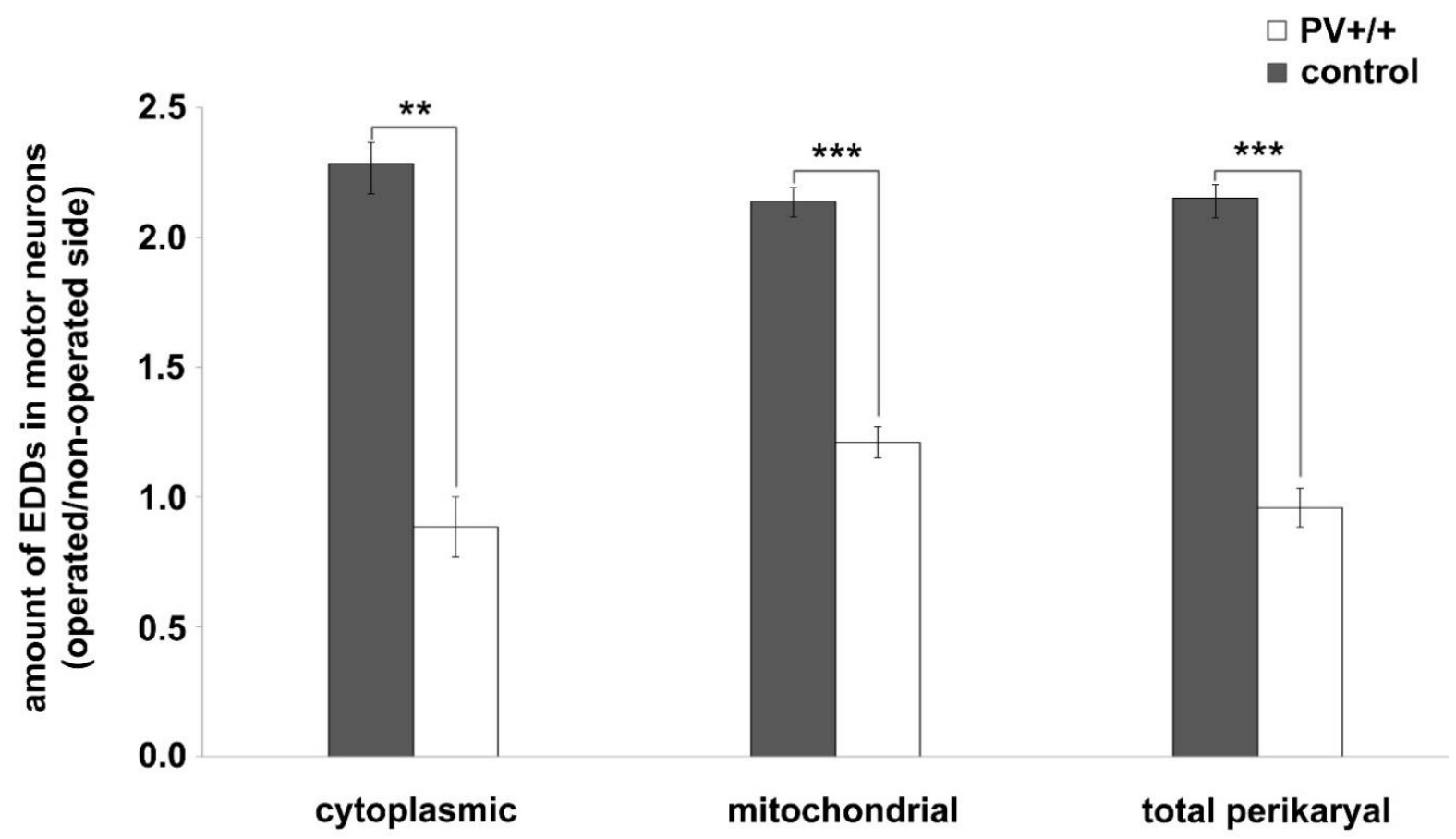

Fig. 14. Quantification of the amount of EDDs in the spinal motor neurons of control and PV+/+ mice at postoperative day 7. Cytoplasmic-, mitochondrial-and total perikaryal calcium elevation at the operated side were expressed as a fold increase relative to the contralateral side. In the different cellular compartments of the PV+/+ strain (white bars) no calcium increase could be seen, while in the same compartments of the control strains (grey bars) a 2-fold increase was noted. (**: $p<0.01$, ***: $p<0.001$ ).

Effect of diazoxide treatment on microgliosis in the axotomized motor nuclei

Motor neurons with different susceptibility against injury in the oculomotor-, hypoglossal- and facial nucleus were challenged with axotomy, then the anti-inflammatory effect of diazoxide was tested.
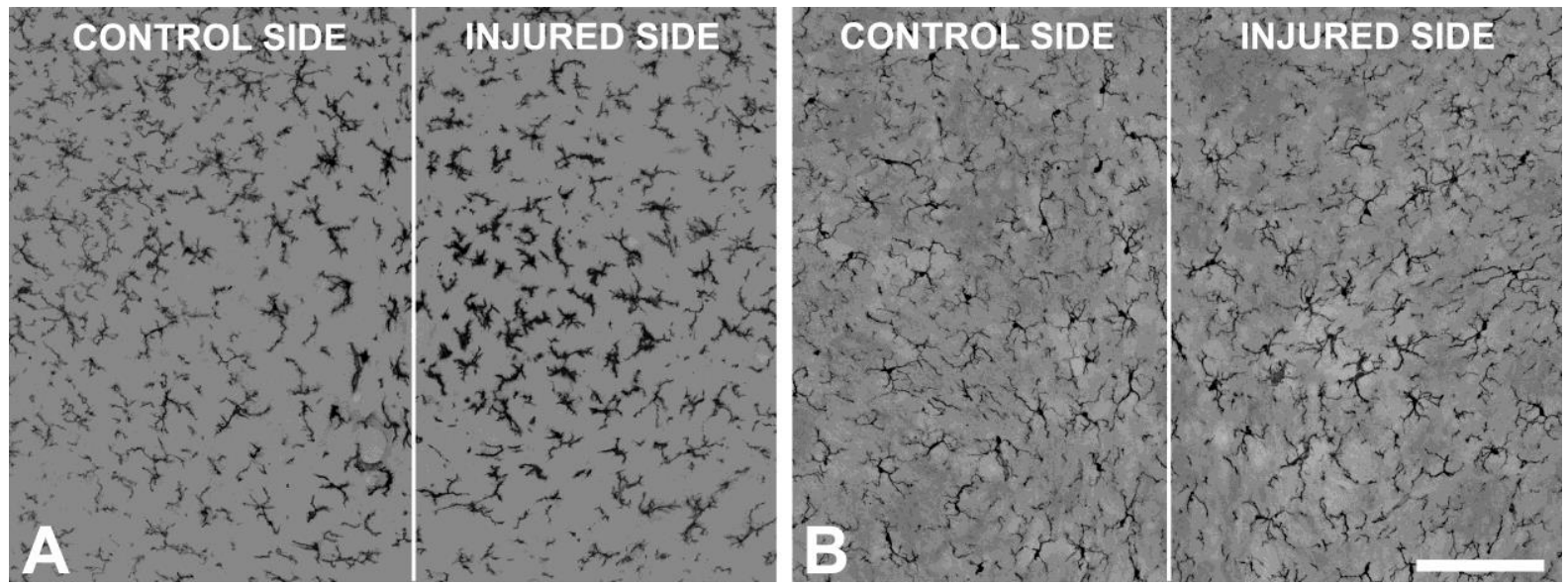

Fig. 15. Difference in the microglial activation after axotomy in the oculomotor nucleus with and without diazoxide treatment. Severe microgliosis can be observed in the injured side of the untreated, axotomized mice (A), however microglial activation is reduced after diazoxide treatment (B). Scale bar: $100 \mu \mathrm{m}$ 
Qualitatively, at postoperative day 4, in each examined nucleus marked microgliosis was observed, which could be attenuated by diazoxide treatment.
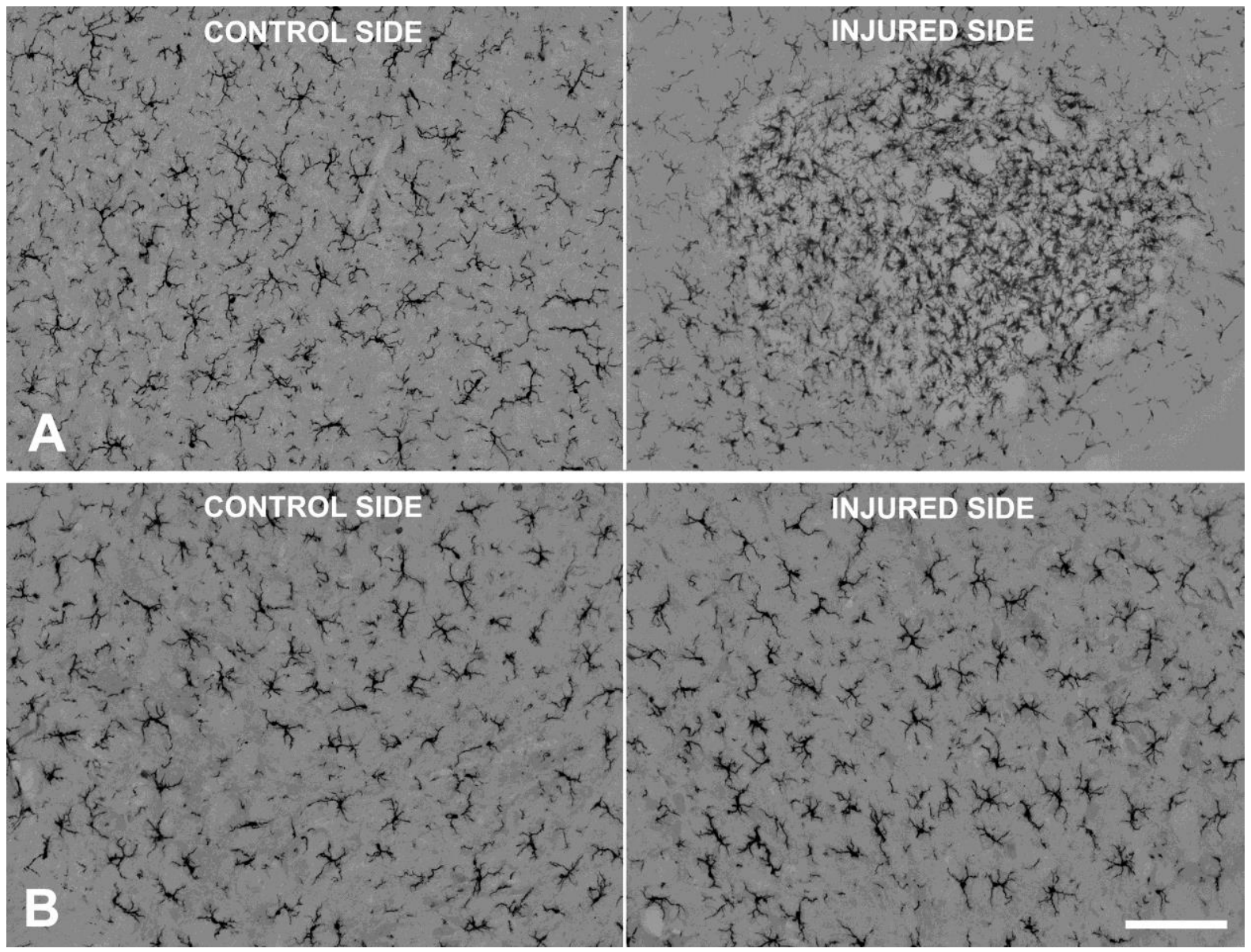

Fig 16. Difference in the microglial activation after axotomy in the facial nucleus with and without diazoxide treatment. Severe microgliosis can be observed in the injured side of the untreated, axotomized mice $(A)$, however injured side shows a reduced microglial activation after diazoxide treatment (B). Scale bar: $100 \mu \mathrm{m}$
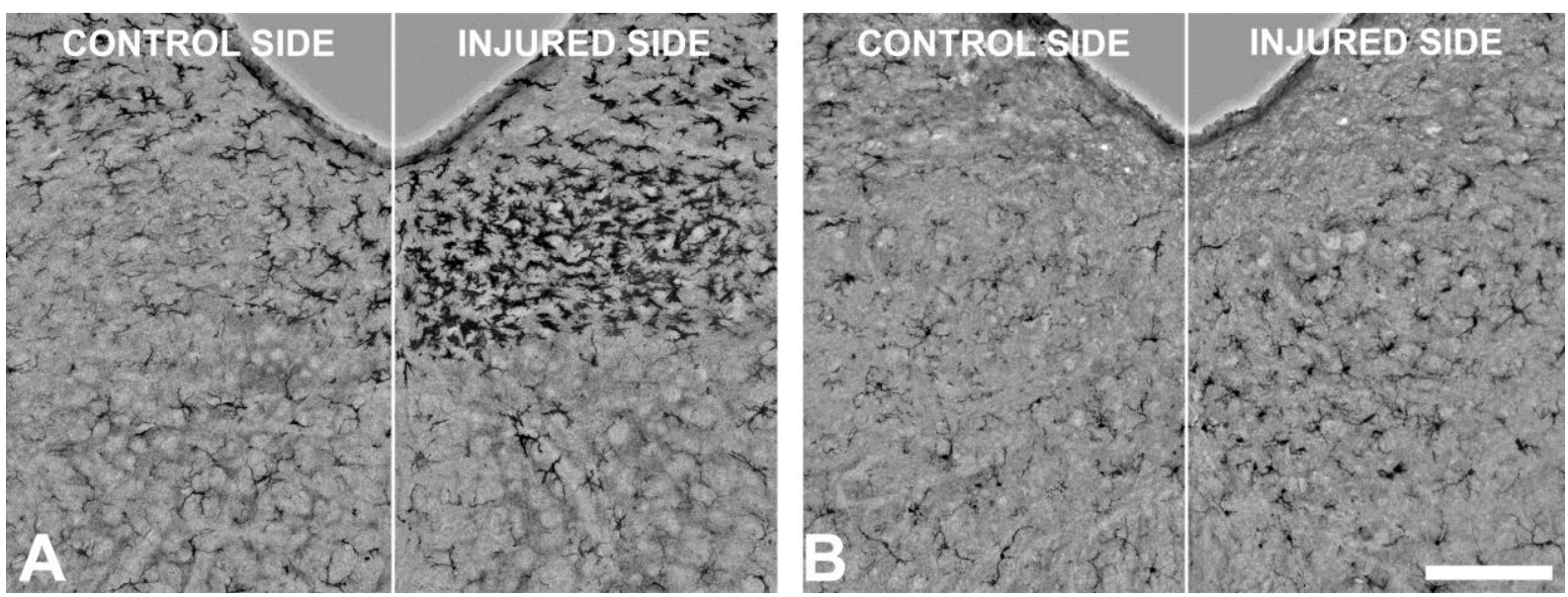

Fig. 17. Difference in the microglial activation after axotomy in the hypoglossal nucleus with and without diazoxide treatment. Severe microgliosis can be observed in the injured side of the untreated, axotomized mice (A), however microglial activation is reduced after diazoxide treatment (B). Scale bar: $100 \mu \mathrm{m}$ 
To express quantitative effect of diazoxide on axotomy-induced microgliosis, the exact boundaries of the affected nuclei should be known, which may require double staining for motor neurons and microglial cells respectively (Fig. 18).

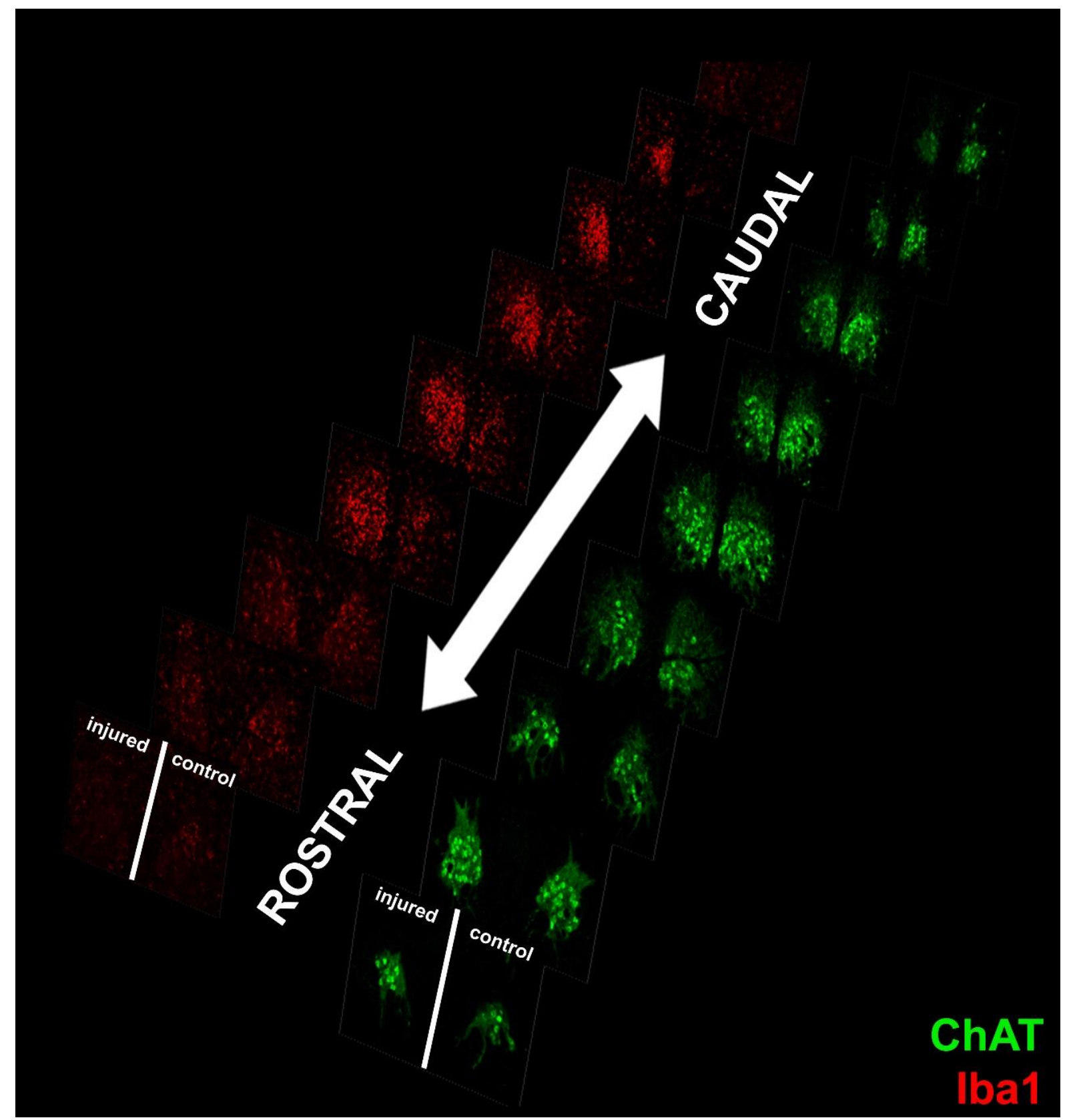

Fig.18. Presentation of the microglial activation (Iba1) along the rostrocaudal axis in the oculomotor nucleus visualized by ChAT-labeled motor neurons. The activated pattern of microglial cells shifts from the ipsilateral- to the contralateral side of the nucleus which corresponds to the crossing of the muscle innervating nerves ${ }^{178,179,180}$.

Since fluorescent double staining cannot be used for reliable quantification due to the unavoidable and uncontrollable changes in the imaging parameters ${ }^{181}$, we developed a staining protocol to overcome this problem. Accordingly, a combination of DAB-based and 
fluorescent based immunostaining protocol was developed, in which the fluorescent staining of the cell type to be quantified was substituted with DAB-based visualization, while the other cell type, used for anatomical orientation was still fluorescently stained (Fig. 19).
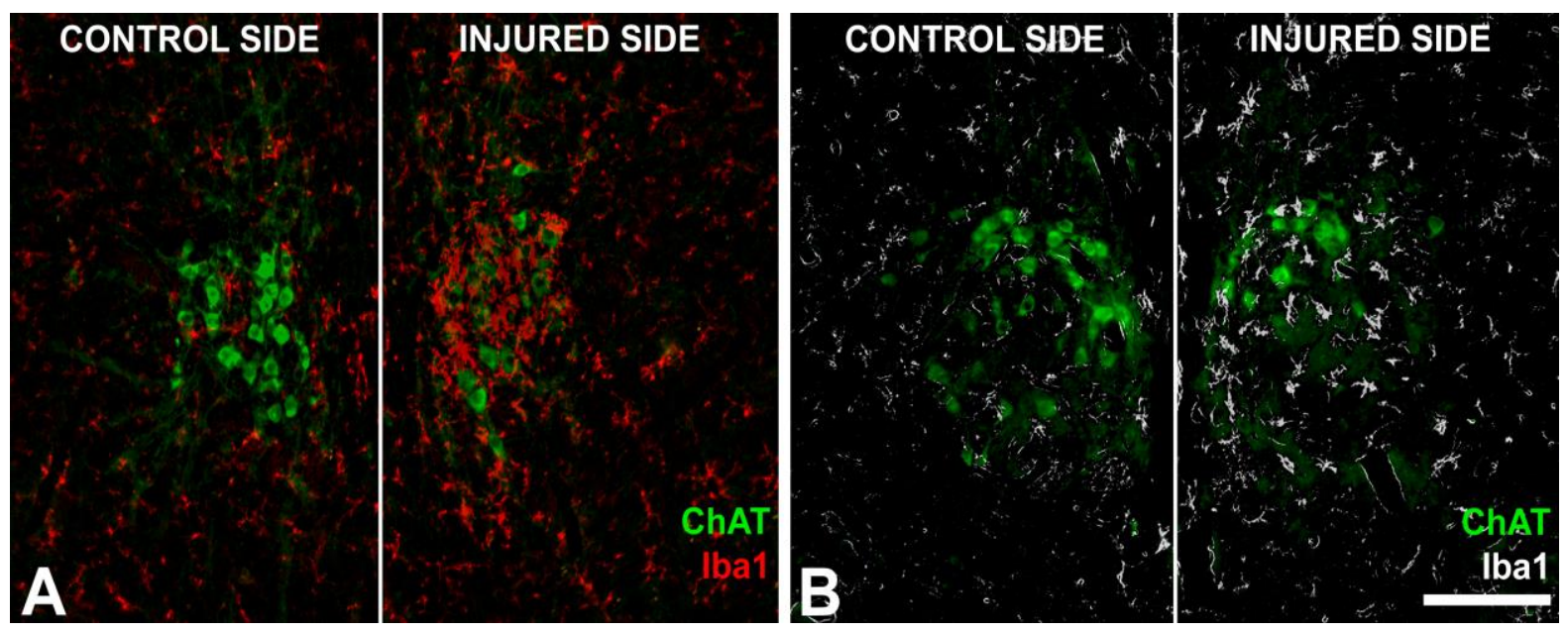

Fig. 19. Comparison of the conventional double fluorescent and the combined DAB-fluorescent staining. A: Double fluorescent staining of motor neurons (ChAT) and microglial cells (Iba1) in the axotomized oculomotor nucleus. B: With combined DAB-fluorescent staining, motor neurons are still visualized with a green fluorescent secondary antibody. Microglial cells are detected with the avidin-biotin technique followed by a background subtraction procedure, based on internal standards, to visualize microglial cells which are stained significantly above the background level. The pattern of significantly stained microglial cells, false colored to white, is superimposed on the image displaying the distribution of motor neurons. Scale bar: $100 \mu m$

Using the combined DAB-fluorescent technique, the exact boundaries of the motor nuclei involved in the analysis could be delineated, within which the microglial activation, relative to the ipsilateral, unoperated side, could be determined. These differences from section-to-section could be plotted along the rostrocaudal axis of each nucleus, which graphs — through summing up the individual values - served to characterize the injury-induced microglial activation with a single number for each animal (Fig. 20). Then these numbers could be averaged in each experimental group $(n=4-5)$, which revealed a significant 3.75fold decrease in the microglial area of the diazoxide treated group compared to the control group after target deprivation of the oculomotor nucleus $(p<0.05)$. Similarly, statistically significant beneficial effect can be observed in the facial nucleus (165-fold decrease, $\mathrm{p}<0.001)$ and hypoglossal nucleus (72-fold decrease, $\mathrm{p}<0.001)$ as well.

It is worth to note that the activation of microglial cells in the oculomotor nucleus without diazoxide treatment seemed to be more pronounced in the facial- and the hypoglossal nucleus (Fig. 20A versus Fig. 20C and E), which is consistent with our earlier findings that 
increased calcium binding protein content ( $\mathrm{PV}$, in case of oculomotor neurons) may help reducing the neighboring inflammatory reaction after injury (see Fig. 11, Fig. 12).
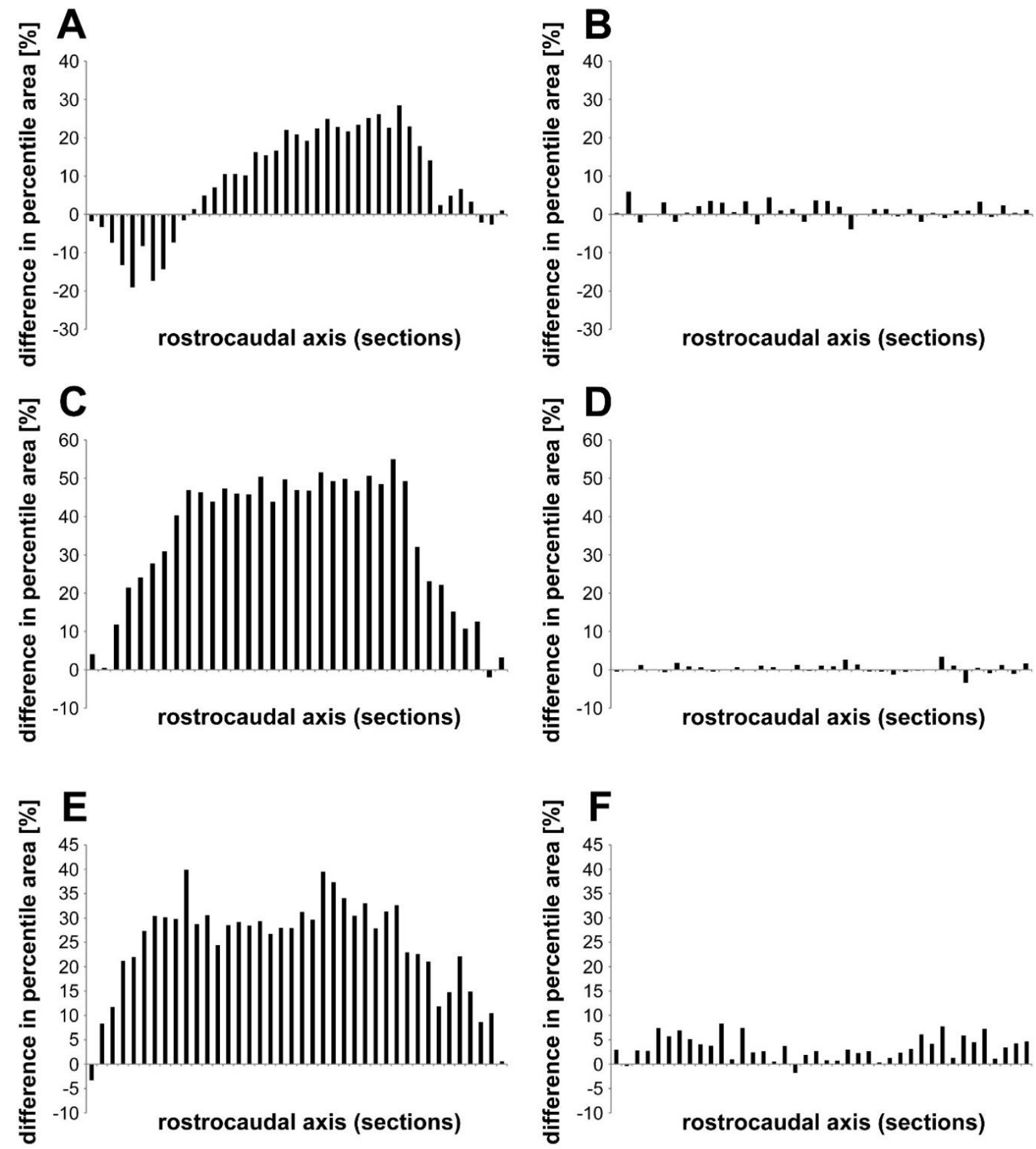

Fig.20. Quantification of the area of microgliosis section by section along the rostrocaudal axis of the examined nuclei. Anatomical region without diazoxide treatment after axotomy or target deprivation shows microglial activation in the oculomotor $(A)$, facial $(C)$ and hypoglossal $(E)$ nuclei. Innervation of the eye muscles is in accordance with the microanatomy of the oculomotor nucleus, since the superior rectus muscle is wired to the contralateral side. However, contralateral microglial activation cannot be detected in the facial and hypoglossal nuclei. Panel $(B),(D)$ and $(F)$ clearly document the anti-inflammatory effect of diazoxide in the oculomotor, facial and hypoglossal nuclei respectively.

\section{DISCUSSION}




\section{Role of AMPA receptors and excitotoxicity in chronic motor neuron degeneration}

In a previous experiment, we showed a protection of motor neurons from calciummediated degeneration by preventing calcium influx through AMPA receptors in mSOD1 transgenic mice with Tal, a non-competitive AMPA receptor antagonist ${ }^{177}$. In these animals the treatment was successful only if it was started during the presymptomatic phase of the disease. Notably, this was in agreement with the results of another in vivo study based on AMPA-mediated excitotoxicity, in which the known neuroprotective effect of vascular endothelial growth factor ${ }^{182}$ was abolished if administered after the onset of the motor symptoms ${ }^{183}$. These observations are compatible with the widely accepted view that one of the major causes of the recurrent failures to translate successful protective regimes in animals to the bedside might be a mismatch between the initiation of the medication in the animal experiments and in the clinical trials ${ }^{184,185,186}$. The loss of the treatment efficacy in early symptomatic mSOD1 mice could be attributed to the progressive nature of the degeneration, which might propagate from the upper to the lower motor neurons, imposing an excitotoxic burden on ventrolateral spinal motor neurons ("dying forward"), or retrogradely from the neuromuscular junction (“dying back"), or may occur independently 8,187. At least in the mSOD1 animal model of ALS, this could be tested by analyzing changes in the level of intracellular calcium in the motor axon terminals and in the motoneuronal somata in same age animals. Our data indicate that in the cell bodies of spinal motor neurons and in motor axon terminals in the interosseus muscle calcium elevation could be uniformly prevented by Tal treatment at a presymptomatic stage, furthermore, the efficacy of the treatment diminished equally in these positions at an early symptomatic stage (Fig. 4A and B). The only noted (qualitative) change was a mild mitochondrial degeneration, observed as swelling, in the axon terminals of mSOD1 mice at 19 weeks of age (Fig. 3D), which is consistent with the observation that neuronal death in chronic progressive excitotoxicity due to AMPA receptor overactivation might be associated with impaired mitochondrial energy metabolism ${ }^{188,189}$. Thus, we may conclude that this soma-targeted protective treatment could also rescue distant, semi-autonomously functioning motor nerve terminals ${ }^{190}$, if applied early enough, in which the noted commencement of mitochondrial lesion at a later stage could be the consequence of a less efficient housekeeping support from the distant perikaryon ${ }^{187}$. It is feasible that the similar stress conditions at the perikarya and the axon terminals could be handled less effectively in the terminals due to their limited homeostatic capacity compared to the somata, reflected in their higher increase of intracellular calcium content (Fig. 4A and B). As a 
consequence, when the calcium buffering of mitochondria in the axon terminals is overwhelmed, a calcium-dependent local death-cascade might be initiated ${ }^{191,192}$ leading to early synaptic degeneration ${ }^{193}$. Since synaptic/axonal degeneration alone might be able to initiate the disease ${ }^{194}$, the loss of efficacy of the treatment at an advanced stage might be the consequence of the retrograde spread of death machinery ${ }^{195}$.

This concept implies that the degeneration of motor neurons in mSOD1-induced stress is the consequence of compromised housekeeping support to the axon terminals from the perikarya under calcium-mediated stress. Such malfunction initiates a retrograde degeneration from the motor nerve terminals, the homeostatically weakest points of the motor neurons, i.e. both compartments should be simultaneously protected. This suggestion is consistent with the observation that neuromuscular junction dysfunction rather than motor neuron loss is predictive of a more aggressive disease phenotype in SOD1 mice ${ }^{196}$. In this scenario, if the calcium-mediated processes play a central role in degeneration, a lower or later commencing calcium increase is expected equally in the cell bodies and motor axon terminals of oculomotor neurons of mSOD1 mice, which are reported to be resistant in $\mathrm{ALS}^{154}$. Indeed, in these experiments, at the time points when a 1.61 -fold increase of perikaryal and a 1.27-fold increase of intraterminal calcium content of spinal motor neurons (12 weeks of age), as well as a 1.63-fold increase of perikaryal and a 1.75-fold increase of intraterminal calcium content of spinal motor neurons (19 weeks of age) were documented (Fig. 4), no calcium increase could be measured in either of the compartments of the oculomotor neurons (Fig. 7). This could be well explained by their higher CaBP content, such as $\mathrm{PV}^{15}$, a protein with EF-hand structural motif, traditionally considered a calcium buffer ${ }^{148}$. Calcium buffers reduce the diffusion of calcium ions into the cytosol, predisposing them for rapid extrusion, which results in smaller calcium increases after channel openings ${ }^{19}$. However, more surprising was the lack of any effects of Tal on the calcium level of oculomotor neurons at any time points. Although the literature data are not fully consistent $^{160,197}$, it could be the consequence of increased GluR2 content, which makes AMPA receptors on oculomotor neurons less permeable to calcium ${ }^{163}$, thus invoking a reduced calcium stress in these cells. Either alone, or in combination, these factors, in addition to the clinical observation that these motor neurons lack monosynaptic connections with cortico-motor neurons ${ }^{7,8}$ cause an inferior calcium-mediated stress in these neurons, thus making them less susceptible to mSOD1-induced lesion.

\section{Role of the neuron-microglia communication in neuronal degeneration}


Since photobleaching and non-standardized excitation are the major controversy during quantification of fluorescent dyes, a development of a photostable visualization technique was necessary. Therefore, a DAB-fluorescent combined immunohistochemical method suitable for proper quantification of the intensity and area of the region of interests with a secondary staining for anatomical mapping was introduced (Fig 19). Furthermore, this technique was tested in a neuroprotective paradigm using a benzothiadiazine derivative, diazoxide, which acts on mitochondrial adenosin triphosphate (ATP)-dependent potassium channels ${ }^{198}$, therefore it is capable of modulating the mitochondrial homeostasis ${ }^{199}$. Diazoxide has been applied as a pretreatment in various in vivo and in vitro cerebral ischemia ${ }^{200,201}$ and in different neurodegenerative models ${ }^{202}$. For instance, multiple sclerosis is known as an acquired inflammatory demyelinating disorder of the CNS, therefore activated microglial cells play a crucial role in the pathogenesis by secreting cytokines and other neurotoxic molecules.

Diazoxide treatment successfully ameliorates the progression of multiple sclerosis in murine model via inhibition of nitric monoxide, tumor necrosis factor $\alpha$ and interleukin-6 produced by activated microglial cells ${ }^{203}$. Furthermore, in vitro results from diazoxide treatment has shown effective protection on NSC-34 motoneurons via alleviation of glutamatergic, oxidative and inflammatory damage ${ }^{204}$. Ex vivo studies elucidate the antiinflammatory effect of diazoxide on organotypic hippocampal slices challenged by glutamate excitotoxicity and pro-inflammatory demyelinating damage ${ }^{204}$. However, numerous components of the neuroprotective mechanism behind the anti-inflammatory remain unclear, attenuation of the microglial activation might be a viable protective strategy. Recent studies suggest that activation of the ATP-dependent potassium channels may cause hyperpolarization in the plasma membrane which prevents calcium entry into the cytoplasm via voltage gated calcium channels ${ }^{205}$. In concordance with these findings, in our previous studies we demonstrated the malicious effect of calcium elevation in different animal models as well as on human samples ${ }^{2,4,5,6}$. The effect of diazoxide treatment was reported mostly in in vitro studies which serve as models for chronic neurodegenerative diseases for example Parkinson's disease ${ }^{206}$. Moreover, we demonstrated the anti-inflammatory effect of diazoxide on acute neurodegenerative models challenging motor nuclei with different susceptibility for degeneration. Our data - obtained with the quantification of combined immunohistochemistry - indicate that microglial activation, induced with axotomy or target deprivation, could be alleviated with diazoxide treatment in the examined nuclei (Fig. 20). However, anatomical mapping of the region of interest is a crucial parameter of the 
evaluation since anatomical boundaries of the nuclei or contralateral innervation capable of amending the outcome of the quantification protocol.

\section{Protective effect of calcium binding proteins in motoneuronal injury}

Deregulated calcium homeostasis, with a self-propagating cycle of increased intracellular calcium concentration, production of reactive oxidative species and impairment of the respiratory cycle of mitochondria ${ }^{147,207}$ may result in a primary neuronal lesion and release of cytokines/chemokines leading to the activation of inflammatory cells ${ }^{50,208}$ and injury/activation of astrocytes augmenting the primary insult ${ }^{209}$. We demonstrated that, an enhanced intracellular calcium buffer capacity of motor neurons in PV overexpressing transgenic mice could attenuate the intracellular increase of motoneuronal calcium after acute injury, could narrow the duration of the emission of distress signals by motor neurons, and could reduce the activation of microglial cells in their neighborhood.

PV is normally not expressed in spinal motor neurons of wild type rats ${ }^{150}$ or mice ${ }^{210}$. Here, adult PV $+/+$ mice were used to test the protective role of elevated PV in spinal motor neurons against acute injury. As standard controls, B6/SJL mice, the parental strain of PV+/+ animals $^{159}$ were used. Previously we demonstrated a significant calcium increase in the calcium content of hypoglossal motor neurons of B6/SJL mice at day 7 and 14 after axotomy, which could be prevented by upregulating $\mathrm{PV}^{169}$. This protective effect of PV was also demonstrated in oculomotor and hypoglossal motor neurons of Balb/c mice, i.e. in motor nerve cells with naturally different PV content, by comparing calcium increase after acute axonal injury ${ }^{5}$. To gain additional experimental support for the view of the possible universal protective role of CaBPs, and to exclude species differences in the sensitivity of motor neurons against injury, the present experiments were extended to both $\mathrm{Balb} / \mathrm{c}$ and $\mathrm{B} 6 / \mathrm{SJL}$ control strains. At postoperative day 7, when the peak increase of intracellular calcium was expected, about 2-fold calcium increase could be observed in the spinal motor neurons of both control strains, with no significant difference from each other ${ }^{169}$. This was comparable to that of hypoglossal motor neurons of both Balb/c and B6/SJL mice ${ }^{5,169}$. Furthermore, in the present experiments, practically no calcium increase could be observed in the spinal motor neurons of PV+/+ mice at this postoperative time (Fig. 14), which suggests, that similar to the hypoglossal neurons of $\mathrm{PV}+/+$ mice $^{169}$, PV upregulation can transform the vulnerable cells to oculomotor-type resistant ones, at least as the intracellular calcium increase after acute injury is concerned. CCL2, also known as monocyte chemoattractant protein-1, the involvement of which has been evidenced in many neurodegenerative diseases, is one of the essential and 
most widely studied chemokines that controls the migration and infiltration of monocytes/macrophages ${ }^{211}$. Although CCL2 could be produced by astrocytes and microglia, its constitutive neuronal expression as well as the induction of its neuronal secretion under pathological conditions was documented ${ }^{212}$, specifically in acute lesion models, such as after focal ischemia ${ }^{213}$ and in motor neurons, after axonal injury ${ }^{214,215}$. Thus, since cytokine/chemokine signaling is known to precede the activation of further immune responses $^{216}$, in our study, CCL2 was selected as a marker of distress signals of motor neurons after acute lesion.

The relevance of microglial activation in acute injury of motor neurons has been demonstrated in several classic models of remote injury ${ }^{96,217,218,219}$. Its significance in chronic motoneuronal degeneration was also documented, exemplified by the upregulated expression of microglial markers, like cluster of differentiation 68 (CD68), and CD11b, which were consistently detected in autopsy material of ALS patients and in the spinal cord of mSOD1 mouse model of $\mathrm{ALS}^{98}$. The ALS example, furthermore, implies a possible graded microglial response after injury, since a correlation was found between increased microglial activation in the motor cortex of ALS patients and the severity of upper motor neuron signs ${ }^{100}$.

Publications documenting that microglia express C-C chemokine receptor type 2 for the ligand, CCL2 220,221 and the suggestion that CCL2 may serve as a driving signal for them after neuronal injury ${ }^{215,217}$ are consistent with the fact that microglial cells are of myeloid origin, with several properties similar to those of peripheral monocytes/macrophages ${ }^{222}$. In the present study, using CD11b as a microglia marker, differences in the axotomy-induced microglial activation could be detected around motor neurons with different PV contents, potentially with different resistance against injury, which could be analogous to the graded response noted in chronic degeneration.

With regard to the temporal change of CCL2 expression and microglia activation following sciatic nerve injury, our data reveal a transient increase of both parameters in the postoperative 3-week-long period (Fig. 11B and Fig. 12B), and show a good correlation with similar data in the literature ${ }^{215}$. Fig. 11B and Fig. 12B demonstrate a reduced inflammatory reaction in the spinal cords of PV+/+ mice characterized by either of CCL2 or CD11b intensity. However, the measured staining intensity of CCL2 returns faster to the baseline, already at postoperative day 14 , than that of CD11b at day 21. Assuming that motor neurons with different susceptibility against calcium-mediated injury start responding to the lesion in the same way, not the amplitude/strength of the distress signal would be smaller in motor neurons with stronger cellular homeostasis, provided by an improved calcium buffer in our 
case but its duration might be shorter, as documented in Fig. 11. Thus, the cessation of the activation/migration of immune-competent cells, characterized by CD11b staining in our study, should follow the termination of the release of their driving signal, CCL2, with a time lag, as it could be seen by comparing Fig. 11B and Fig. 12B. In the present experiments, an attenuated calcium increase could be documented in spinal motor neurons of $\mathrm{PV}+/+$ mice which is assumed to reflect an increased resistance against calcium-mediated degeneration after axotomy, and, thus, similarly to other models of acute injury where a graded microglial response was documented ${ }^{223,224}$, a reduced activation of microglia could be evoked.

Besides the clinical observations that motor neurons rich in certain CaBPs are relatively spared in chronic degenerative diseases like $\mathrm{ALS}^{15,153}$, there are abundant experimental data providing further support for the protective role of naturally occurring CaBPs against calcium-mediated injury in oculomotor neurons ${ }^{156,157}$, in contrast to hypoglossal ${ }^{18}$ or spinal motor neurons with low $\mathrm{CaBP}$ content ${ }^{155}$. Furthermore, a more direct evidence of the protective role of increased PV in motor neurons could be obtained from studies in $\mathrm{PV}+/+$ mice either by demonstrating that spinal motor neurons of neonatal animals otherwise destined to die after sciatic nerve crush could be rescued ${ }^{158}$, or documenting that calcium increase in adult hypoglossal motor neurons could be attenuated after axotomy in $\mathrm{PV}+/+$ mice $^{169}$. Unlike in the experiment of Dekkers et al. ${ }^{158}$, in our experiments change in the intracellular calcium level after axotomy was selected as a sole parameter to check resistance against injury, since in adult animals no major loss of motor neurons is expected after axotomy ${ }^{225}$. Indeed, Vanden Noven et al. described that adult spinal motoneurons remain viable despite prolonged absence of functional synaptic contact with muscle ${ }^{226}$. Furthermore, Goettl et al. documented that sciatic nerve axotomy had no effect on the number of motoneurons in the retrodorsal lateral nucleus of the spinal cord, and noted only a short-lasting attenuation of cholinergic phenotype in these cells after axotomy ${ }^{227}$. This is in accord with our previous observation, made in the hypoglossal nucleus after axotomy ${ }^{5}$, where, based on cresyl violet staining, no motoneuronal loss could be seen, but a decreased neuron specific neuronal nuclei staining was noted at days 1-14 suggesting a reversible injury of hypoglossal neurons, which are similarly vulnerable to axotomy as the spinal motor neurons. Nevertheless, increasing the calcium buffer capacity of cells under chronic stress condition like in the mSOD1 transgenic model of ALS, may not provide sufficient protection, as it was shown in the double transgenic, $\mathrm{PV}+/+\times$ mSOD1 mice, in which the disease onset could be delayed but the progression of the disease could not be stopped ${ }^{159}$. This inferior 
protection could be the consequence of the limited capacity of the buffer, which sooner or later saturates if the stress endures. Although the contribution of the added calcium buffers might not be sufficient for full protection, these data provide support for the idea that the strategy, addressing the stabilization of the calcium homeostasis, might be promising in attempts to rescue motoneurons, particularly in the view of the present results demonstrating that stabilization of motoneuronal calcium homeostasis during injury influences the reaction of non-motor neuronal compartments as well.

\section{SUMMARY}

- In SOD1 transgenic mice, Tal treatment showed a significant protective effect in the axon terminals of susceptible muscles compared to Veh treatment. The efficacy of the treatment is related to the alleviation of extensive calcium influx via AMPA receptors with a calcium permeable, pathological feature. This neuroprotection lost its efficacy when applied in the symptomatic stage of ALS. However, both perikarya and distal axon terminals can be equally protected with a soma-targeted treatment.

- Oculomotor neurons might possess a special attribute which protects from the calcium-mediated degeneration. This attribute might be related to the elevated $\mathrm{CaBP}$ content such as PV. Since these neurons show increased resistance against calciummediated degeneration, SOD1 transgenic strain did not show elevated calcium level. Furthermore, Tal treatment was unable to decrease the intracellular calcium content further.

- Since nature provides us motor neurons with different CaBP contents, the effect of such proteins on neuroprotection could be tested in acute injury models using different groups of motor neurons. Our results showed that inflammatory processes represented by microglial activation are significantly lower in oculomotor neurons compared to the susceptible groups of motor neurons with low $\mathrm{CaBP}$ content.

- To attenuate the microglial reaction after acute injury, diazoxide treatment was applied. This neuroprotective trial shows a significant alleviation of inflammatory response in all examined motor neuron groups. Efficacy of the diazoxide treatment might be related to the anti-inflammatory mechanism, however the pharmacological effect can be extended to the alleviation of calcium elevation in motor neurons.

- To test the interplay between calcium-mediated degeneration and microglial activation, $\mathrm{PV}+/+$ mice were examined after unilateral axotomy. After the surgical 
procedure, intracellular calcium changes can be observed in the control strains only where the calcium shows significant elevation compared to the $\mathrm{PV}+/+$ strain, therefore, we could confirm, that CaBPs are capable of reducing calcium mediated degeneration.

- Furthermore, in the same PV+/+ animals' chemokine signalization, represented by CCL2, was decaying faster, which resulted in a faster attenuation in the nearby microglia-mediated inflammation.

The results are in concordance with the hypothesis of the central role of calcium elevation in chronic degeneration and support its key role in acute motor neuron degeneration paradigms as well. Furthermore, we showed that both an AMPA receptor targeted treatment and an augmentation of the $\mathrm{CaBP}$ content are capable of reducing degeneration due to the reduced calcium influx. Imbalanced calcium homeostasis might be establishing a local inflammatory reaction with the activation of microglial cells. However, this microglial recruitment could be attenuated by the augmentation of calcium homeostasis. According to our findings, measurement of the direct effect between inflammation and calcium elevation might give us new opportunities for neuroprotective trials and "eavesdropping" on the neuron-microglia crosstalk is strongly suggested to understand the pathomechanism behind motor neuron degeneration. 


\section{BIBLIOGRAPHY}

1. Siesjö BK. Calcium mediated processes in motor neuronal degeneration. Ann N Y Acad Sci. 1994; 747: 140-161.

2. Siklós L, Engelhardt, J, Harati Y, Smith RG, Joó F, Appel SH. Ultrastructural evidence for altered calcium in motor nerve terminals in amyotrophic lateral sclerosis. Ann Neurol. 1996; 39: 203-216.

3. Colom LV, Alexianu ME, Moiser DR, Smith RG, Appel SH. Amyotrophic lateral sclerosis immunoglobulins increase intracellular calcium in a motoneuron cell line. Exp Neurol. 1997; 146: 354-360.

4. Siklós L, Engelhardt JI, Alexianu ME, Gurney ME, Siddique T, Appel SH. Intracellular calcium parallels motoneuron degeneration in SOD-1 mutant mice. J Neuropathol Exp Neurol. 1998; 57: 571-587.

5. Obál I, Engelhardt JI, Siklós L. Axotomy induces contrasting changes in calcium and calcium-binding proteins in oculomotor and hypoglossal nuclei of Balb/c mice. J Comp Neurol. 2006; 499: 17-32.

6. Adalbert R, Morreale G, Paizs M, Conforti L, Walker SA, Roderick HL, Bootman MD, Siklós L, Coleman MP. Intra-axonal calcium changes after axotomy in wild-type and slow Wallerian degeneration axons. Neuroscience. 2012; 225: 44-54.

7. Kiernan MC, Vucic S, Cheah BC, et al. Amyotrophic lateral sclerosis. Lancet. 2011; 377: 942-955.

8. Vucic S, Rothstein JD, Kiernan MC. Advances in treating amyotrophic lateral sclerosis: insights from pathophysiological studies. Trends Neurosci. 2014; 37: 433-442.

9. Barber SC, Shaw PJ, Oxidative stress in ALS: Key role in motor neuron injury and therapeutic target. Free Rad Biol Med. 2010; 48: 629-641.

10. Bozzo F, Mirra A, Carrì MT. Oxidative stress and mitochondrial damage in the pathogenesis of ALS: New perspectives. Neurosci. Letters. 2017; 636: 3-8.

11. Carrì MT, Valle C, Bozzo F, Cozzolino M. Oxidative stress and mitochondrial damage: importance in non-SOD1 ALS. Front. Cell. Neurosci. 2015; 9: Art. 41.

12. Mattson MP, Gleichmann M, Cheng A. Mitochondria in neuroplasticity and neurological disorders. Neuron. 2008; 60: 748-766.

13. Hooten KG, Beers DR, Zhao W, Appel SH. Protective and toxic neuroinflammation in amyotrophic lateral sclerosis. Neurotherapeutics. 2015; 12: 364-375. 
14. Patai R, Nógrádi B, Engelhardt JI, Siklós L. Calcium in the pathomechanism of amyotrophic lateral sclerosis - Taking the center stage? Biochem Biophys Res Commun. 2017; 483: 1031-1039.

15. Alexianu ME, Ho BK, Mohamed AH, La Bella V, Smith RG, Appel SH. The role of calcium-binding proteins in selective motoneuron vulnerability in amyotrophic lateral sclerosis. Ann Neurol. 1994; 36: 846-858.

16. Elliot JL, Snider WD. Parvalbumin is a marker of ALS resistant motor neurons. NeuroReport. 1995; 6: 449-452.

17. Ho B-K, Alexianu ME, Colom LV, Mohamed AH, Serrano F, Appel SH. Expression of calbindin- $\mathrm{D}_{28 \mathrm{k}}$ in motoneuron hybrid cells after retroviral infection with calbindin- $\mathrm{D}_{28 \mathrm{k}}$ cDNA prevents amyotrophic lateral sclerosis IgG-mediated cytotoxicity. Proc Natl Acad Sci. 1996; 93: 6796-6801.

18. Lips MB, Keller BU. Endogenous calcium buffering in motoneurones of the nucleus hypoglossus from mouse. J Physiol. 1998; 511: 105-117.

19. von Lewinski F, Keller BU. $\mathrm{Ca}^{2+}$, mitochondria and selective motoneuron vulnerability: implications for ALS. Trends Neurosci. 2005; 28: 494-500.

20. Paizs M, Patai R, Engelhardt JI, Katarova Z, Obál I, Siklós L. Axotomy Leads to Reduced Calcium Increase and Earlier Termination of CCL2 Release in Spinal Motoneurons with Upregulated Parvalbumin Followed by Decreased Neighboring Microglial Activation. CNS Neurol. Disord. Drug Targets. 2017; 16: 356-367.

21. Paizs M, Engelhardt JI, Siklós L. Quantitative assessment of relative changes of immunohistochemical staining by light microscopy in specified anatomical regions. $J$ Microsc. 2009; 234: 103-112.

22. Shultz RB, Zhong Y. Minocycline targets multiple secondary injury mechanisms in traumatic spinal cord injury. Neural Regen. Res. 2017; 12: 702-713.

23. Cleveland DW, Rothstein JD. From Charcot to Lou Gehrig. Deciphering selective motor neuron death in ALS. Nat Rev Neurosci. 2001; 2: 806-819.

24. Rowland LP, Shneider NA. Amyotrophic lateral sclerosis, New Eng J Med. 2001; 344: $1688-1700$.

25. Leigh PN, Ray-Chaudhuri K. Motor neuron disease. J Neurol Neurosurg Psychiatry. 1994; 57: 886-896. 
26. Rosen DR, Siddique T, Patterson D, et al. Mutations in $\mathrm{Cu} / \mathrm{Zn}$ superoxide dismutase gene are associated with familial amyotrophic lateral sclerosis. Nature.1993; 362:59-62.

27. Harms MB, Baloh RH. Clinical Neurogenetics: Amyotrophic Lateral Sclerosis. Neurol. Clin. 2013; 31: 929-950.

28. Turner MR, Hardiman O, Benatar M, et al., Controversies and priorities in amyotrophic lateral sclerosis. Lancet Neurol. 2013; 12: 310-322.

29. Robberecht W, Philips T. The changing scene of amyotrophic lateral sclerosis, Nature Rev. Neurosci. 2013; 14: 248-264.

30. Lopez-Bastida J, Perestelo-Perez L, Monton-Alvarez F, Serrano-Aguilar P, AlfonsoSanchez JL. Social economic costs and health-related quality of life in patients with amyotrophic lateral sclerosis in Spain. Amyotroph Lateral Scler. 2009; 10: 237-243.

31. Schepelmann K, Winter Y, Spottke AE, Claus D, Grothe C, Schroder R, Heuss D, Vielhaber S, Mylius V, Kiefer R, Schrank B, Oertel WH, Dodel R. Socioeconomic burden of amyotrophic lateral sclerosis, myasthenia gravis and facioscapulohumeral muscular dystrophy. J Neurol. 2010; 257: 15-23.

32. Chiò A, Logroscino G, Traynor BJ, Collins J, Simeone JC, Goldstein LA, White LA. Global Epidemiology of Amyotrophic Lateral Sclerosis: a Systematic Review of the Published Literature. Neuroepidemology. 2013; 41: 118-130.

33. McCombe PA, Henderson RD. Effect of Gender in Amyotrophic Lateral Sclerosis. Gend. Med. 2010; 7:557-570.

34. Merchenthaler I, Dellovade TL, Shughrue PJ. Neuroprotection by estrogen in animal models of global and focal ischemia. Ann N Y Acad Sci. 2003; 1007: 89-100.

35. Bede P, Elamin M, Byrne S, Hardiman O. Sexual dimorphism in ALS: exploring gender-specific neuroimaging signatures. Amyotroph Lateral Scler Frontotemporal Degener. 2014; 15: 235-243.

36. Agosta F, Al-Chalabi A, Filippi M, et al. The El Escorial criteria: strengths and weaknesses. Amyotroph Lateral Scler Frontotemporal Degener. 2015; 16: 1-7.

37. Swash M. Clinical features and diagnosis of amyotrophic lateral sclerosis. In: Amyotrophic Lateral Sclerosis. (eds: Brown RH Jr, Meininger V, Swash M), Martin Dunitz, 2000; pp. 3-30. 
38. Cwik VA. ALS clinical motor signs and symptoms. In: Amyotrophic Lateral Sclerosis. (eds: Mitsumoto H, Przedborski S, Gordon PH), Taylor \& Francis Group, New York, London, 2006; pp. 99-115.

39. Mulder DW. Clinical limits of amyotrophic lateral sclerosis. Adv Neurol, 1982; 36: 1522.

40. Isaacs JD, Dean AF, Shaw CE, Al Chalabi A, Mills KR, Leigh PN. Amyotrophic lateral sclerosis with sensory neuropathy: part of a multisystem disorder? J Neurol Neurosurg Psychiatry. 2007; 78: 750-753

41. Pugdahl K, Fuglsang-Frederiksen A, de Carvalho M, et al. Generalised sensory system abnormalities in amyotrophic lateral sclerosis: a European multicentre study. J Neurol Neurosurg Psychiatry. 2007; 78: 746-749.

42. de Carvalho M, Dengler R, Eisen A, et al. Electrodiagnostic criteria for diagnosis of ALS. Clin Neurophysiol. 2008; 119: 497-503.

43. Charcot JM, Joffroy A. Deux cas d'atrophie musculaire progressive avec lesion de la substance grise et des faisceaux antéro-latéraux de la moelle épinière. Arch Physiol Neurol Path. 1869; 2: 744-754.

44. Hays AP. The pathology of amyotrophic lateral sclerosis. In: Amyotrophic Lateral Sclerosis. (eds: Mitsumoto H, Przedborski S, Gordon PH), Taylor \& Francis Group, New York, London, 2006; pp. 43-80.

45. Yaron A, Schuldiner O. Common and Divergent Mechanisms in Developmental Neuronal Remodeling and Dying Back Neurodegeneration. Curr Biol. 2016; 26: 628639.

46. Kato S. Amyotrophic lateral sclerosis models and human neuropathology: similarities and differences. Acta Neuropathol. 2008; 115: 97-114.

47. Swinnen B, Robberecht W. The phenotypic variability of amyotrophic lateral sclerosis. Nature Rev Neurol. 2014; 10: 661-670.

48. Julien JP. ALS: astrocytes move in as deadly neighbors. Nature Neurosci. 2007; 10: $535-537$.

49. Appel SH, Zhao W, Beers DR, Henkel S. The microglial-motoneuron dialogue in ALS, Acta Myologica. 2011; 30: 4-8.

50. Malaspina A, Puentes F, Amor S. Disease origin and progression in amyotrophic lateral sclerosis: an immunology perspective. Int Immunol. 2014; 27: 117-129. 
51. Boillée S, Vande Velde C, Cleveland DW. ALS: a disease of motor neurons and their nonneuronal neighbors. Neuron. 2006; 52: 39-59.

52. Ilieva H, Polymenidou M, Cleveland DW. Non-cell autonomous toxicity in neurodegenerative disorders: ALS and beyond. J Cell Biol. 2009; 187: 761-772.

53. Rothman SM, Olney JW. Excitotoxicity and the NMDA receptor. Trends Neurosci. 1987; 10: 299-302.

54. Choi DW. Amyotrophic lateral sclerosis and glutamate - too much of a good thing? New Eng J Med. 1992; 326: 1493-1495.

55. Plaitakis A, Caroscio JT. Abnormal glutamate metabolism in amyotrophic lateral sclerosis. Ann Neurol. 1987; 22: 575-579.

56. Rothstein JD, Kuncl RW, Chaudry V, et al. Excitatory amino acids in amyotrophic lateral sclerosis. Ann Neurol. 1991; 30: 224-225.

57. Rothstein JD, Van Kammen M, Levey AI, et al. Selective loss of glial glutamate transporter GLT-1 in amyotrophic lateral sclerosis. Ann Neurol. 1995; 38: 73-84.

58. Mitsumoto H, Chad DA, Pioro EP. Excitotoxicity and oxidative damage in ALS pathogenesis. In: Amyotrophic Lateral Sclerosis. (eds: Mitsumoto H, Chad DA, Pioro EP), F.A. Davis Company, Philadelphia, 1997; pp. 197-225.

59. Sommer B, Kohler M, Spregel R, Seeburg PH. RNA editing in brain controls a determinant of ion flow in glutamate-gated channels. 1991; Cell. 67: 11-19.

60. Williams TL, Day NC, Ince PG, et al. Calcium-permeable alpha-amino-3-hydroxy-5methyl-4-isoxazole propionic acid receptors: a molecular determinant of selective vulnerability in amyotrophic lateral sclerosis. Ann Neurol. 1997; 42: 200-207.

61. Takuma H, Kwak S, Yoshizawa T, Kamazawa I. Reduction of GluR2 RNA editing, a molecular change that increases calcium influx through AMPA receptors, selective in the spinal ventral gray of patients with amyotrophic lateral sclerosis. Ann Neurol. 1999; 46: 806-815.

62. Shaw PJ, Ince PG, Falkous G, Mantle D. Oxidative damage to protein in sporadic motor neuron disease spinal cord. Ann Neurol. 1995; 38: 691-695.

63. Ferrante RJ, Browne SE, Shinobu LA, et al. Evidence of increased oxidative damage in both sporadic and familial amyotrophic lateral sclerosis. J Neurochem. 1997; 69: 20642074. 
64. D’Amico E, Factor-Litvak P, Santella RM, Mitsumoto H. Clinical perspective on oxidative stress in sporadic amyotrophic lateral sclerosis. Free Rad Biol Med. 2013; 65: $509-527$.

65. Beal MF, Ferrante RJ, Browne SE, et al. Increased 3-nitrotyrosine in both sporadic and familial amyotrophic lateral sclerosis. Ann Neurol. 1997; 42: 644-654.

66. Bogdanov M, Brown RH, Mattson W, et al. Increased oxidative damage to DNA in ALS patients. Free Rad Biol Med. 2000; 29: 652-658.

67. Ihara Y, Nobukuni K, Takata H, Hayabara T. Oxidative stress and metal content in blood and cerebrospinal fluid of amyotrophic lateral sclerosis patients with and without a Cu,Zn-superoxide dismutase mutation. Neurol Res. 2005; 27: 105-108.

68. Smith RG, Henry YK, Mattson MP, Appel SH. Presence of 4-hydroxynonenal in cerebrospinal fluid of patients with sporadic amyotrophic lateral sclerosis. Ann Neurol. 1998; 44: 696-699.

69. Simpson EP, Henry YK, Henkel JS, et al. Increased lipid peroxidation in sera of ALS patients: a potential biomarker of disease burden? Neurology. 2004; 62: 1758-1765.

70. Annunziato L, Pannaccione A, Cataldi M, et al. Modulation of ion channels by reactive oxygen and nitrogen species: a pathophysiological role in brain aging? Neurobiol Aging. 2002; 23: 819-834.

71. Melachroinou K, Xilouri M, Emmanouilidou E, et al. Deregulation of calcium homeostasis mediates secreted $\alpha$-synuclein-induced neurotoxicity. Neurobiol Aging. 2013; 34: 2853-2865.

72. Li A, Ségui J, Heinemann SH, Hoshi T. Oxidation regulates cloned neuronal voltagedependent Ca2+ channels expressed in Xenopus oocytes. J Neurosci. 1998; 18: 67406747.

73. Kiselyov K, Muallem S. ROS and intracellular ion channels. Cell Calcium. 2016; 60: $108-114$.

74. Clerk P, Lipnick S, Willett C. A look into the future of ALS research. Drug Discov Today. 2016; 21: 939-949.

75. Peters OM, Ghasemi M, Brown RH Jr. Emerging mechanisms of molecular pathology in ALS. J Clin Invest 2015; 125: 1767-1779. 
76. Barber SC, Mead RJ, Shaw PJ. Oxidative stress in ALS: A mechanism of neurodegeneration and a therapeutic target. Biochim Biophys Acta. 2006; 1762: 10511067.

77. Harraz MM, Marden JJ, Zhou W, et al. SOD1 mutations disrupt redox-sensitive Rac regulation of NADPH oxidase in a familial ALS model. J Clin Invest. 2008; 118: 659670.

78. Atsumi T. The ultrastructure of intramuscular nerves in amyotrophic lateral sclerosis. Acta Neuropathol. (Berl.) 1981; 55: 193-198.

79. Sasaki S, Iwata M. Ultrastructural study of synapses in the anterior neurons of patients with amyotrophic lateral sclerosis. Neurosci Lett. 1996; 204: 53-56.

80. Sasaki S, Iwata M. Mitochondrial alteration in the spinal cord of patients with sporadic amyotrophic lateral sclerosis. J Neuropathol Exp Neurol. 2007; 66: 10-16.

81. Wiedemann FR, Manfredi G, Mawrin C, et al. Mitochondrial DNA and respiratory chain function in spinal cords of ALS patients. J Neurochem. 2002; 80: 616-625.

82. Swerdlow RH, Parks JK, Cassarino DS, et al. Mitochondria in sporadic amyotrophic lateral sclerosis. Exp Neurol. 1998; 153: 135-142.

83. Manfredi G, Xu Z. Mitochondrial dysfunction and its role in motor neuron degeneration in ALS. Mitochondrion. 2005; 5: 77-87.

84. Dal Canto MC, Gurney ME. Development of central nervous system pathology in a murine transgenic model of human amyotrophic lateral sclerosis. Am J Pathol. 1994; 145: $1271-1279$.

85. Bendotti C, Calvaresi N, Chiveri L, et al. Early vacuolization and mitochondrial damage in motor neurons of FALS mice are not associated with apoptosis or with changes in cytochrome oxidase histochemical reactivity. J Neurol Sci. 2001; 191: 25-33.

86. Brini M, Cali T, Ottolini D, Carafoli E. Neuronal calcium signaling: function and dysfunction. Cell Mol Life Sci. 2014; 71: 2787-2814.

87. Carrì MT, Cozzolino M. SOD1 and mitochondria in ALS: a dangerous liaison. $J$ Bioenerg Biomembr. 2011; 43: 593-599.

88. Tan W, Pasinelli P, Trotti D. Role of mitochondria in mutant SOD1 linked amyotrophic lateral sclerosis. Biochim Biophys Acta. 2014; 1842: 1295-1301. 
89. Damiano M, Starkov AA, Petri $\mathrm{S}$, et al. Neural mitochondrial $\mathrm{Ca} 2+$ capacity impairment precedes the onset of motor symptoms in $\mathrm{G} 93 \mathrm{~A} \mathrm{Cu} / \mathrm{Zn}$-superoxide dismutase mutant mice. J Neurochem. 2006; 96: 1349-1361.

90. Jaiswal MK, Keller BU. Cu/Zn superoxide dismutase typical for familial amyotrophic lateral sclerosis increases the vulnerability of mitochondria and perturbs $\mathrm{Ca} 2+$ homeostasis in SOD1G93A mice. Mol Pharm. 2009; 75: 478-489.

91. Carrì MT, Ferri A, Battistoni $\mathrm{A}$, et a. Expression of a $\mathrm{Cu}, \mathrm{Zn}$ superoxide dismutase typical of familial amyotrophic lateral sclerosis induces mitochondrial alteration and increase of cytosolic Ca2+ concentration in transfected neuroblastoma SH-SY5Y cells. FEBS Letters. 1997; 414: 365-368.

92. Meininger V. ALS, what new 144 years after Charcot? Arch Ital Biol. 2011; 149: 2937.

93. Schiffer D, Cordera S, Cavalla O, Migheli A. Reactive astrogliosis of the spinal cord in amyotrophic lateral sclerosis. J Neurol Sci. 1996; 139: Suppl. 27-33.

94. Aloisi F. The role of microglia and astrocytes in CNS immune surveillance and immunopathology. In: The functional role of glial cells in health and disease. (eds: Matsas R, Tsacopoulos M), Kluwer Academic/Plenum Publishers, New York, 1999; pp. $123-133$.

95. Farina C, Aloisi F, Meinl E. Astrocytes are active players in cerebral innate immunity. Trends Immunol. 2007; 28: 138-145.

96. Kreutzberg GW. Microglia: a sensor for pathological events in the CNS. Trends Neurosci. 1996; 19: 312-318.

97. Streit WJ, Walter SA, Pennell NA. Reactive microgliosis. Prog Neurobiol. 1999; 57: $563-581$.

98. Philips T, Robberecht W. Neuroinflammation in amyotrophic lateral sclerosis: role of glial activation in motor neuron disease. Lancet Neurol. 2011; 10: 253-263.

99. Hanisch UK, Kettenmann H. Microglia: active sensor and versatile effector cells in the normal and pathologic brain. Nature Neurosci. 2007; 10: 1387-1394.

100. Turner MR, Cagnin A, Turkheimer FE, et al. Evidence for widespread cerebral microglial activation in amyotrophic lateral sclerosis: an [11C](R)-PK11195 positron emission tomography study. Neurobiol Dis. 2004; 15: 601-609. 
101. Sitte HH, Wanschitz J, Budka H, Berger ML, Autoradiography with [11C](R)-PK11195 of spinal tract degeneration in amyotrophic lateral sclerosis. Acta Neuropathol. 2001; $10175-78$.

102. Corcia P, Tauber C, Vercoullie J, et al. Molecular imaging of microglial activation in amyotrophic lateral sclerosis. Plos One. 2012; 7: e52941.

103. Zürcher NR, Loggia M-L, Lawson R, et al. Increased in vivo glial activation in patients with amyotrophic lateral sclerosis: assessed with [11C]-PBR28. Neuroimage: Clinical 2015; 7: 409-414.

104. Evans MC, Couch Y, Sibson N, Turner MR. Inflammation and neurovascular changes in amyotrophic lateral sclerosis. Mol Cell Neurosci. 2013; 53: 34-41.

105. Rojas F, Gonzalez D, Cortes N, et al. Reactive oxygen species trigger motoneuron death in non-cell-autonomous models of ALS through activation of c-Abl signaling. Front Cell Neurosci. 2015; 9: Article 203.

106. Boillée S, Cleveland DW. Revisiting oxidative damage in ALS: microglia, Nox, and mutant SOD1. J Clin Invest. 2008; 118: 474-478.

107. May C, Nordhoff E, Casjens S, et al. Highly immunoreactive $\mathrm{IgG}$ antibodies directed against a set of twenty human proteins in the sera of patients with amyotrophic lateral sclerosis identified by protein array. Plos One. 2014; e89596.

108. Pagani MR, Reisin RC, Uchitel OD. Calcium signaling pathways mediating synaptic potentiation triggered by amyotrophic lateral sclerosis $\mathrm{IgG}$ in motor nerve terminals. $J$ Neurosci. 2006; 26: 2661-2672.

109. Pagani MR, Gonzalez LE, Uchitel OD. Autoimmunity in amyotrophic lateral sclerosis: Past and present. Neurol Res Int. 2011; Art ID 497080.

110. Appel SH, Smith RG, Alexianu M, et al. Increased intracellular calcium triggered by immune mechanisms in amyotrophic lateral sclerosis. Clin Neurosci. 1996; 3: 368-374.

111. Smith RG, Hamilton S, Hofmann F, et al. Serum antibodies to L-type calcium channels in patients with amyotrophic lateral sclerosis. New Eng J Med. 1992; 327: 1721-1728.

112. Kimura F, Smith RG, Nyormoi O, et. al. Amyotrophic lateral sclerosis patient antibodies label Ca2+ channel $\alpha 1$ subunit. Ann Neurol. 1994; 35: 164-171.

113. Magnelli V, Sawada T, Delbono O, et al. The action of amyotrophic lateral sclerosis immunoglobulins on mammalian single skeletal muscle Ca2+ channels. J Physiol 1993; 461: 103-118. 
114. Llinas R, Sugimori M, Cherksey BD, et al. IgG from amyotrophic lateral sclerosis patients increases current through P-type calcium channels in mammalian cerebellar Purkinje cells and isolated channel protein in lipid bilayer. Proc Natl Acad Sci USA. 1993; 90: 11743-11747.

115. Mosier DR, Baldelli $\mathrm{P}$, Delbono $\mathrm{O}$, et al. Amyotrophic lateral sclerosis immunoglobulins increase Ca2+ currents in a motoneuron cell line. Ann Neurol. 1995; 37: 102-109.

116. Carafoli E. Calcium signaling: a tale for all seasons. Proc Natl Acad Sci USA. 2002; 99: $1115-1122$.

117. Brini M, Carafoli E. Calcium signalling: a historical account, recent developments and future perspectives. Cell Mol Life Sci. 2000; 57: 354-370.

118. Ringer S. A further contribution regarding the influence of the different constituents of the blood on the contraction of the heart. J Physiol. 1883; 4: 29-42.

119. Berliocchi L, Bano D, Nicotera P. Ca2+ signals and death programmes in neurons. Phil Trans $R$ Soc B. 2005; 360: 2255-2258.

120. Celsi F, Pizzo P, Brini M, et al. Mitochondria, calcium and cell death: a deadly triad in neurodegeneration. Biochim Biophys Acta. 2009; 1787: 335-344.

121. Gleichmann M, Mattson MP. Neuronal calcium homeostasis and dysregulation. Antiox Redox Signaling 2011; 14: 1261-1273.

122. Bano D, Nicotera P. Ca2+ signals and neuronal death in brain ischemia. Stroke. 2007; 38: 674-676.

123. Yonutas HM, Vekaria HJ, Sullivan PG. Mitochondrial specific therapeutic targets following brain injury. Brain Res. 2016; 1640: 77-93.

124. Bano D, Zanetti F, Mende Y, Nicotera P. Neurodegenerative processes in Huntington's disease. Cell Death Dis. 2011; 2: e228.

125. Parihar MS, Parihar A, Fujita M, et al. Mitochondrial association of alpha-synuclein causes oxidative stress. Cell Mol Life Sci. 2008; 65: 1272-1284.

126. Berridge MJ. Calcium hypothesis of Alzheimer's disease. Pflugers Arch - Eur J Physiol. 2010; 459: 441-449.

127. Popugaeva E, Vlasova OL, Bezprozvanny I. Restoring calcium homeostasis to treat Alzheimer's disease: a future perspective. Neurodegener Dis Manag. 2015; 5: 395-398. 
128. Kurnellas MP, Donahue KC, Elkabes S. Mechanisms of neuronal damage in multiple sclerosis and its animal models: role of calcium pumps and exchangers. Biochem Soc Trans. 2007; 35: 923-926.

129. Appel SH, Siklós L, Engelhardt JI, Mosier DR. Calcium: the Darth Vader of ALS. ALS other Mot Neuron Disord. 2001; 2: s47-s54.

130. Grosskreutz J, Van Den Bosch L, Keller BU. Calcium dysregulation in amyotrophic lateral sclerosis. Cell Calcium. 2016; 47: 165-174.

131. Mattson MP. Calcium and neurodegeneration. Aging Cell. 2007; 6: 337-350.

132. Fairless R, Williams SK, Diem R. Dysfunction of neuronal calcium signaling in neuroinflammation and neurodegeneration. Cell Tissue Res. 2014; 357: 455-462.

133. Fedorenko OA, Popugaeva E, Enomoto $\mathrm{M}$, et al. Intracellular calcium channels: inositol-1,4,5-trisphosphate receptors. Eur J Pharmacol. 2014; 739: 39-48.

134. Abeti R, Abramov AY. Mitochondrial Ca2+ in neurodegenerative disorders. Pharmacol Res. 2015; 99: 377-381.

135. Krols M, van Isterdael G, Asselbergh B, et al. Mitochondria-associated membranes as hubs for neurodegeneration. Acta Neuropathol. 2016; 131: 505-523.

136. Chan SL, Mattson MP. Caspase and calpain substrates: roles in synaptic plasticity and cell death. J Neurosci Res. 1999; 58: 167-190.

137. Wang HG, Pathan N, Ethell IM, et al. Ca2+ induced apoptosis through calcineurin dephosphorylation of BAD. Science 1999; 284: 339-343.

138. Kim MJ, Jo DG, Hong GS, et al. Calpain-dependent cleavage of cain/cabin1 activates calcineurin to mediate calcium-triggered cell death. Proc Natl Acad Sci. USA. 2002; 99: 9870-9875.

139. Kruman II, Mattson MP. Pivotal role of mitochondrial calcium uptake in neural cell apoptosis and necrosis. J Neurochem. 1999; 72: 529-540.

140. Werth JL, Thayer SA. Mitochondria buffer physiological calcium loads in cultured rat dorsal root ganglion neurons. J Neurosci. 1994; 14: 348-356.

141. Dykens JA. Isolated cerebral and cerebellar mitochondria produce free radicals when exposed to elevated $\mathrm{Ca} 2+$ and $\mathrm{Na}+$ : implications for neurodegeneration. J Neurochem. 1994; 63: 584-591. 
142. Beckman JS, Beckman TW, Chen J, et al. Apparent hydroxyl radical production by peroxynitrite: implication for endothelial injury from nitric oxide and superoxide. Proc Natl Acad Sci USA. 1990; 87: 162-1624.

143. McCord M. Oxygen-derived free radicals in post ischemic tissue injury. New Eng $J$ Med. 1985; 312: 159-163.

144. Lafon-Cazal M, Pletri S, Culcasi M, Bockaert J. NMDA-dependent superoxide production and neurotoxicity. Nature. 1993; 364: 535-537.

145. Milanese M, Zappettini S, Onofri F, et al. Abnormal exocytotic release of glutamate in a mouse model of amyotrophic lateral sclerosis. J Neurochem. 2011; 116: 1028-1042.

146. Leal SS, Cardoso I, Valentine JS, Gomes CM. Calcium ions promote superoxide dismutase 1 (SOD1) aggregation into non-fibrillar amyloid. A link to toxic effects of calcium overload in amyotrophic lateral sclerosis? J Biol Chem. 2013; 288: 2521925228.

147. Leal SS, Gomes CM. Calcium dysregulation links ALS defective proteins and motor neuron selective vulnerability. Front Cell Neurosci. 2015; 9: Article 225.

148. Lewit-Bentley A, Réty S. EF-hand calcium-binding proteins. Curr Op Struct Biol. 2000; 10: 637-643.

149. Yap KL, Ames JB, Swindells MB, Ikura M. Diversity of conformational states and changes within the EF-hand protein superfamily. Proteins. 1999; 37: 499-507.

150. Celio M. Calbindin D-28k and parvalbumin in the rat nervous system. Neuroscience. 1990; 35: 375-475.

151. Ren K, Ruda MA. A comparative study of the calcium-binding proteins calbindinD28K, calretinin, calmodulin and parvalbumin in the rat spinal cord. Brain Res Rev. 1994; 19: 163-179.

152. Reiner A, Medina L, Figueredo-Cardenas G, Anfinson S. Brainstem motoneuron pools that are selectively resistant in amyotrophic lateral sclerosis are preferentially enriched in parvalbumin: Evidence from monkey brainstem for a calcium-mediated mechanism in sporadic ALS. Exp Neurol. 19995; 131: 239-250.

153. Elliott JL, Snider WD. Parvalbumin is a marker of ALS-resistant motor neurons. NeuroReport. 1665; 6: 449-452.

154. Ince $\mathrm{P}$, Stout $\mathrm{N}$, Shaw $\mathrm{P}$, et al. Parvalbumin and calbindin $\mathrm{D}-28 \mathrm{k}$ in the human motor system and in motor neuron disease. Neuropathol Appl Neurobiol. 1993; 19: 291-299. 
155. Palecek J, Lips MB, Keller BU. Calcium dynamics and buffering in motoneurones of the mouse spinal cord. J Physiol. 1999; 520: 485-502.

156. Vanselow BK, Keller BU. Calcium dynamics and buffering in oculomotor neurones from mouse that are particularly resistant during amyotrophic lateral sclerosis (ALS)related motoneurone disease. J Physiol. 2000; 525: 433-445.

157. Mosier DR, Siklós L, Appel SH. Resistance of extraocular motoneuron terminals to effects of amyotrophic lateral sclerosis sera. Neurology. 2000; 54: 252-255.

158. Dekkers J, Bayley P, Dick JRT, et al. Over-expression of parvalbumin in transgenic mice rescues motoneurons from injury-induced cell death. Neuroscience. 2004; 123: $459-466$.

159. Beers DR, Ho B-K, Siklós L, et al. Parvalbumin overexpression alters immunemediated increases in intracellular calcium, and delays disease onset in a transgenic model of familial amyotrophic lateral sclerosis. J Neurochem. 2001; 79: 499-509.

160. Laslo P, Lipski J, Nicholson LFB, et al. GluR2 AMPA receptor subunit expression in motoneurons at low and high risk for degeneration in amyotrophic lateral sclerosis. Exp Neurol. 2001; 169: 461-471.

161. Vandenberghe W, Robberecht W, Brorson JR. AMPA receptor calcium permeability, GluR2 expression, and selective motoneuron vulnerability. J Neurosci. 2000; 20: $123-$ 132.

162. Shaw PJ, Williams TL, Slade JY, et al. Low expression of GluR2 AMPA receptor subunit protein by human motor neurons. NeuroReport. 1999; 10: 261-265.

163. Brockington A, Ning K, Heath PR, et al. Unravelling the enigma of selective vulnerability in neurodegeneration: motor neuron resistant to degeneration in ALS show distinct gene expression characteristics and decreased susceptibility to excitotoxicity. Acta Neuropathol. 2013; 125: 95-109.

164. Kawahara Y, Ito K, Sun H, et al. Glutamate receptors: RNA editing and death of motor neurons. Nature. 2004; 427: 801.

165. Hideyama T, Yamashita T, Suzuki T, et al. Induced loss of ADAR2 endangers slow death of motor neurons from Q/R site-unedited GluR2. J Neurosci. 2010; 30: 1191711925.

166. Pizzasegola C, Caron I, Daleno C, Ronchi A, Minoia C, Carrì MT, Bendotti C, Treatment with lithium carbonate does not improve disease progression in two different strains of SOD1 mutant mice. Amyotroph Lateral Scler. 2009; 10: 221-228. 
167. Borgers M, De Brabander M, Van Reempts J, Awouters F, Jacob WA. Intranuclear microtubules in lung mast cells of guinea pigs in anaphylactic shock. Lab Invest. 1977; 37: $1-8$.

168. Borgers M, Thone F, van Nueten JM. The subcellular distribution of calcium and the effects of calcium-antagonists as evaluated with a combined oxalate-pyroantimonate technique. Acta Histoch. 1981; 24: 327-332.

169. Paizs M, Engelhardt JI, Katarova Z, Siklós L. Hypoglossal motor neurons display a reduced calcium increase after axotomy in mice with upregulated parvalbumin. J Comp Neurol. 2010; 518: 1946-1961.

170. Adalbert R, Engelhardt JI, Siklós L. DL-homocysteic acid application disrupts calcium homeostasis and induces degeneration of spinal motor neurons in vivo. Acta Neuropathol. 2002; 103: 428-436.

171. Siklós L, Kuhnt U, Párducz Á, Szerdahelyi P. Intracellular calcium redistribution accompanies changes in total tissue $\mathrm{Na}+, \mathrm{K}+$, and water during the first two hours of in vitro incubation of hippocampal slices. Neuroscience. 1997; 79: 1013-1022.

172. Maxwell MH. Two rapid and simple methods used for the removal of resins from 1.0 micron thick epoxy sections. J Microscopy. 1978; 112: 253-255.

173. Richardson KC, Jarett L, Finke EH. Embedding in epoxy resins for ultrathin sectioning in electron microscopy. Stain Technol. 1960; 35: 313-323.

174. Weibel ER. Stereological methods, Vol. 1. Practical methods for biological morphometry. Academic Press, London, New York, Toronto, Sydney, San Francisco, 1979.

175. Mayhew TM. A review of recent advances in stereology for quantifying neural structure. J Neurocytol. 1992; 21: 313-328.

176. Siklós L. Assembly and reliability of an X-ray microanalyser system with a possibility for independent mass measurement. Acta Biochim Biophys. 1983; 18: 211-222.

177. Paizs M, Tortarolo M, Bendotti C, Engelhardt JI, Siklós L. Talampanel reduces the level of motoneuronal calcium in transgenic mutant SOD1 mice only if applied presymptomatically. Amyotroph Lat Scler. 2011; 12: 340-344.

178. Miyazaki S. Location of motoneurons in the oculomotor nucleus and the course of their axons in the oculomotor nerve. Brain Res. 1985; 348: 57-63. 
179. Yamaguchi K. Development of the human oculomotor nuclear complex: Somatic nuclei. Ann Anat. 2014; 196: 394-401.

180. White LE, Hall WC. The Actions and Innervation of Extraocular Muscles. In: Neuroscience $5^{\text {th }}$ edition. (eds: Purves D, Augustine GJ, Fitzpatrick D, Hall WC, LaMantia A-S, White LE), Sinauer Associates, Sunderland, MA. pp. 436-438.

181. Gallardo-Escárate C, Alvarez-Borrego J, Von Brand E, Dupré E, Del Río-Portilla MA. Relationship between DAPI-fluorescence fading and nuclear DNA content: An alternative method to DNA quantification? Biol. Res. 2007; 40: 29-40.

182. Tovar-y-Romo LB, Zepeda A, Tapia R. Vascular endothelial growth factor prevents paralysis and motoneuron death in a rat model of excitotoxic spinal cord neurodegeneration. J Neuropathol Exp Neurol. 2007; 66: 913-922.

183. Tovar-y-Romo LB, Tapia R. Delayed administration of VEGF rescues spinal motor neurons from death with a short effective time frame in excitotoxic experimental models in vivo. ASN Neuro. 2012; 4: 121.

184. Benatar M. Lost in translation: Treatment trials in the SOD1 mouse and human ALS, Neurobiol Disease. 2007; 26: 1-13.

185. Rothstein JD. Of mice and men: Reconciling preclinical ALS mouse studies and human clinical trials. Ann Neurol. 2003; 53: 423-426.

186. Zhang W, Narayanan M, Friedlander RM. Additive neuroprotective effects of minocycline with creatine in a mouse model of ALS. Ann Neurol. 2003; 53: 267-270.

187. Baker MR. ALS - dying forward, backward, or outward? Nature Rev Neurol. 2014; 10: 660.

188. Netzahualcoyotzi C, Tapia R. Degeneration of spinal motor neurons by chronic AMPAinduced excitotoxicity in vivo and protection by energy substrates. Acta Neuropathol Comm. 2015; 3: 27.

189. Santa-Cruz LD, Guerrero-Castillo S, Uribe-Carvajal S, Tapia R. Mitochondrial dysfunction during the early stages of excitotoxic spinal motor neuron degeneration in vivo. ACS Chem Neurosci. 20216; 7: 886.

190. Bettini NL, Moores TS, Baxter B, Deuchars J, Parson SH. Dynamic remodeling of synapses can occur in the absence of the parent cell body. BMC Neurosci. 2007; 8: 79.

191. Mattson MP, Keller JN, Begley JG. Evidence for synaptic apoptosis. Exp Neurol. 1998; 153: 35-48. 
192. Mattson MP. Apoptotic and anti-apoptotic synaptic signaling mechanisms. Brain Pathol. 2000; 10: 300-312.

193. Dadon-Nachum M, Melamed E, Offen D. The "dying-back" phenomenon of motor neurons in ALS. J Mol Neurosci. 2011; 43: 470-477.

194. Fischer-Hayes LR, Brotherton T, Glass JD. Axonal degeneration in the peripheral nervous system: implications for the pathogenesis of amyotrophic lateral sclerosis. Exp Neurol. 2013; 246: 6-13.

195. Fischer LR, Culver DG, Tennant $\mathrm{P}$, et al. Amyotrophic lateral sclerosis is a distal axonopathy: evidence in mice and man. Exp Neurol. 2004; 185: 232-240.

196. Nardo G, Trolese MC, Tortarolo M, et al. New Insights on the Mechanisms of Disease Course Variability in ALS from Mutant SOD1 Mouse Models. Brain Pathol. 2016; 26: $237-47$.

197. Williams TL, Ince PG, Oakley AE, Shaw PJ. An immunocytochemical study of the distribution of AMPA selective glutamate receptor subunits in the normal human motor system. Neurosci. 1996; 74: 185-198.

198. Ashcroft FM, Ashcroft SJ, Harrison DE. Properties of single potassium channels modulated by glucose in rat pancreatic beta-cells. J Physiol. 1988; 400: 501-527.

199. Correia SC, Santos RX, Perry G, Zhu X, Moreira PI, et al. Mitochondria: the missing link between preconditioning and neuroprotection. J Alzheimers. 2010; Dis 2: S475S485.

200. Zhu Y, Wendler CC, Shi O, Rivkees SA. Diazoxide promotes oligodendrocyte differentiation in neonatal brain in normoxia and chronic sublethal hypoxia. Brain Res. 2014; 1586: 64-72.

201. He X, Mo X, Gu H, et al. Neuroprotective effect of diazoxide on brain injury induced by cerebral ischemia/reperfusion during deep hypothermia. J Neurol. 2008; 268: 18-27.

202. Nakagawa I, Wajima D, Tamura K, Nishimura F, Park Y-S, Nakase H. The neuroprotective effect of diazoxide is mediated by mitochondrial ATP-dependent potassium channels in a rat model of acute subdural hematoma. J Clin Neurosci. 2013; 20: $144-147$.

203. Virgili N, Espinosa-Parrilla JF, Mancera P, et al. Oral administration of the KATP channel opener diazoxide ameliorates disease progression in a murine model of multiple sclerosis. J Neuroinflammation. 2011; 8: 149. 
204. Virgili N, Mancera P, Wappenhans B, Sorrosal G, et al. K(ATP) channel opener diazoxide prevents neurodegeneration: a new mechanism of action via antioxidative pathway activation. PLoS One. 2013; 8: e75189.

205. Ohba T, Sawada E, Suzuki Y, et al. Enhancement of Ca2+ Influx and Ciliary Beating by Membrane Hyperpolarization due to ATP-Sensitive K+ Channel Opening in Mouse Airway Epithelial Cells. J Pharm Exp Therap. 2013; 347:145-53.

206. Maneuf YP, Duty S, Hille CJ, Crossman AR, Brotchie JM. Modulation of GABA transmission by diazoxide and cromakalim in the globus pallidus: implications for the treatment of Parkinson's disease. Exp Neurol. 1996; 139: 12-16.

207. Irwin CW, Kim RB, Mitchell CS. Seeking homeostasis: temporal trends in respiration, oxidation, and calcium in SOD1 G93A amyotrophic lateral sclerosis mice. Front Cell Neurosci. 2015; 9: 248.

208. Zhao W, Beers DR, Appel SH. Immune-mediated mechanisms in the pathoprogression of amyotrophic lateral sclerosis. J Neuroimm Pharmacol. 2013; 8: 888-899.

209. Barbeito LH, Pehar M, Cassina P, et al. A role for astrocytes in motor neuron loss in amyotrophic lateral sclerosis. Brain Res Rev. 2004; 47: 263-274.

210. Van Den Bosch L, Schwaller B, Vleminckx V, et al. Protective effect of parvalbumin on excitotoxic motor neuron death. Exp Neurol. 2002; 174: 150-161.

211. Bose S, Cho J. Role of chemokine CCL2 and its receptor CCR2 in neurodegenerative diseases. Arch Pharm Res. 2013; 36: 1039-1050.

212. de Haas AH, van Weering HRJ, de Jong EK, Boddeke HWGM, Biber KPH. Neuronal chemokines: versatile messengers in central nervous system cell interaction. Mol Neurobiol. 2007; 36: 137-151.

213. Che X, Ye W, Panga L, Wu DC, Yang GY. Monocyte chemoattractant protein-1 expressed in neurons and astrocytes during focal ischemia in mice. Brain Res. 2001; 902: 171-177.

214. Flügel A, Hager G, Horvat A, et al. Neuronal MCP-1 expression in response to remote nerve injury. J Cereb Blood Flow Metab. 2001; 21: 69-76.

215. Zhang J, De Koninck Y. Spatial and temporal relationship between monocyte chemoattractant protein-1 expression and spinal glial activation following peripheral nerve injury. J Neurochem. 2006; 97: 772-783. 
216. Gyoneva S, Ransohoff RM. Inflammatory reaction after traumatic brain injury: therapeutic potential of targeting cell-cell communication by chemokines. Trends Pharm Sci. 2015; 36: 471-480.

217. Aldskogius H. Mechanisms and consequences of microglial responses to peripheral axotomy. Front Biosci. 2011; S3: 857-868.

218. Moran LB, Graeber MB. The facial nerve axotomy model. Brain Res Rev. 2004; 44: $154-178$.

219. Svensson M, Eriksson P, Persson JKL, Molander C, Arvidsson J, Aldskogius H. The response of central glia to peripheral nerve injury. Brain Res Bull. 1993; 30: 499-506.

220. Gao YJ, Ji RR. Chemokines, neuronal-glial interactions, and central processing of neuropathic pain. Pharmacol Therapeutics. 2010; 126: 56-68.

221. Zhang J, Shi XQ, Echeverry S, Mogil JS, De Koninck Y, Rivest S. Expression of CCR2 in both resident and bone marrow-derived microglia plays a critical role in neuropathic pain. J Neurosci. 2007; 27: 12396-12406.

222. Biber K, Boddeke E. Neuronal CC chemokines: the distinct roles of CCL21 and CCL2 in neuropathic pain. Front Cell Neurosci. 2014; 8: 210.

223. Igarashi T, Potts MB, Noble-Haeusslei LJ. Injury severity determines cell loss and microglial activation in the cerebellum after cortical contusion injury. Exp Neurol. 2007; 203: 258-268.

224. Kato H, Kogure K, Araki T, Itoyama Y. Graded expression of immunomolecules on activated microglia in the hippocampus following ischemia in a rat model of ischemic tolerance. Brain Res. 1995; 694: 85-93.

225. Koliatsos VE, Price DL. Axotomy as an experimental model of neuronal injury and cell death. Brain Pathol. 1996; 6: 447-465.

226. Vanden Noven S, Wallace N, Muccio D, Turtz A, Pinter MJ. Adult spinal motoneurons remain viable despite prolonged absence of functional synaptic contact with muscle. Exp Neurol. 1993; 123: 147-156.

227. Goettl MV, Neff NH, Hadjiconstantinou M. Sciatic nerve axotomy in aged rats: response of motoneurons and the effect of GM1 ganglioside treatment. Brain Res. 2003; 968: 44-53. 


\section{ACKNOWLEDGEMENTS}

All experiments that provided the basis of this thesis were performed in the Laboratory of Neuronal Plasticity, Molecular Neurobiology Research Unit, Institute of Biophysics, Biological Research Centre of the Hungarian Academy of Sciences.

I would like to express my gratitude to my supervisor, László Siklós, Ph.D., D.Sc., Head of Molecular Neurobiology Research Unit, who introduced me to the field of neuroscience and microscopy. He supported me in all aspects of laboratory workflow and guided me through the difficulties of designing and performing experiments.

I am thankful for the technical assistance of Erika Bánfiné Rácz, Béla Varga and Szabolcs Ábrahám.

I am also grateful for TEVA Pharmaceutical Works Industries (Petah Tiqva, Israel) for kindly providing the talampanel. Furthermore, I express my thank Sonja Welsch (FEI Company, Eindhoven, Netherlands) for electron microscopic tomography data acquisition and reconstruction and Régis Ravelle-Chapuis (JEOL EUROPE SAS, Croissy-sur-Seine, France) for electron microscopic X-ray microanalysis measurements and spectrum analysis.

Special thanks to my family and for their support and love, and last but not least, to my friends and colleagues who stood by me during the course of my doctorate study.

These studies have been performed within the framework of the "Neuroscience Program" of the Doctoral School of Theoretical Medicine of the Faculty of Medicine, University of Szeged. This Ph.D. school headed by Prof. Gábor Jancsó MD, D.Sc.

The presented studies have been partially supported by the Ministry of Human Capacities of Hungary (TÁMOP-4.2.2.A-11/1KONV-2012-0052 program) and by the Ministry for National Economy of Hungary (GINOP-2.3.2-15-2016-00001 and GINOP-2.3.3.-15-2016-00001 programs). 


\section{APPENDIX I. - MATERIALS AND COMMERCIAL EQUIPMENT USED}

\section{Fine chemicals}

\begin{tabular}{|c|c|c|}
\hline Chemical & Distributor & Catalog No. \\
\hline Acetic acid & $\begin{array}{l}\text { Molar Chemicals Kft., Halásztelek, } \\
\text { Hungary }\end{array}$ & 02795 \\
\hline Chloral hydrate & $\begin{array}{l}\text { Sigma Aldrich Inc., St. Louis, MO, } \\
\text { USA }\end{array}$ & C8383 \\
\hline Diaminobenzidine tetrahydrochloride & $\begin{array}{l}\text { Sigma Aldrich Inc., St. Louis, MO, } \\
\text { USA }\end{array}$ & D5637 \\
\hline Diazoxide & $\begin{array}{l}\text { Sigma Aldrich Inc., St. Louis, MO, } \\
\text { USA }\end{array}$ & D9035 \\
\hline Dimethyl sulfoxide & $\begin{array}{l}\text { Sigma Aldrich Inc., St. Louis, MO, } \\
\text { USA }\end{array}$ & D8418 \\
\hline Durcupan ACM & Fluka, Buchs, Switzerland & 44610 \\
\hline Entellan & Merck, Kenilworth, NJ, USA & 10796 \\
\hline Ethanol & $\begin{array}{l}\text { Molar Chemicals Kft., Halásztelek, } \\
\text { Hungary }\end{array}$ & 02910 \\
\hline Gel/Mount & $\begin{array}{l}\text { Biomeda Corporation, Foster City, } \\
\text { CA, USA }\end{array}$ & M02 \\
\hline Glutaraldehyde & $\begin{array}{l}\text { Polysciences Inc., Warrington, PA, } \\
\text { USA }\end{array}$ & 00376 \\
\hline Hydrogen peroxide & $\begin{array}{l}\text { Molar Chemicals Kft., Halásztelek, } \\
\text { Hungary }\end{array}$ & 03650 \\
\hline Lead citrate & $\begin{array}{l}\text { Electron Microscopy Sciences, } \\
\text { Hatfield, PA, USA }\end{array}$ & 17800 \\
\hline Methoxyflurane & Fluka, Buchs, Switzerland & 1418004 \\
\hline Normal donkey serum & $\begin{array}{l}\text { Sigma Aldrich Inc., St. Louis, MO, } \\
\text { USA }\end{array}$ & D9663 \\
\hline Normal Goat Serum & $\begin{array}{l}\text { Vector Laboratories, Burlingame, CA, } \\
\text { USA }\end{array}$ & S-1000 \\
\hline Normal horse serum & $\begin{array}{l}\text { Vector Laboratories, Burlingame, CA, } \\
\text { USA }\end{array}$ & S-2000 \\
\hline Osmic acid & $\begin{array}{l}\text { Sigma Aldrich Inc., St. Louis, MO, } \\
\text { USA }\end{array}$ & $\begin{array}{l}\mathrm{O} 5500- \\
250 \mathrm{MG}\end{array}$ \\
\hline Paraformaldehyde & $\begin{array}{l}\text { Sigma Aldrich Inc., St. Louis, MO, } \\
\text { USA }\end{array}$ & P6148 \\
\hline Phenobarbital & $\begin{array}{l}\text { Sigma Aldrich Inc., St. Louis, MO, } \\
\text { USA }\end{array}$ & P1636 \\
\hline Potassium hydroxide & $\begin{array}{l}\text { Molar Chemicals Kft., Halásztelek, } \\
\text { Hungary }\end{array}$ & $\begin{array}{l}04300-101- \\
190 \mathrm{a}\end{array}$ \\
\hline
\end{tabular}


Potassium oxalate

Potassium pyroantimonate

Propylene oxide

Sucrose

Sucrose

Talampanel

Tissue-Tek Optimal cutting temperature medium

Tribromoethanol

Triton $\mathrm{x}-100$

Tween 80

Uranyl acetate

Vectastain Elite Avidin-biotin complex

Xylene
Sigma Aldrich Inc., St. Louis, MO, USA

Merck, Kenilworth, NJ, USA

105110

Sigma Aldrich Inc., St. Louis, MO, USA

Sigma Aldrich Inc., St. Louis, MO, USA

16104

Molar Chemicals Kft., Halásztelek, 02200-203-

Hungary

$190 \mathrm{a}$

TEVA Pharmaceutical Works Ind., Petah Tiqva, Israel

no Cat. No.

Electron Microscopy Sciences,

Hatfield, PA, USA

62550

Fluka, Buchs, Switzerland

48402

Sigma Aldrich Inc., St. Louis, MO, USA

$\mathrm{T} 8787$

Sigma Aldrich Inc., St. Louis, MO, USA

P1754

Electron Microscopy Sciences,

Hatfield, PA, USA

22400

Vector Laboratories, Burlingame, CA, USA

PK-6100

Molar Chemicals Kft., Halásztelek, Hungary

09690

\section{Equipment}

\begin{tabular}{lll}
\hline Equipment & Distributor & Catalog No. \\
\hline \hline 300 mesh copper grid & $\begin{array}{l}\text { Electron Microscopy Sciences, } \\
\text { Hatfield, PA, USA }\end{array}$ & G7530-Cu \\
8 MP CMOS camera & JEOL Ltd., Tokyo, Japan & On request \\
CEM 902 transmission electron & Zeiss, Oberkochen, Germany & CEM 902 \\
microscope & JEOL Ltd., Tokyo, Japan & SD30GV \\
Dry SD30GV SDD X-ray detector & FEI, Eindhoven, The Netherlands & On request \\
Eagle 4k CCD camera & Nikon, Tokyo, Japan & Eclipse 80i \\
Eclipse 80i fluorescent microscope & Olympus, Tokyo, Japan & FV1000 \\
FV1000 laser confocal microscope & JEOL Ltd., Tokyo, Japan & JED-2300 \\
$\begin{array}{l}\text { JED-2300 Analysis Station } \\
\text { JEM-1400-Plus transmission electron } \\
\text { microscope }\end{array}$ & JEOL Ltd., Tokyo, Japan & JEM-1400P
\end{tabular}


Menzel BBAD02400600

\#A113MNZ\#0\#\# coverslip

MFP-3D AFM head unit

MicroPublisher 5.0 RTV CCD camera

MNT cryostat

Molecular Force Probe controller

Silicon cantilever with tetrahedral tip

Single-hole formvar coated copper grid

SPOT RT 14.0 monochrome CCD camera

Stainless steel gavage

Superfrost Plus Adhesion Slide

Tecnai Spirit transmission electron microscope

Ultracut UCT ultramicrotome

Vanox-T AH-2 microscope
ThermoFisher Scientific, Waltham, MA, USA

11778691

Asylum Research, Goleta, CA, USA MFP-3D

MP5.0-

QImaging, Surrey, BC, Canada RTV-R-

CLR-10

Slee Medical GmbH, Mainz, Germany 10160000

Asylum Research, Goleta, CA, USA On request

Olympus, Tokyo, Japan

OMCL-

AC240TS

Electron Microscopy Sciences,

Hatfield, PA, USA

G2010-Cu

Diagnostic Instruments Inc., Sterling

Heights, MI, USA

Instech Laboratories Inc., Plymouth

Meeting, PA, USA

25

ThermoFisher Scientific, Waltham, MA, USA

10143352

FEI, Eindhoven, The Netherlands

FP 5018/41

Leica, Wetzlar, Germany

On request

Olympus, Tokyo, Japan

608002

\section{Software}

\begin{tabular}{ll}
\hline Software & Distributor \\
\hline \hline AutoQuant X & Media Cybernetics, Rockville, MD, USA \\
Image-Pro Plus & Media Cybernetics, Rockville, MD, USA \\
Inspect 3D tomography software & FEI, Eindhoven, The Netherlands \\
R (3.3.1) statistical computing software & The R Foundation, Vienna, Austria \\
RStudio Integrated Development Environment & The R Foundation, Vienna, Austria \\
version (3.0) & \\
Visual Identification- and Thin Film & JEOL Ltd., Tokyo, Japan \\
Standardless Quantitative Analysis Program & \\
\hline
\end{tabular}

\section{Antibodies}




\begin{tabular}{|c|c|c|}
\hline Anti-CCL2 antibody & PeproTech, Rocky Hill, NJ, USA & 500-P113 \\
\hline Anti-CD11b antibody & AbD Serotec Raleigh, NC, USA & MCA711 \\
\hline Biotinylated goat-anti-rat antibody & $\begin{array}{l}\text { Vector Laboratories, Burlingame, CA, } \\
\text { USA }\end{array}$ & BA-9400 \\
\hline Biotinylated goat-anti-rabbit antibody & $\begin{array}{l}\text { Vector Laboratories, Burlingame, CA, } \\
\text { USA }\end{array}$ & BA-1000 \\
\hline Donkey-anti rabbit Alexa Fluor 546 & $\begin{array}{l}\text { Life Technologies, Carlsbad, CA, } \\
\text { USA }\end{array}$ & A10040 \\
\hline Donkey-anti-goat Alexa Fluor 488 & $\begin{array}{l}\text { Life Technologies, Carlsbad, CA, } \\
\text { USA }\end{array}$ & A11055 \\
\hline Donkey-anti-sheep Alexa Fluor 488 & $\begin{array}{l}\text { Jackson Immunoresearch Laboratories } \\
\text { Inc., West Grove, PA, USA }\end{array}$ & $713-545-003$ \\
\hline Goat-anti-rabbit Alexa Fluor 546 & $\begin{array}{l}\text { Life Technologies, Carlsbad, CA, } \\
\text { USA }\end{array}$ & A11010 \\
\hline Goat-anti-ChAT antibody & EMD Millipore, Billerica, MA, USA & $\mathrm{AB} 144 \mathrm{P}$ \\
\hline Goat-anti-rat Alexa Fluor 488 & $\begin{array}{l}\text { Life Technologies, Carlsbad, CA, } \\
\text { USA }\end{array}$ & A11006 \\
\hline Rabbit-anti-Iba1 antibody & Wako Chemicals, Osaka, Japan & 019-19741 \\
\hline Rabbit-anti-rat PV antibody & Swant, Marly, Switzerland & PV-28 \\
\hline Sheep-anti-ChAT antibody & EMD Millipore, Billerica, MA, USA & AB1582 \\
\hline
\end{tabular}

\section{APPENDIX II. - CHARACTERIZATION OF THE PRIMER ANTIBODIES}

The information regarding the specificity of these reagents is based either on our previous experiments or derived from published results obtained with the same antibody, or collected from data sheets supplied by the manufacturers. Application of these antibodies was in accord with the guideline of the reagent; however, titration was used to determine the optimal dilution for our own system.

The rat monoclonal anti-CD11b clone 5C6 (AbD Serotec Cat\# MCA711) recognizes the integrin alpha $\mathrm{M}$ chain also known as CD11b which is implicated in various adhesive interactions of monocytes, macrophages and granulocytes, as well as in mediating the uptake of the complement-coated particles. This antibody was frequently used to visualize microglial cells $^{1,2}$ and its specificity was confirmed by using the appropriate knockout ${ }^{3}$.

The rabbit polyclonal anti-CCL2 antibody (PeproTech Cat\# 500-P113-100 $\mu \mathrm{g}$ ) recognizes E. coli derived recombinant murine JE/MCP-1, also known as CCL2, member of the $\beta$-chemokine family that signal through CCR2. The antibody produced from sera of rabbits pre-immunized with highly pure (>98\%) recombinant mJE(MCP-1). Anti-murine 
JE(MCP-1) specific antibody was purified by affinity chromatography employing immobilized mJE(MCP-1) matrix. Reactivity and specificity has been verified by immunostaining ${ }^{4}$ and using knockout animals ${ }^{5}$ respectively and by ELISA $^{6}$ and neutralization ${ }^{7}$.

The rabbit polyclonal anti-PV (Swant Cat\# PV-28) recognizes PV, a CaBP from a family of small acidic proteins equipped with peculiar cavities which accepts calcium with high selectivity. The antibody derived from an antiserum, produced against rat muscle PV. It labels a subpopulation of neurons in the normal brain with high efficiency, but does not stain the brain of PV knockout mice according to the manufacturer's data sheet. In addition, the preincubation of the PV antibody with recombinant rat PV completely blocked the PV immunoreactivity ${ }^{8}$. This antibody is frequently used to label PV in the central nervous system ${ }^{9}$.

The goat-anti-choline acetyltransferase (anti-ChAT) polyclonal antibody (Millipore Cat\# AB144P) recognizes ChAT enzyme, which catalyzes the reversible synthesis of acetylcholine from acetyl coenzyme A and choline at cholinergic synapses. This antibody uses human placental enzyme as an immunogen and recognizes a single band of $\approx 68 \mathrm{kD}$ on western blots of rat peripheral nerves ${ }^{10}$. The staining pattern on immunostained sections coincided with that of the native red fluorescence of ChAT-Cre-tdTomato mice developed for labeling cholinergic structures ${ }^{11}$.

The sheep-anti-ChAT polyclonal antibody (EMD Millipore, Cat\# AB1582; 1:200) is labeling the ChAT enzyme. This antibody is staining specific cholinergic neurons in the central and peripheral nervous system. According to the data sheet, this antibody validated for use in immunohistochemistry and western blot. In accordance with the information provided by the manufacturer, several studies used this antibody for immunohistochemical observation $^{12,13}$.

Ionized calcium-binding adaptor molecule 1 (Iba1) is a calcium-binding protein with a molecular weight of $17 \mathrm{kD}$ specifically expressed in macrophage and microglia. The rabbitanti-Iba1 polyclonal antibody (Wako Chemicals Cat\# 019-19741) specific to microglia and macrophage in human, mouse and rat, but not cross-reactive with neuron and astrocyte. The antibody derived from a rabbit antiserum where the antigen was a synthetic peptide corresponding to C-terminus of Ibal protein and it was purified by antigen affinity chromatography. Wako anti-Iba1 is routinely used for immunohistochemistry and western blot $^{14,15}$. 


\section{Bibliography of antibody characterization}

1. Yamanaka M, Ishikawa T, Griep A, et al. PPAR $\gamma / R X R \alpha$-induced and CD36-mediated microglial amyloid- $\beta$ phagocytosis results in cognitive improvement in amyloid precursor protein/presenilin 1 mice. J Neurosci. 2012; 32: 17321-17331.

2. Babcock AA, Ilkjær L, Clausen BH, et al. Cytokine-producing microglia have an altered beta-amyloid load in aged APP/PS1 Tg mice. Brain Behav Immun. 2015; 48: 86-101.

3. Makwana M, Werner A, Acosta-Saltos A, et al. Peripheral facial nerve axotomy in mice causes sprouting of motor axons into perineuronal central white matter: time course and molecular characterization. J Comp Neurol. 2010; 518: 699-721.

4. Lobo PI, Bajwa A, Schlegel KH, et al. Natural IgM anti-leukocyte autoantibodies attenuate excess inflammation mediated by innate and adaptive immune mechanisms involving Th-17. J Immunol. 2012; 188 : $1675-1685$.

5. Stowe AM, Wacker BK, Cravens PD, et al. CCL2 upregulation triggers hypoxic preconditioning-induced protection from stroke. J Neuroinflamm. 2012; 9: 33.

6. Roodveldt C, Labrador-Garrido A, Gonzalez-Rey E, et al. Glial innate immunity generated by nonaggregated alpha-synuclein in mouse: differences between wild-type and Parkinson's disease-linked mutants. PLoS One. 2010; 5: e13481.

7. Yu RY, Wang X, Pixley FJ, et al. BCL-6 negatively regulates macrophage proliferation by suppressing autocrine IL-6 production. Blood. 2005; 105: 1777-1784.

8. Xu X, Roby KD, Callaway EM. Immunochemical characterization of inhibitory mouse cortical neurons: three chemically distinct classes of inhibitory cells. J Comp Neurol. 2010; 518: 389-404.

9. Armstrong C, Szabadics J, Tamás G, Soltesz I. Neurogliaform cells in the molecular layer of the dentate gyrus as feed-forward $\gamma$-aminobutyric acidergic modulators of entorhinal-hippocampal interplay. J Comp Neurol. 2011; 519: 1476-1491.

10. Brunelli G, Spano P, Barlat S, et al. Glutamatergic reinnervation through peripheral nerve graft dictates assembly of glutamatergic synapses at rat skeletal muscle. Proc Natl Acad Sci USA. 2005; 102: 875-8757.

11. Gautron L, Rutkowski JM, Burton MD, Wei W, Wan Y, Elmquist JK. Neuronal and nonneuronal cholinergic structures in the mouse gastrointestinal tract and spleen. J Comp Neurol. 2013; 521: 3741-3767.

12. Jiang YH, Jiang P, Yang JL et al. Cardiac Dysregulation and Myocardial Injury in a 6-HydroxydopamineInduced Rat Model of Sympathetic Denervation. PLoS One. 2015; 10: e0133971.

13. Morona R, González A. Immunohistochemical localization of calbindin-D28k and calretinin in the brainstem of anuran and urodele amphibians. J Comp Neurol. 2009; 515(5):503-537.

14. Sasaki Y1, Ohsawa K, Kanazawa H, Kohsaka S, Imai Y. Iba1 is an actin-cross-linking protein in macrophages/microglia. Biochem Biophys Res Commun. 2001; 286(2):292-297.

15.Ziehn MO, Avedisian AA, Dervin SM, Umeda EA, O'Dell TJ, Voskuhl RR. Therapeutic Testosterone Administration Preserves Excitatory Synaptic Transmission in the Hippocampus During Autoimmune Demyelinating Disease. J Neurosci. 2012; 32: 12312-12324. 